\title{
Volcanología y geocronología de extensos flujos basálticos neógeno cuaternarios del sureste de Payenia, centro-oeste de Argentina
}

\author{
${ }^{*}$ Mauro I. Bernardi' ${ }^{1}$, Gustavo W. Bertotto ${ }^{1}$, Yuji Orihashi², Hirochika Sumino ${ }^{3}$, Alexis D. Ponce ${ }^{1}$ \\ I Incitap (Conicet-Universidad Nacional de La Pampa)-Uruguay 151, 6300, Santa Rosa, La Pampa, Argentina. \\ mi_bernardi@hotmail.com; gwbertotto@yahoo.com.zr; poncealexis_wini@hotmail.com \\ 2 Earthquake Research Institute, University of Tokyo, 1-1-1 Yayoi, Bunkyo-ku, Tokyo, Japón. \\ oripachi@eri.u-tokyo.ac.jp \\ 3 Department of Basic Science, Graduate School of Arts and Sciences, University of Tokyo, 3-8-1 Komaba, Meguro-Ku, Tokyo, Japón. \\ sumino@igcl.c.u-tokyo.ac.jp \\ *Autor de correspondencia:mi_bernardi@hotmail.com
}

RESUMEN. Las coladas de lava basáltica consideradas en este estudio, se encuentran localizadas en el sureste de la provincia volcánica de Payenia, Argentina, y presentan longitudes variables entre 40 y $181 \mathrm{~km}$. Estas exhiben secciones transversales caracterizadas por cortezas vesiculares externas que envuelven un núcleo masivo portador de estructuras vesiculadas por lo que fueron definidas como flujos pahoehoe de tipo P. En base a su topografía superficial se establecieron 2 tipos de flujos: laminares y hummocky. Los primeros se emplazaron a través de inflación y coalescencia lateral de lóbulos en el frente del flujo, dando lugar a coladas de techos planos y gran amplitud lateral. Los segundos exhiben un microrelieve otorgado por estructuras de inflación local (e.g., túmulos). Se propone que las coladas se emplazaron inicialmente como flujos laminares bajo un régimen de altas tasas de efusión sobre pendientes de bajo ángulo $\left(<1,5^{\circ}\right)$ sometidas a un proceso de inflación generalizado. La reducción gradual del suministro lávico restringió la circulación de lava a una red interna de túneles que condujo a procesos de inflación localizados. Se plantea además que el notable desarrollo longitudinal de estas coladas es el resultado del transporte de lava a través de túneles en conjunto con muy bajos valores de viscosidad ( 9 a $38 \mathrm{~Pa} \mathrm{~s}$ ) y tasas de enfriamiento. Nuevas edades K-Ar (unspiked) para algunas de las coladas de lavas estudiadas indican valores de 2,85 $\pm 0,18 \mathrm{Ma}$ (colada Pampa de Luanco), 0,862 $\pm 0,056 \mathrm{Ma}$ (colada

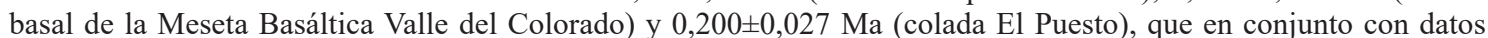
radimétricos previos permiten establecer un lapso de tiempo comprendido entre los $\sim 5 \mathrm{Ma} \mathrm{y} \mathrm{0,2} \mathrm{Ma} \mathrm{para} \mathrm{la} \mathrm{emisión}$ de estos flujos lávicos.

Palabras clave: Basalto, Retroarco, K-Ar, Payenia.

\begin{abstract}
Volcanology and geochronology of very long Neogene-Quaternary basaltic flows from southeast Payenia, central-west Argentina. The basaltic lava flows located in the southeast of Payenia Volcanic Province, Argentina, show lengths between 40 and $181 \mathrm{~km}$. These flows have transversal sections characterized by external vesicular crusts that surround a massive core hosting vesiculated structures. These characteristics defined them as P-type pahoehoe flows. Based on their surface topography, 2 types of flows were determined: sheet flows and hummocky flows. The first were emplaced through inflation and lateral coalescence of lobes in the front of the flow, giving rise to flat roofs and large lateral width. The second ones exhibit a microrelief given by local inflation structures (e.g., tumuli). It is proposed that the lava flows were initially emplaced as sheet flows on low angle slopes $\left(<1.5^{\circ}\right)$, under a regime of high effusion rates which led to a generalized inflation process. The gradual reduction of the lava supply restricted the circulation of lava to an internal network of tunnels that led to localized inflation processes. It is further stated that the remarkable longitudinal development of these flows is the result of the lava delivery through tunnels together with very low viscosity values ( 9 to $38 \mathrm{~Pa} \mathrm{~s}$ ) and low cooling rates. New K-Ar (unspiked) ages were obtained for some of the flows with values of $2.85 \pm 0.18 \mathrm{Ma}$ (Pampa de Luanco flow), $0.862 \pm 0.056 \mathrm{Ma}$ (basal flow of the Valle del Colorado Basaltic Plateau) and $0.200 \pm 0.027 \mathrm{Ma}$ (El Puesto flow) while in conjunction with other previous radiometric data, a time lapse between $\sim 5 \mathrm{Ma}$ and $\sim 0.2$ Ma was established for the emission of these flows.
\end{abstract}




\section{Introducción}

La provincia volcánica Payenia (Polanski, 1954) se encuentra situada al pie de los Andes, a aproximadamente $500 \mathrm{~km}$ al este de la zona de subducción actual. Comprende la provincia volcánica neógeno-cuaternaria de mayor extensión en Sudamérica, con más de 800 volcanes monogenéticos (e.g., Inbar y Risso, 2001; Bertotto et al., 2006a; Risso et al., 2008; Mazzarini et al., 2008; Folguera et al., 2009).

Las numerosas reseñas bibliográficas que tienen como marco a Payenia comienzan con los estudios regionales realizados por Stappenbeck (1913), Groeber (1929) y Wichmann (1928). Este último autor asignó una edad pliocena a las coladas lávicas que afloran en la zona de estudio, mientras que, Sobral (1942) incluyó en el Pleistoceno a las coladas basálticas aflorantes en el sector sur de la misma zona y Holmberg (1962) indicó que las coladas del volcán Huanul fueron emitidas en el Pleistoceno superior. Las primeras dataciones (K-Ar) sobre unidades basálticas en esta zona corresponden a Cortelezzi y Dirac (1969), quienes determinaron valores entre 2,2 y 5 Ma. Núñez (1976) obtuvo una edad K-Ar de $24 \pm 4$ Ma para el centro eruptivo La Parva y entre 1 y 2,3 Ma para coladas lávicas situadas a $25 \mathrm{~km}$ al sur del mismo. Este mismo autor sugirió que las coladas basálticas provenientes del Campo Volcánico Payún Matru fueron eruptadas durante el Holoceno. Por su parte, Linares et al. (1980) afirmaron que los flujos lávicos que cubren gran parte del oeste de la provincia de La Pampa provienen de volcanes situados en la provincia de Mendoza, sugiriendo la existencia de varios ciclos efusivos en el Cenozoico. Posteriormente, Bermúdez et al. (1993) reunieron las rocas de los campos volcánicos Payún Matru y Llancanelo en los Grupos Chapúa, Puente y Tromen siguiendo la terminología empleada por Groeber (1946) para las diferentes épocas eruptivas. Éstos y otros autores (e.g., Stern, 2004) indicaron que los fundidos fueron generados como consecuencia de la subducción en el margen occidental de Sudamérica. Por su parte, Melchor y Casadío (1999) obtuvieron una edad K-Ar de 0,4 Ma para el flujo lávico aflorante en Punta de la Barda (La Pampa) y asignaron estas rocas al Grupo Puente, definido por Bermúdez et al. (1993). Bertotto (2000) y Bertotto et al. (2006a y b, 2009) estudiaron la evolución volcanológica y geoquímica de varios centros eruptivos y unidades basálticas asociadas en el oriente de Payenia, postulando que los magmas se originaron a partir de bajos grados de fusión de una fuente mantélica, en algunos casos con influencia de la placa subductada. Kay y Mancilla (2001), Kay (2002) y Kay et al. (2004) obtuvieron edades $\mathrm{K}-\mathrm{Ar}$ y $\mathrm{Ar}^{40} / \mathrm{Ar}^{39}$ comprendidas entre 7,3 y 4,9 Ma para las secuencias volcánicas de Chachahuén y relacionaron la generación de estos magmas con la fusión de un manto hidratado luego de un episodio de subducción de bajo ángulo ocurrido en el Mioceno superior. Bertotto et al. (2006b) determinaron nuevas edades $\mathrm{K}-\mathrm{Ar}$ en cuatro centros eruptivos de Mendoza y La Pampa, con valores que varían entre 0,64 y 14,8 Ma. Pasquaré et al. (2008) y Espanon et al. (2014a) estudiaron la colada Pampas Onduladas la cual se extiende desde el campo volcánico Payún Matru hasta el valle del río Salado en La Pampa y la propusieron como el flujo cuaternario continental más largo del planeta. Además, Espanon et al. (2014a) determinaron una edad ${ }^{40} \mathrm{Ar} /{ }^{39} \mathrm{Ar}$ de $0,37 \pm 0,01 \mathrm{Ma}$ para la colada Pampas Onduladas. Gudnason et al. (2012) obtuvieron edades ${ }^{40} \mathrm{Ar} /{ }^{39} \mathrm{Ar}$ para varios de los centros eruptivos y coladas lávicas ubicados en los campos volcánicos Payún Matru, Llancanelo, Nevado, Río Colorado, Chachahuén y sectores aledaños, comprendidas entre los 20,7 y 0,06 Ma. Por su parte Søager y Holm (2013) y Søager et al. (2013) llevaron a cabo un relevamiento geoquímico de gran parte de la región de Payenia sugiriendo un engrosamiento de la litosfera hacia el sector oriental y la presencia de un manto subcontinental con regiones a diferentes temperaturas, donde se generaron estos magmas. Recientemente May et al. (2018) obtuvieron un conjunto de edades para los campos volcánicos Llancanelo y Payún Matru mediante las metodologías ${ }^{40} \mathrm{Ar} /{ }^{39} \mathrm{Ar}$, termoluminiscencia e isótopos cosmogénicos de ${ }^{3} \mathrm{He} \mathrm{y}^{21} \mathrm{Ne}$. Estas edades están comprendidas en un rango de entre $0,127 \pm 0,029$ y $0,138 \pm 0,004$ Ma para el primer campo volcánico y de entre $0,384 \pm 0,050$ y $0,019 \pm 0,001$ Ma para el segundo campo volcánico.

\section{Contexto geológico}

El área de estudio comprende el sector de retroarco extraandino ubicado en el sureste de la provincia volcánica de Payenia, incluyendo el sureste de la provincia de Mendoza y el oeste en la provincia de La Pampa (Argentina) (Fig. 1). La zona exhibe características geomorfológicas típicas de Patagonia 


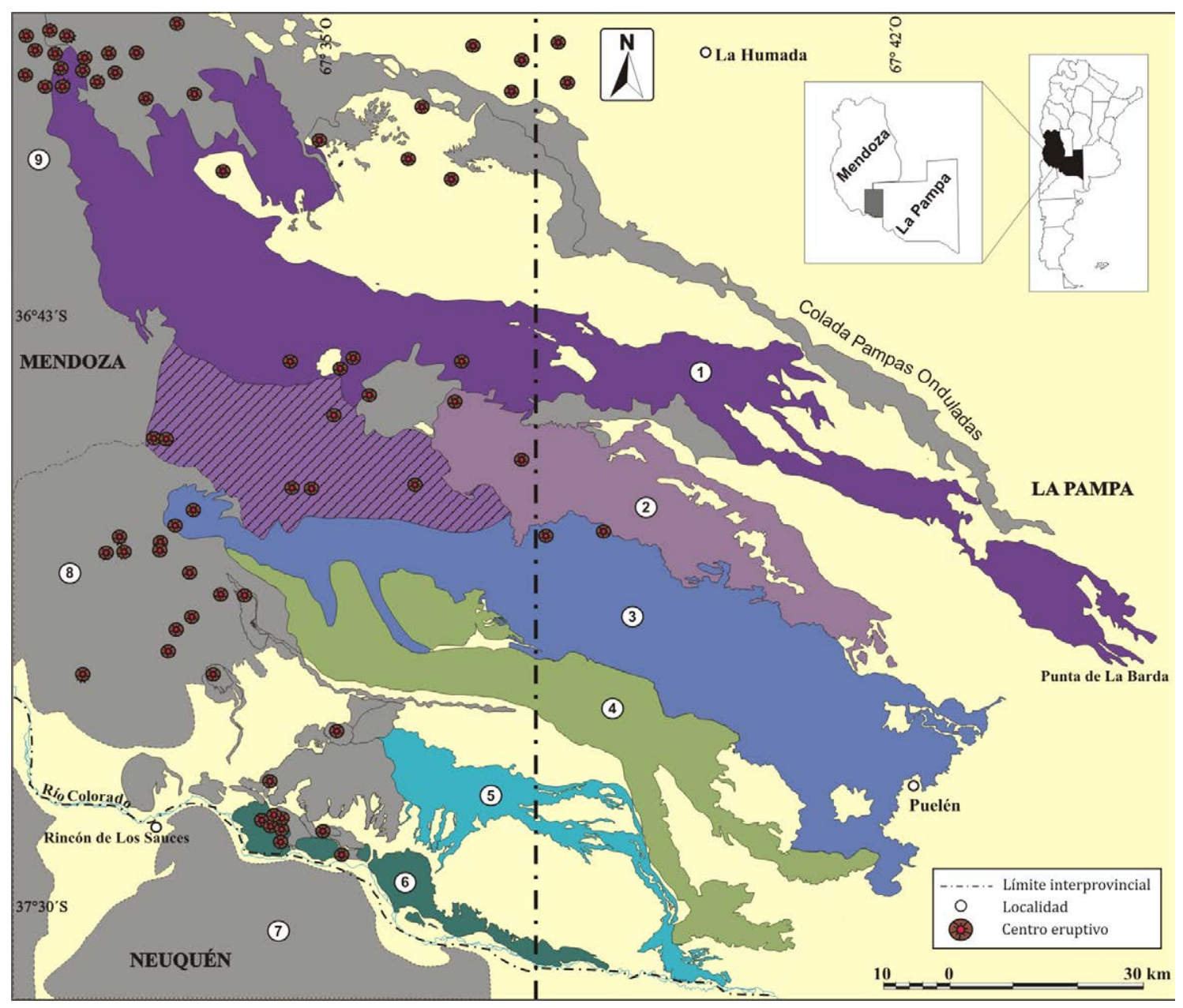

FIG. 1. Mapa de los flujos lávicos relevados en el área de estudio: 1. Pampa de Los Carrizales, 2. El Puesto, 3. Pampa de Ranquelcó, 4. Pampa de Luanco, 5. El Corcovo, 6. Meseta Basáltica Valle del Colorado, 7. Sector norte del Campo Volcánico Auca Mahuida, 8. Campo Volcánico Chachahuén, 9. Sector sudoriental del Campo Volcánico Payún Matru.

extraandina con predominio de un relieve mesetiforme escalonado. El volcanismo basáltico presente en esta región se emplazó progresivamente sobre terrenos volcánicos y sedimentarios de edad cretácica-terciaria. Según Holmberg (1962), los diferentes pulsos eruptivos que originaron estos flujos lávicos se intercalaron con períodos de erosión, ascenso y peneplanización de los terrenos de la región como consecuencia de los movimientos andinos neógeno-cuaternarios.

La actividad volcánica desarrollada en el retroarco a estas latitudes transcurrió bajo un régimen tectónico compresional durante el Mioceno, como resultado de una etapa de subducción de bajo ángulo de la placa de Nazca, lo que condujo al desarrollo de fajas plegadas y corridas y a la sedimentación sinorogénica en el frente del arco (Ramos y Folguera, 2005; Ramos y Kay, 2006). Luego de una breve pausa de la actividad magmática en el límite Mioceno-Plioceno, comenzó un periodo extensional como resultado del empinamiento gradual de la placa (Kay et al., 2006a; Ramos y Kay, 2006; Gudnason et al., 2012). Esto trajo como consecuencia la progresiva migración del arco volcánico hacia el oeste, favoreciendo el ascenso de magmas de origen astenosférico que generó un volcanismo relativamente homogéneo en la región extraandina (e.g., Bermúdez et al., 1993; James y Sacks, 1999; Inbar y Risso, 2001; Kay et al., 2004, 2005; Ramos y Folguera, 2005). 
El volcanismo vinculado a este marco tectónico se encuentra evidenciado por la presencia de numerosos aparatos volcánicos alineados a través de extensas fracturas generadas o reactivadas durante la extensión pliocena-pleistocena (e.g., Araña Saavedra et al., 1984; Bermúdez y Delpino, 1989; Kay et al., 2005, 2006a; Ramos y Folguera, 2005; Ramos y Kay, 2006; Bertotto et al., 2006a). Las rocas que conforman los productos volcánicos de Payenia son de composición principalmente basáltica a andesítica y exhiben signaturas geoquímicas de arco e intraplaca (e.g., Kay et al., 2006b; Ramos y Kay, 2006).

El objetivo de este trabajo es determinar la morfometría de las coladas basálticas, identificar los centros de emisión y establecer un ordenamiento cronoestratigráfico para las mismas a partir de las relaciones de yacencia y de las edades radimétricas obtenidas.

\section{Materiales y métodos}

La morfometría de una colada de lava incluye aspectos tales como superficie de cobertura, volumen, características de la superficie, espesor y longitud, entre otros. Estos parámetros están controlados por la duración de la erupción, tasa de efusión, las propiedades físicas de la lava (reología, temperatura, tasa de enfriamiento, desgasificación, etc.), la pendiente y topografía del terreno y las características del centro eruptivo (Macdonald, 1972; Walker, 1973; Kilburn y Lopes, 1991; Pinkerton y Norton, 1995; Kilburn, 2000; Castruccio et al., 2013). Las estimaciones del volumen de lava de cada una de las coladas estudiadas se realizaron a partir de datos obtenidos del procesamiento de imágenes satelitales y durante los trabajos de campo. Se utilizaron modelos digitales de elevación SRTM-DEM $(90 \mathrm{~m})$ y se dividieron las coladas por sectores sobre la base de cambios de pendiente y espesores promedio de las mismas. Se estimó el volumen de basalto de cada uno de los sectores y se sumaron los subtotales. El volumen total resultante corresponde a un valor mínimo debido a que muchos de los espesores determinados no corresponden al espesor real de la colada sino a su espesor aflorante en el sitio de estudio.

Las edades fueron determinadas mediante el método "unspiked K-Ar" (Tabla 1). El análisis de Ar fue realizado usando un espectrómetro de masas de gases nobles MSIII (VG5400 modificado) en la Universidad de Tokio, Japón. Los errores en la determinación del ${ }^{40} \mathrm{Ar}$ y de la relación ${ }^{40} \mathrm{Ar} /{ }^{36} \mathrm{Ar}$ se estimaron en $5 \%$ y $0,2 \%$, respectivamente, basados en mediciones repetidas del estándar atmosférico conteniendo $1,5 \times 10^{-7} \mathrm{~cm}^{3}$ STP de ${ }^{40} A r$. La concentración de $\mathrm{K}$ fue determinada para una alícuota de la misma muestra de roca total usada para el análisis de Ar, por FRX (equipo Phillips PW2400). La precisión analítica fue chequeada a partir de análisis del estándar JB-1a (Geological Survey of Japan). Detalles del procedimiento aplicado para la datación K-Ar fueron descriptos por Nagao et al. (1991) y Orihashi et al. (2004).

Para el cálculo de la viscosidad se utilizaron datos analíticos de elementos mayores tomados de Bernardi (2016). Los mismos fueron ingresados al programa K-Ware-Magma, fijando el valor de temperatura en $1200{ }^{\circ} \mathrm{C}$ y la presión en 1 bar. Mediante este programa se obtuvieron valores de viscosidad aparente a partir de las ecuaciones de Bottinga y Weill (1972).

TABLA 1. EDADES K-Ar (UNSPIKED) OBTENIDAS A PARTIR DE MUESTRAS DE ALGUNAS DE LAS COLADAS DE LAVA CONSIDERADAS EN ESTE ESTUDIO.

\begin{tabular}{cccccc}
\hline $\begin{array}{c}\text { Muestra } \\
\text { No. }\end{array}$ & $\begin{array}{c}\mathbf{K} \\
\text { (Wt.\%) }\end{array}$ & $\begin{array}{c}{ }^{\mathbf{4 0}} \mathbf{A r} \mathbf{R a d} \\
\mathbf{1 0}^{-\mathbf{8}} \mathbf{C m}^{\mathbf{3}} \mathbf{s t p} / \mathbf{G}\end{array}$ & ${ }^{38} \mathbf{A r}{ }^{36} \mathbf{A r}$ & $\begin{array}{c}\text { Edad } \\
(\mathbf{M a})\end{array}$ & $\begin{array}{c}\text { Fracc. Aire } \\
(\mathbf{\%})\end{array}$ \\
\hline M129 & $0,829 \pm 0,041$ & $0,644 \pm 0,084$ & $0,18805 \pm 0,0008$ & $0,200 \pm 0,027$ & 96,51 \\
MO148 & $1,034 \pm 0,052$ & $3,19 \pm 0,18$ & $0,18793 \pm 0,00053$ & $0,795 \pm 0,050$ & 85,84 \\
RI42 & $1,444 \pm 0,072$ & $6,26 \pm 0,35$ & $0,18954 \pm 0,00075$ & $0,984 \pm 0,092$ & 89,26 \\
MD37 & $0,853 \pm 0,043$ & $2,73 \pm 0,14$ & $0,18820 \pm 0,0007$ & $2,73 \pm 0,14$ & 89,92 \\
MD46 & $1,127 \pm 0,056$ & $3,77 \pm 0,22$ & $0,18840 \pm 0,0006$ & $0,862 \pm 0,056$ & 71,68 \\
MD63 & $0,389 \pm 0,019$ & $4,31 \pm 0,23$ & $0,18861 \pm 0,0007$ & $2,85 \pm 0,18$ & 77,58 \\
\hline
\end{tabular}

$\left({ }^{40} \mathrm{Ar} /{ }^{36} \mathrm{Ar}\right)$ inicial $=$ se asumió un valor de 296. Error: $1 \sigma$ 


\section{Flujos basálticos considerados en este estudio}

A continuación se detallan los principales aspectos relacionados al emplazamiento, erupción, edades, morfometría y estructura de 6 flujos lávicos de notable desarrollo areal y longitudinal emplazados en la zona de estudio. También se mencionan algunas coladas menores asociadas. En la Tabla 2 se resumen los parámetros más relevantes.

\subsection{Colada de lava Pampa de Los Carrizales}

El complejo volcánico Payún Matru comprende un conjunto de volcanes cuaternarios de composición traquítico-basáltica situados en el retroarco con centro en los $36^{\circ} 24^{\prime}$ S y $69^{\circ} 12^{\prime}$ W (Germa y Quidelleur, 2007). Tanto el centro principal Payún Matru como los numerosos conos basálticos menores se vinculan con un sistema de fracturas de $70 \mathrm{~km}$ de extensión y orientación oeste-este denominado La Carbonilla (Llambías, 1966; González Díaz, 1972a). La actividad de este complejo volcánico abarca parte del Pleistoceno y Holoceno entre 0,7 y 0,002 Ma (e.g., Germa et al., 2010; Gudnason et al., 2012; Espanon et al., 2014b; Hernando et al., 2014). Desde la fractura La Carbonilla fueron emitidos varios flujos basálticos que conforman el sector oriental del Campo Volcánico Payún Matru. Los mismos fueron previamente mapeados por
Groeber (1929, 1946), González Díaz (1972a y b, 1979) como un único campo de lava y fueron asignados al Holoceno (González Díaz, 1972a). Núñez (1976) llamó la atención sobre la extensión de la colada Pampas Onduladas y Pasquarè et al. (2008) delimitaron esta colada y el campo de lava Pampa de Los Carrizales, señalando que el mismo presenta una extensión similar a Pampas Onduladas y que además involucró mayores volúmenes de lava.

La colada de lava Pampa de Los Carrizales (CPC) comprende un extenso flujo basáltico compuesto que extruyó desde el segmento oriental de la fractura La Carbonilla (Fig. 2) y que culminó su recorrido en un sector denominado Punta de la Barda, situado a los $37^{\circ} 8^{\prime} \mathrm{S}$ y $67^{\circ} 14^{\prime} \mathrm{O}$. El flujo lávico Pampa de Los Carrizales fue datado mediante

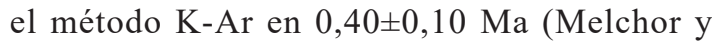
Casadío, 1999). En la presente investigación se obtuvo una nueva edad para la colada adyacente denominada Pampas Onduladas de 0,307 $\pm 0,020 \mathrm{Ma}$, similar a las obtenidas por Espanon et al. (2014a) de $0,373 \pm 0,010 \mathrm{Ma}$ y por May et al. (2018) de $0,384 \pm 0,050 \mathrm{Ma}$ mediante las metodologías ${ }^{40} \mathrm{Ar} /{ }^{39} \mathrm{Ar}$ e isótopos ${ }^{3} \mathrm{He}_{\mathrm{c}} \mathrm{y}{ }^{21} \mathrm{Ne}_{\mathrm{c}}$, respectivamente. La efusión de los dos flujos precedió la formación de la caldera del Payún Matru ocurrida entre los 0,148 y 0,082 Ma (Germa et al., 2010; Hernando et al., 2014).
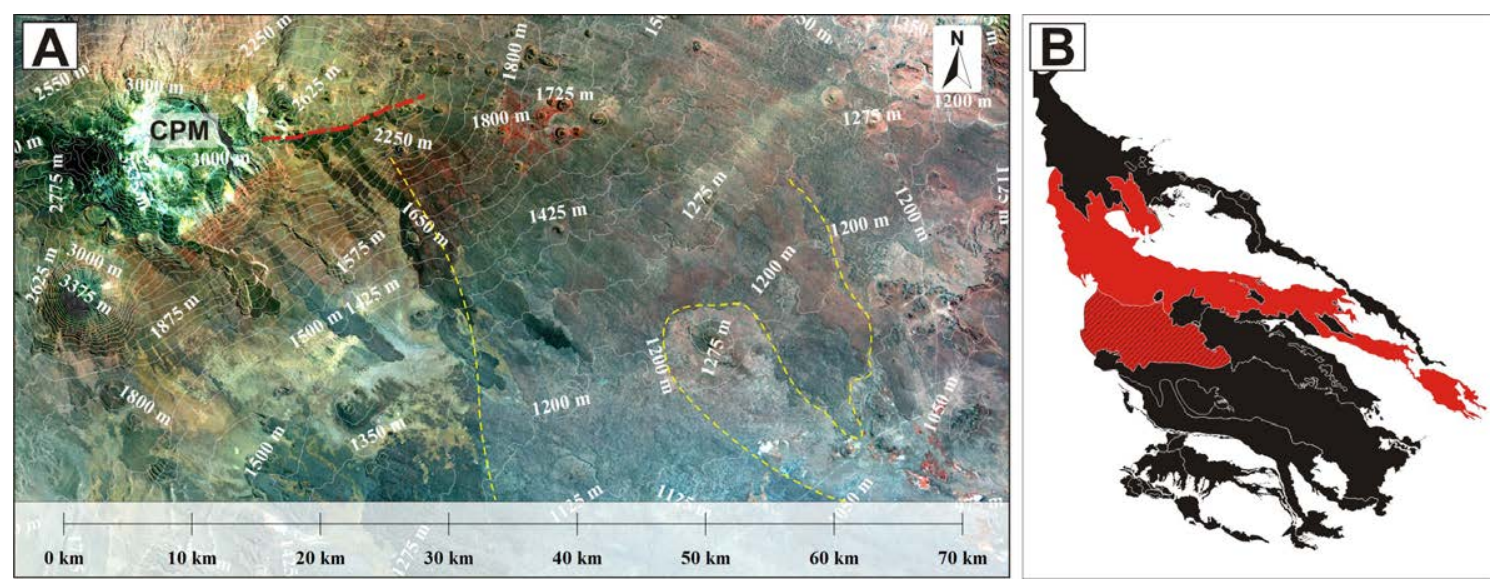

FIG. 2. A. Imagen Landsat 7 (RGB321) del sector de extrusión de la colada de lava Pampa de Los Carrizales (CPC). Se observa el sector oriental de la fractura La Carbonilla (indicada en línea de trazos rojos), la caldera del Payún Matru (CPM) al oeste y la porción proximal de la CPC (indicada en líneas de trazos amarillos). También se indican las curvas de nivel. B. Localización de la colada Pampa de Los Carrizales (en rojo) en el marco de las coladas consideradas en el transcurso de este estudio. 
TABLA 2. CARACTERÍSTICAS Y EDADES DE LAS COLADAS DE LAVA CONSIDERADAS EN ESTE ESTUDIO. EL ORDENAMIENTO ESTRATIGRÁFICO SE LLEVÓ A CABO SOBRE LA BASE DE LAS RELACIONES DE CAMPO Y EDADES RADIMÉTRICAS OBTENIDAS POR OTROS AUTORES Y EN EL TRANSCURSO DE ESTE TRABAJO.

\begin{tabular}{|c|c|c|c|c|c|c|c|}
\hline $\begin{array}{l}\text { Época } \\
\text { eruptiva }\end{array}$ & Colada & Centro eruptivo & $\begin{array}{l}\text { Edad } \\
\text { (Ma) }\end{array}$ & $\begin{array}{r}\text { Long. } \\
(\mathrm{km})\end{array}$ & Sup. $\left(\mathbf{k m}^{2}\right)$ & $\begin{array}{l}\text { Vol. } \\
\left(\mathbf{k m}^{3}\right)\end{array}$ & Tipo de flujo \\
\hline \multirow{3}{*}{$\begin{array}{l}\text { Pleistoceno } \\
\text { medio }\end{array}$} & CEP & VN Morado (C) & $0,200 \pm 0,027$ (1) & 70 & 856,2 & 4 & $\begin{array}{l}\text { Pahoehoe tipo "P". Relieve hummocky uniformemente } \\
\text { distribuido }\end{array}$ \\
\hline & $\mathrm{CPO}$ & \multirow[t]{2}{*}{$\begin{array}{l}\text { CAMPO Volcánico } \\
\text { Payún Matru }\end{array}$} & $\begin{array}{l}0,307 \pm 0,02(1) \\
0,373 \pm 0,01(2) \\
0,384 \pm 0,050\end{array}$ & $\begin{array}{l}167 \text { (a) } \\
181 \text { (b) }\end{array}$ & $\begin{array}{l}739 \text { (a) } \\
978 \text { (b) }\end{array}$ & 7,2 (a) & $\begin{array}{l}\text { PAHOEHOE tipo "P". Techo plano con relieve } \\
\text { hummocky localizado. }\end{array}$ \\
\hline & $\mathrm{CPC}$ & & $0,40 \pm 0,10(4)$ & 181,2 & 2.570 & 16,5 & $\begin{array}{l}\text { Pahoehoe tipo "P". Techo plano con relieve hummocky } \\
\text { localizado. }\end{array}$ \\
\hline \multirow{4}{*}{$\begin{array}{l}\text { Pleistoceno } \\
\text { inferior }\end{array}$} & $\mathrm{CDM}$ & VN Morado (S) & $0,795 \pm 0,050(1)$ & 2,6 & 4,2 & 0,01 & Pahoehoe tipo "P". Techo plano. \\
\hline & CEC & VN Huanul & $\sim 0,84 \pm 0,05(5)$ & 70 & 415 & 2 & $\begin{array}{l}\text { Pahoehoe tipo "P". Techo plano con relieve hummocky } \\
\text { localizado. }\end{array}$ \\
\hline & MBVC & $\begin{array}{l}\text { CAMPO Volcánico } \\
\text { Auca Mahuida }\end{array}$ & $0,862 \pm 0,050(1)$ & $40-60$ & 176 & - & Pahoehoe tipo "P". Techo plano. \\
\hline & CLB & $\mathrm{N} / \mathrm{D}$ & $\begin{array}{l}\sim 1,8 \pm 1(6) \\
\sim 2,3 \pm 1(6)\end{array}$ & - & - & - & - \\
\hline $\begin{array}{l}\text { Plioceno } \\
\text { superior }\end{array}$ & CPL & \multirow{2}{*}{$\begin{array}{l}\text { CAMPO volcánico } \\
\text { Chachahuén }\end{array}$} & $2,85 \pm 0,18(1)$ & 122 & 1.020 & 7,5 & $\begin{array}{l}\text { Pahoehoe tipo "P" con transiciones locales pahoehoe- } \\
\text { a'a. Techo plano. }\end{array}$ \\
\hline $\begin{array}{l}\text { Plioceno } \\
\text { Inferior }\end{array}$ & $\mathrm{CPR}$ & & $\begin{array}{l}\sim 3,8 \pm 0,3(7) \\
\sim 5,1 \pm 0,9(7)\end{array}$ & 116 & 1.890 & 9,5 & $\begin{array}{l}\text { Pahoehoe tipo "P". Techo plano con relieve hummocky } \\
\text { localizado. }\end{array}$ \\
\hline
\end{tabular}

Referencias. Edades: (1) K-Ar, este trabajo; (2) $\mathrm{Ar}^{40} / \mathrm{Ar}^{39}$, Espanon et al. (2014a); (3) ${ }^{3} \mathrm{He}_{\mathrm{c}}-{ }^{21} \mathrm{Ne}$, May et al., 2018; (4) K-Ar, Melchor y Casadío (1999); (5) K-Ar, Bertotto et al. (2006a); (6) K-Ar, Núñez (1976); (7) K-Ar, Cortelezzi y Dirac (1969). Morfometría: este trabajo excepto (a) Espanon et al. (2014a); (b) Pasquaré et al. (2008). Siglas de coladas: CPR: Pampa de Ranquelcó; CPL: Pampa de Luanco; CLB: La Barranca; MBVC: Meseta Basáltica Valle del Colorado; CEC: El Corcovo; CDM: Del Morado; CPC: Pampa de Los Carrizales; CPO: Pampas Onduladas; CEP: El Puesto. 
El sustrato de la colada de lava Pampa de Los Carrizales en sus sectores proximales comprende en parte a la antigua planicie basáltica del Grupo Palaoco (Oligoceno-Mioceno) (Fig. 3). En los sectores medios, el margen norte de la colada Pampa de Los Carrizales es subyacida por un campo lávico más joven que las lavas del Grupo Palaoco, aquí denominado La Barranca. Estos flujos fueron datados por Núñez (1976) entre 2,3 \pm 1 Ma (puesto Piedras Coloradas) y $1,8 \pm 1 \mathrm{Ma}$ (puesto Limarna). En el sector central de la porción media del flujo, entre los puestos Piedras Coloradas y Chos Malal, una ventana lávica permite observar que estas lavas cubrieron localmente granitoides intrusivos asignados al magmatismo permotriásico de Choiyoi (González Díaz, 1972a y c) mientras que, hacia el sur, Pampa de Los Carrizales bordea a la extensa colada de lava Pampa de Ranquelcó (Bernardi, 2016). Se infiere que el límite austral del flujo Pampa de Los Carrizales en sus tramos proximales y medio-inferiores son los sectores basales de las Sierras de Chachahuén
(Fig. 3, área con líneas oblicuas). En las porciones terminales, la colada asienta sobre rocas sedimentarias correspondientes al Cretácico superior-Paleoceno, Eoceno y Mioceno superior.

La CPC está conformada por un flujo compuesto de fisonomía y características morfoestructurales muy similares a la cuasi-contemporánea Pampas Onduladas, la cual se extiende al norte de Pampa de Los Carrizales y presenta una trayectoria casi paralela a esta última (Fig. 3). La CPC exhibe una morfología elongada en planta y un perfil longitudinal plano-cóncavo. La dirección de movimiento de la colada presenta, en general, una componente promedio hacia el sureste. El mismo alcanzó una longitud de 181,2 km, con anchos variables entre $18 \mathrm{~km}$ (medio-proximal) y $\sim 5 \mathrm{~km}$ (distal), cubriendo un área mínima de $2.570 \mathrm{~km}^{2}$. La morfología superficial de la CPC se encuentra definida por un relieve tipo hummocky producido por la alta densidad de estructuras de inflación (túmulos, elevaciones de techo plano, dorsales de inflación y pozos de inflación). Este tipo de relieve

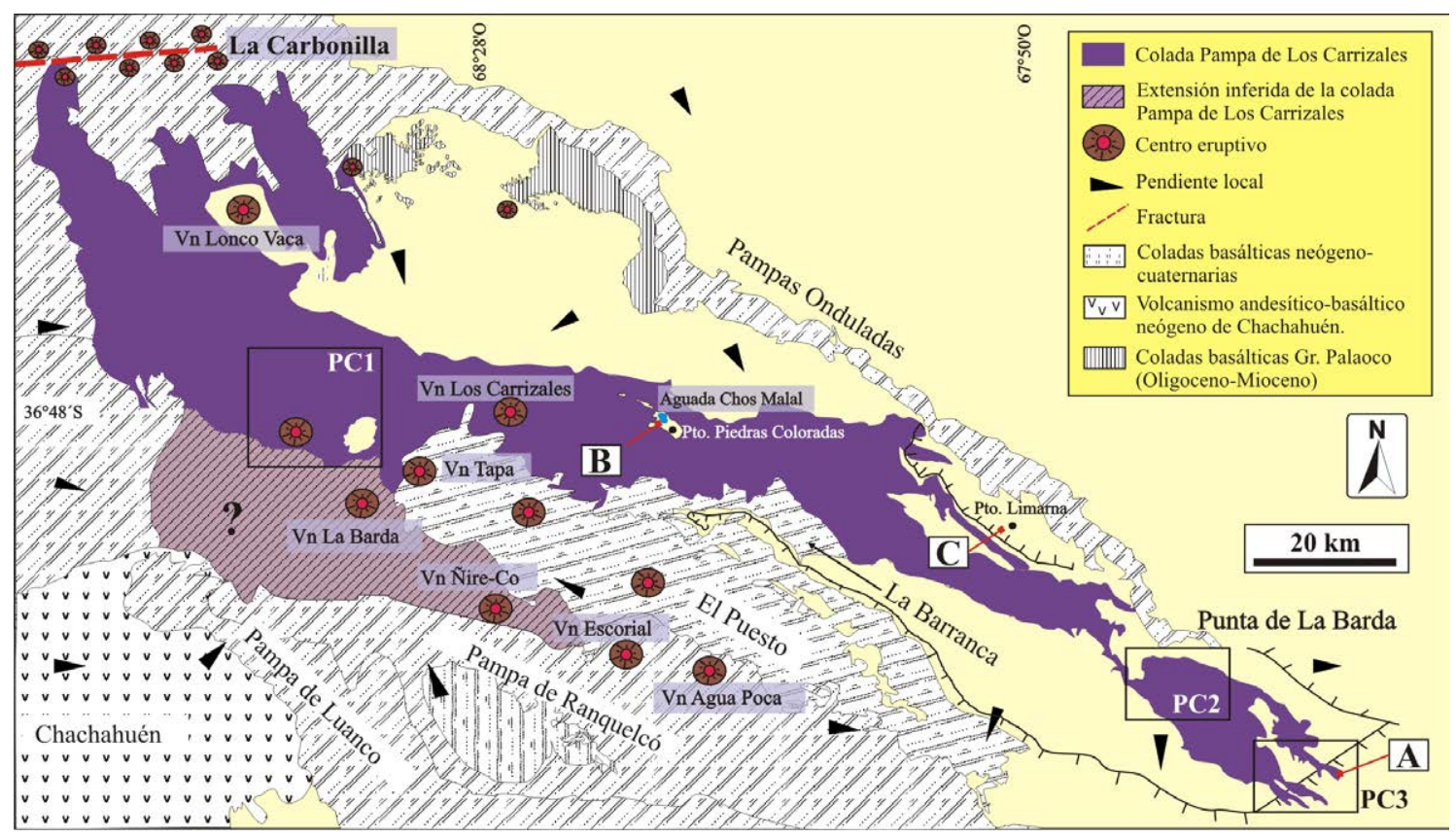

FIG. 3. Mapa de detalle de la colada de lava Pampa de Los Carrizales en la que se observa la ubicación del sector de extrusión, la relación con otros flujos lávicos y las direcciones de las pendientes locales actuales del terreno circundante. Además se indican los centros eruptivos cercanos y la localización de los sitios de estudio (PC1, PC2 y PC3). El área marcada con líneas oblicuas y diferente color es inferida ya que esta zona se presenta cubierta por sedimentación moderna y sólo se observan algunos asomos

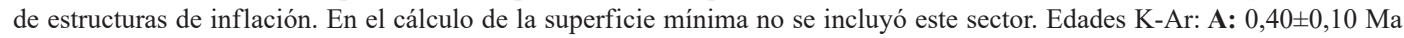

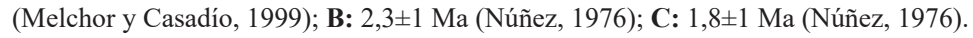


da lugar a una geomorfología en domos y cuencas de escala métrica a hectométrica, donde los sectores deprimidos, corresponden a porciones del flujo sin inflación o a estructuras colapsadas por gravedad o deflación que han sido colmatados por sedimentos modernos. La deflación es el proceso opuesto a la inflación que resulta del vaciamiento de la estructura por drenaje de la lava acumulada en su interior hacia otros sectores de la colada a través de túneles de lava. Los relieves positivos generados por acumulación de lava determinan el contraste con la cobertura arenosa y permiten distinguir las trayectorias del flujo. Las secciones transversales presentan una distribución interna de sectores vesiculares y masivos correspondientes a la de un flujo pahoehoe tipo $\mathrm{P}$ (Wilmoth y Walker, 1993), el cual contiene un núcleo interno denso, una corteza vesicular superior y una corteza vesicular inferior, de menor desarrollo que la primera (Fig. 4).

Se determinaron espesores entre 4, 6 y $8 \mathrm{~m}$ en sus porciones medias superiores y terminales (sitios PC2 y PC3 en Fig. 3). Una gran parte de la superficie de los sectores proximales y medio inferiores se encuentra subaflorando entre la cobertura clástica como islas o planchas de basalto, las cuales corresponden principalmente a los techos de las estructuras infladas de la colada. Es frecuente observar elevaciones de techo plano con fenómenos de deflación con sectores internos colmatados por montículos de arena (Fig. 5A). En el sector proximal sólo se pudieron estimar espesores aflorantes de entre 6 y $12 \mathrm{~m}$ en los márgenes de un kipuka (sitio PC1 en Fig. 3). En los sectores distales muchas de estas estructuras infladas presentan alturas de 4 a $5 \mathrm{~m}$ por sobre el flujo circundante sin inflación, por lo que el espesor total de estos sectores variaría entre $8 \mathrm{y}$ $10 \mathrm{~m}$ ya que se infiere que un $50 \%$ de la superficie de la colada corresponde a estructuras de inflación. A partir de estos aspectos, se estimó un volumen de lava mínimo de $16,5 \mathrm{~km}^{3}$ para la colada Pampa de Los Carrizales. La colada circuló sobre un terreno con algunas irregularidades y obstáculos del relieve evidenciadas por numerosos kipukas que actualmente funcionan como pequeñas cubetas sedimentarias, desagües de cuencas endorreicas que dan lugar a salitrales, o bien conservan remanentes del relieve que obstaculizó el paso de la colada. El sentido general de desplazamiento del flujo es acorde con la dirección de inclinación de la pendiente regional actual, la cual no supera $\operatorname{los} 0,5^{\circ} \mathrm{SE}$. En sectores medios a distales del flujo

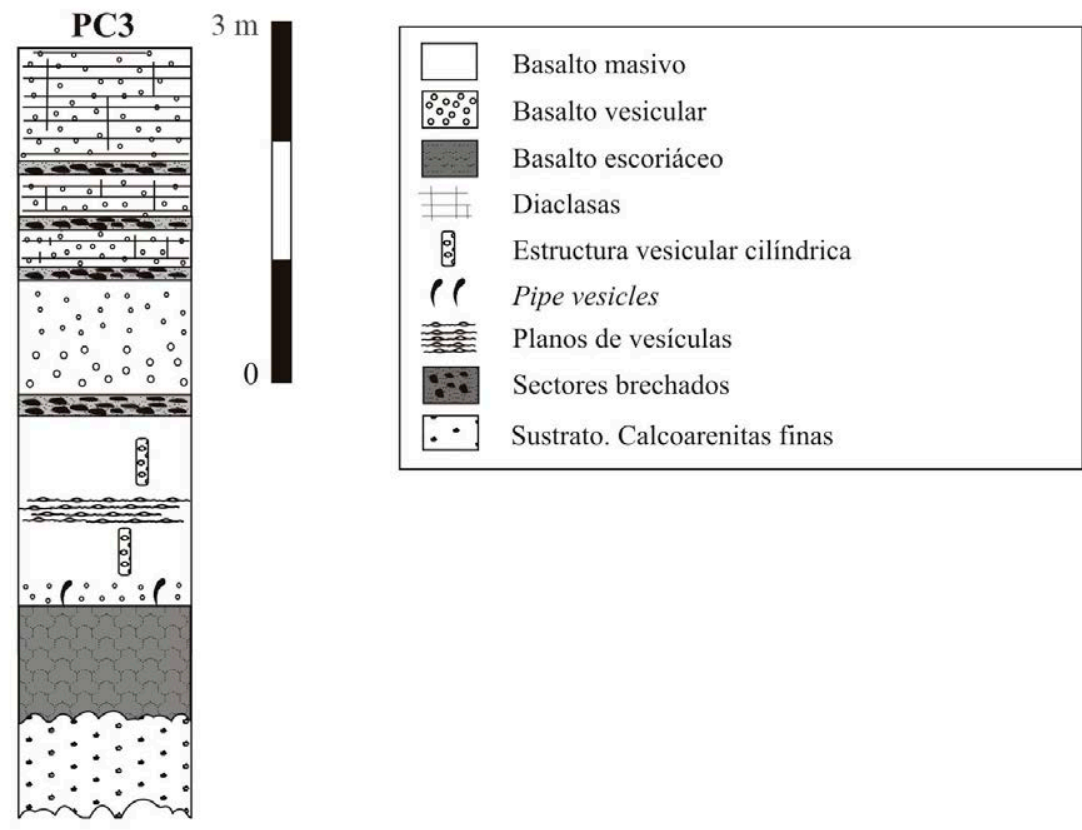

FIG. 4. Perfil de la porción terminal de la colada de lava Pampa de los Carrizales en el sitio PC3. 
es común observar extensas fajas paralelas direccionadas con alta concentración de estructuras de inflación, representadas principalmente por túmulos y elevaciones de techo plano dispuestas a favor del sentido del flujo. Estas fajas poseen entre 500 y $700 \mathrm{~m}$ de ancho y se encuentran separadas entre sí por segmentos de flujo sin inflación (Fig. 5B y C). Por otra parte, se observan frecuentemente cadenas de túmulos y dorsales de inflación alineadas paralelamente a la dirección del flujo (Fig. 5D). Las secciones transversales de estas geoformas son suaves, simétricas y en ocasiones exhiben un débil fracturamiento axial.

\subsection{Colada de lava EI Puesto}

La colada lávica El Puesto (CEP) comprende un flujo basáltico de notable extensión ubicado en el sector central del área de estudio (Fig. 6). Se infiere que extruyó desde el volcán Morado (C) situado a los $36^{\circ} 51^{\prime}$ S y $68^{\circ} 21^{\prime} \mathrm{O}$ (sitio EP1 en Fig. 7) y culminó su recorrido en las proximidades del salitral de $\mathrm{La}$ Copelina, ubicado a los $37^{\circ} 12^{\prime} \mathrm{S}$ y $67^{\circ} 35^{\prime} \mathrm{O}$ (sitio EP3 en Fig. 7). El volcán Morado (C) es una elevación mesetiforme de contorno semicircular sin cráter, con una altura promedio de $25 \mathrm{~m}$ con respecto al terreno circundante, un diámetro basal medio de $260 \mathrm{~m}$ y un diámetro superior de aproximadamente $45 \mathrm{~m}$. Las rocas del cerro Morado (C) fueron asignadas al Plioceno (Wichmann, 1928), Pleistoceno (Sobral, 1942) y Holoceno (Núñez, 1976). En este trabajo se presenta una edad K-Ar de 0,200 $\pm 0,027 \mathrm{Ma}$ (Pleistoceno medio) para las lavas de este cerro.

El sustrato de la colada El Puesto se encuentra conformado al norte por gran parte del margen sur de la colada Pampa de Los Carrizales $(0,40 \pm 0,10 \mathrm{Ma})$ y por el campo lávico La Barranca $(1,8 \pm 1 \mathrm{Ma}, 2,3 \pm 1 \mathrm{Ma})$. $\mathrm{Al}$ centro y sur suprayace al flujo lávico Pampa de Ranquelcó (Fig. 7).
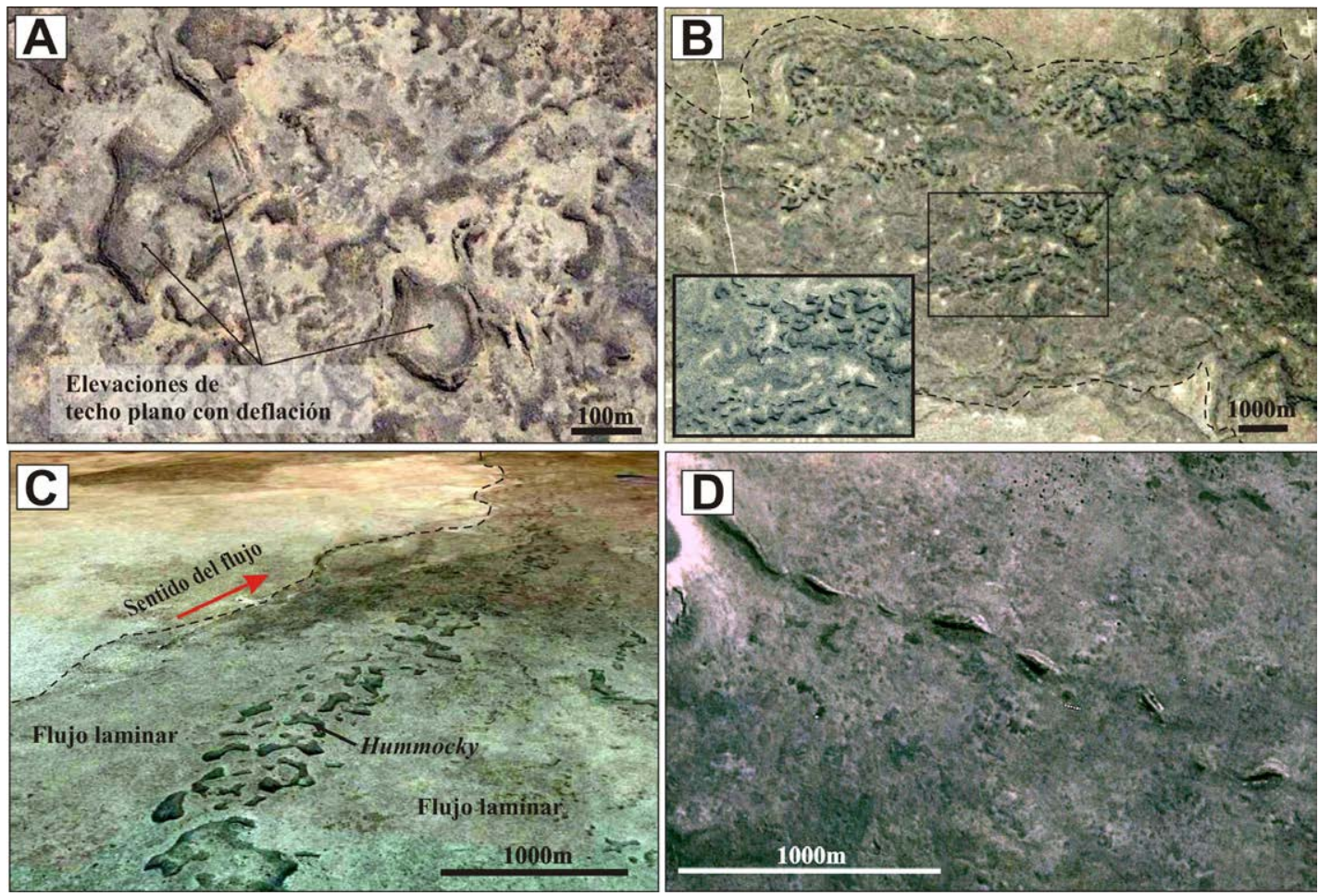

FIG. 5. Estructuras de inflación en el flujo de lava Pampa de los Carrizales. Imágenes satelitales de Google Earth. A. Elevaciones de techo plano con deflación de sus sectores centrales, ubicadas en la porción proximal del flujo de lava. Se observan también las fracturas periféricas que se generan en los márgenes de la estructura durante la inflación; B-C. Fajas de estructuras de inflación desarrolladas sobre un flujo de lava de estructura laminar situadas en el sector distal de la colada; D. Cadena de túmulos y dorsales dispuestos paralelamente a la dirección del flujo. 


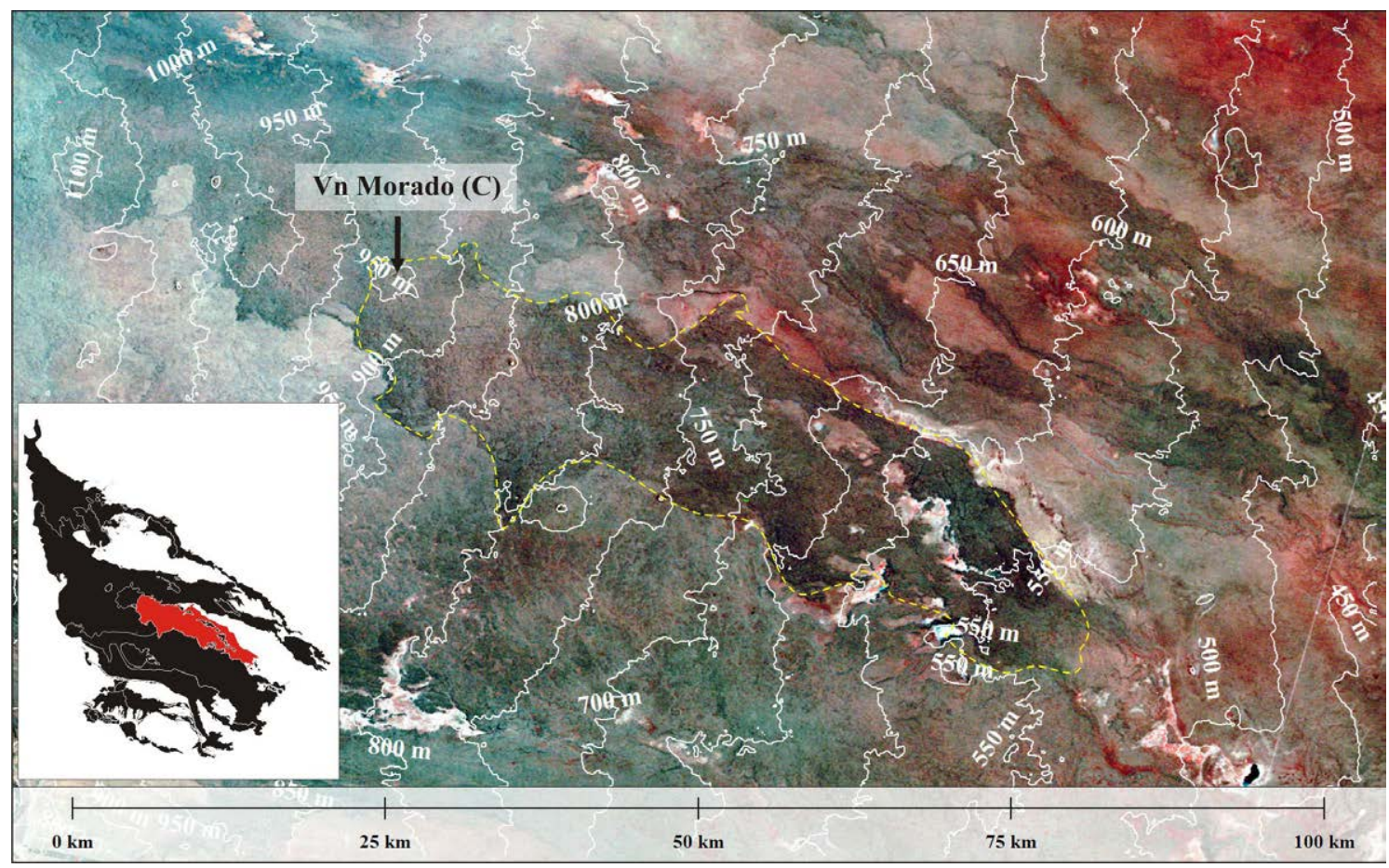

FIG. 6. Colada de lava El Puesto. Geomorfometría. A. Imagen Landsat 7 en falso color compuesto (RGB741). Se indican las curvas de nivel y la ubicación del centro eruptivo. Con línea de trazos amarillos se indica la extensión de la colada. En el recuadro ubicado en la parte inferior izquierda de la figura se indica (en rojo) la posición de la colada de lava El Puesto en relación al resto de los flujos lávicos considerados en este estudio.

La colada El Puesto está representada por un flujo simple en la mayor parte de su recorrido, mientras que en sus $15 \mathrm{~km}$ iniciales exhibe hasta tres unidades superpuestas. La dirección de movimiento del flujo presenta una componente predominantemente sureste con algunos derrames de poca extensión hacia el oeste, noroeste y sur del centro eruptivo (Fig. 7). El flujo alcanzó un desarrollo longitudinal de $70 \mathrm{~km}$, presenta un ancho promedio de $11 \mathrm{~km}$ con un máximo de $20 \mathrm{~km}$ en su sector medio, cubriendo un área mínima de $856,2 \mathrm{~km}^{2}$. Las estructuras de inflación alcanzan alturas variables entre 5 y $10 \mathrm{~m}$ con respecto al terreno adyacente $\mathrm{y}$, en sus márgenes distales, se pudieron determinar potencias promedio de hasta $5 \mathrm{~m}$ para sectores del flujo sin inflación. El volumen mínimo de lava obtenido fue de $4 \mathrm{~km}^{3}$.

La CEP presenta una morfología elongada de traza media rectilínea con márgenes irregulares y numerosos kipukas lo cual hace suponer un sustrato con altos topográficos. Inicialmente, la colada se desplazó sobre un sustrato mayormente basáltico.
En un punto del margen norte de la CEP, situado a unos $12 \mathrm{~km}$ al este del sitio de extrusión, se produjo el primero de varios derrames de rumbo noreste hacia el interior de una paleodepresión elongada en sentido noroeste-sureste denominada Bardas Bayas. Esta paleodepresión tiene un ancho variable entre 5 y $8 \mathrm{~km}$ y se extiende por unos $60 \mathrm{~km}$ culminando en el salitral de La Copelina. Los derrames lávicos hacia el interior de la depresión coalescieron dando lugar a la formación de un flujo secundario, paralelo al cuerpo de lava principal, el cual ocupó de manera parcial a total el fondo plano de la depresión. En este sector, la colada se desplazó sobre depósitos sedimentarios cretácico-paleógenos. Este ramal presenta una longitud de $46 \mathrm{~km}$ y anchos que varían entre los 1,5 y $5 \mathrm{~km}$.

Los afloramientos relevados de la colada El Puesto presentan los rasgos típicos de un flujo pahoehoe tipo $\mathrm{P}$, con dos sectores vesiculares externos rodeando un núcleo de baja vesiculación, el cual aloja estructuras de segregación vesiculadas (Bernardi et al., 2016, 2018). No obstante lo anterior, los 


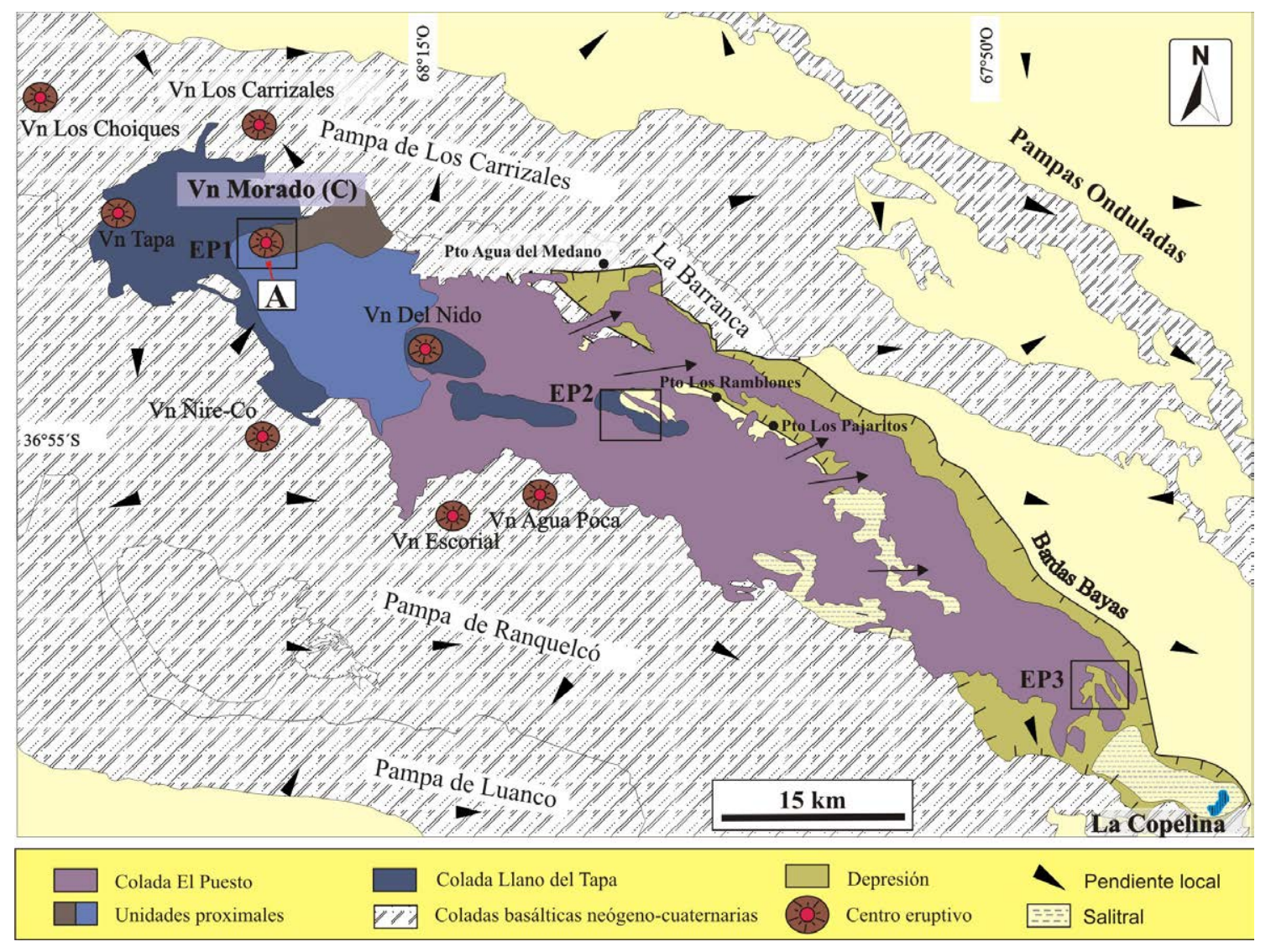

FIG. 7. Mapa de detalle de la colada de lava El Puesto en la que se indica: la relación con los otros flujos lávicos emplazados en el sector, las pendientes locales actuales del terreno circundante, los centros eruptivos cercanos y la localización de los sitios de estudio (EP1, EP2 y EP3). Las flechas negras muestran los sucesivos derrames hacia el paleovalle de Bardas Bayas que

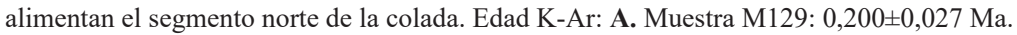

aspectos morfoestructurales más importantes que se observan son aquellos originados principalmente por acumulaciones locales de lava. La CEP es la colada relevada con la mayor concentración de geoformas generadas por inflación de toda el área de estudio. Dentro de las estructuras observadas los túmulos (Fig. 8A) constituyen las de mayor abundancia siguiendo las elevaciones de techo plano (Fig. 8B), dorsales de inflación (Fig. 8C), pozos de inflación (Fig. 8D) y túneles lávicos. El caso más notable de estas últimas estructuras lo constituye la "Cueva de Halada" (Fig. 9). Se trata de un túnel maestro situado a los $36^{\circ} 57^{\prime} \mathrm{S}$ y $68^{\circ} 05^{\prime} \mathrm{O}$, en el sector medio de la CEP (sitio EP2). Morfológicamente comprende un conducto de techo arqueado que se ramifica en tres galerías de escasa longitud. El largo mínimo medido del túnel es de 369,5 m, con un desnivel de 10,2 m respecto a la boca de entrada. La altura máxima es de 2,2 $\mathrm{m}$ y su ancho máximo es de 22,9 m (Bertotto, 1996; Martínez, 1998). Según la clasificación sugerida por Calvari y Pinkerton (1999) basada en la morfología de los túneles lávicos, el túnel de Halada exhibe características de un túnel simple y simétrico, formado a partir del enfriamiento de la corteza alrededor de un flujo inflado estable. Otro tipo de túneles de lava fueron observados en un campo de túmulos situado en la porción distal de la CEP. Se trata de túneles secundarios que exhiben escala métrica a centimétrica y atraviesan longitudinalmente a los túmulos en los que se encuentran alojados. Otros aspectos que revelan la existencia de túneles de lava en profundidad comprenden: alineaciones de túmulos, desarrollo de dorsales de inflación y apófisis que unen y alimentan elevaciones de techo plano. 

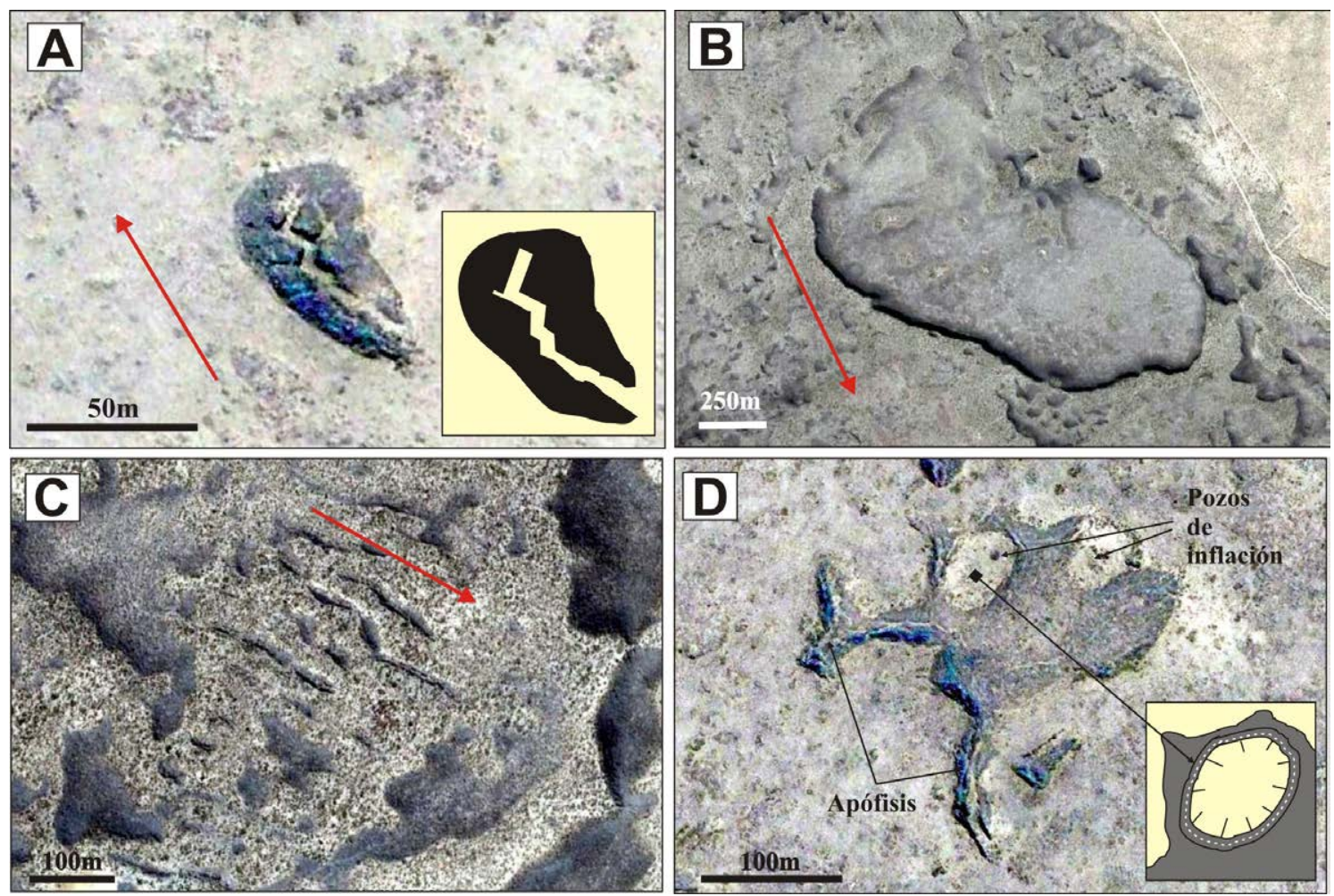

FIG. 8. Estructuras de inflación de la colada de lava El Puesto. A. Túmulo. Geometría en planta y patrón de fractura axial; B. Elevación de techo plano elíptica con una longitud de $1500 \mathrm{~m}$ en su eje mayor y una altura de hasta $10 \mathrm{~m}$ con respecto al flujo circundante; C. Agrupamiento de dorsales de inflación y túmulos con disposición paralela a la dirección de flujo; D. Pozos de inflación de geometría subcircular y rellenos por sedimentos arenosos con estructuras fracturas anulares en sus bordes. Se observan apófisis que sobresalen de la elevación de techo plano, las cuales en ocasiones vinculan dos o más de estas estructuras. Las flechas rojas indican el sentido de movimiento del flujo.

\subsection{Colada de lava Pampa de Ranquelcó}

La colada Pampa de Ranquelcó (CPR) comprende un flujo compuesto de gran extensión situado en la región centro-sur del área de estudio. Se estima que la misma tuvo origen a partir de la efusión de numerosos centros eruptivos situados en el cuadrante noreste del complejo volcánico Chachahuén. La misma se desplazó con sentido este-sureste culminando su recorrido en los alrededores de la localidad de Puelén, en la provincia de La Pampa (Fig. 10).

Las rocas de los conos periféricos al complejo volcánico Chachahuén y algunos de sus productos lávicos básicos asociados fueron asignados al Plioceno superior y Cuaternario (Holmberg, 1962; Kay et al., 2006b). Cortelezzi y Dirac (1969) incluyeron a las lavas de Pampa de Ranquelcó dentro del Plioceno inferior, a partir de la obtención de edades comprendidas entre
$3,8 \pm 0,8$ y $5,1 \pm 0,9$ Ma sobre muestras de las porciones terminales del flujo. La colada Pampa de Ranquelcó está delimitada al sur por la colada Pampa de Luanco e infrayace a las coladas Pampa de Los Carrizales $(0,40 \pm 0,10 \mathrm{Ma})$ y El Puesto $(0,200 \pm 0,027 \mathrm{Ma})$ en su margen norte. Se presentan algunos conos monogenéticos coronando esta planicie lávica los cuales emitieron pequeñas coladas y productos piroclásticos sobre la misma. Entre éstos se encuentran el volcán Escorial y el volcán Agua Poca el cual fue datado en 0,64 $\pm 0,04 \mathrm{Ma}$ (Bertotto et al., 2006a).

El frente de la colada Pampa de Ranquelcó presenta disposición submeridional y bordea parte del margen noroeste de la laguna Gran Salitral, situada a los $37^{\circ} 29^{\prime} \mathrm{S}$ y $67^{\circ} 27^{\prime} \mathrm{O}$. En este sector pudo observarse parte del sustrato sobre el que se desplazó la colada, conformado por depósitos sedimentarios correspondientes al Mioceno superior. 

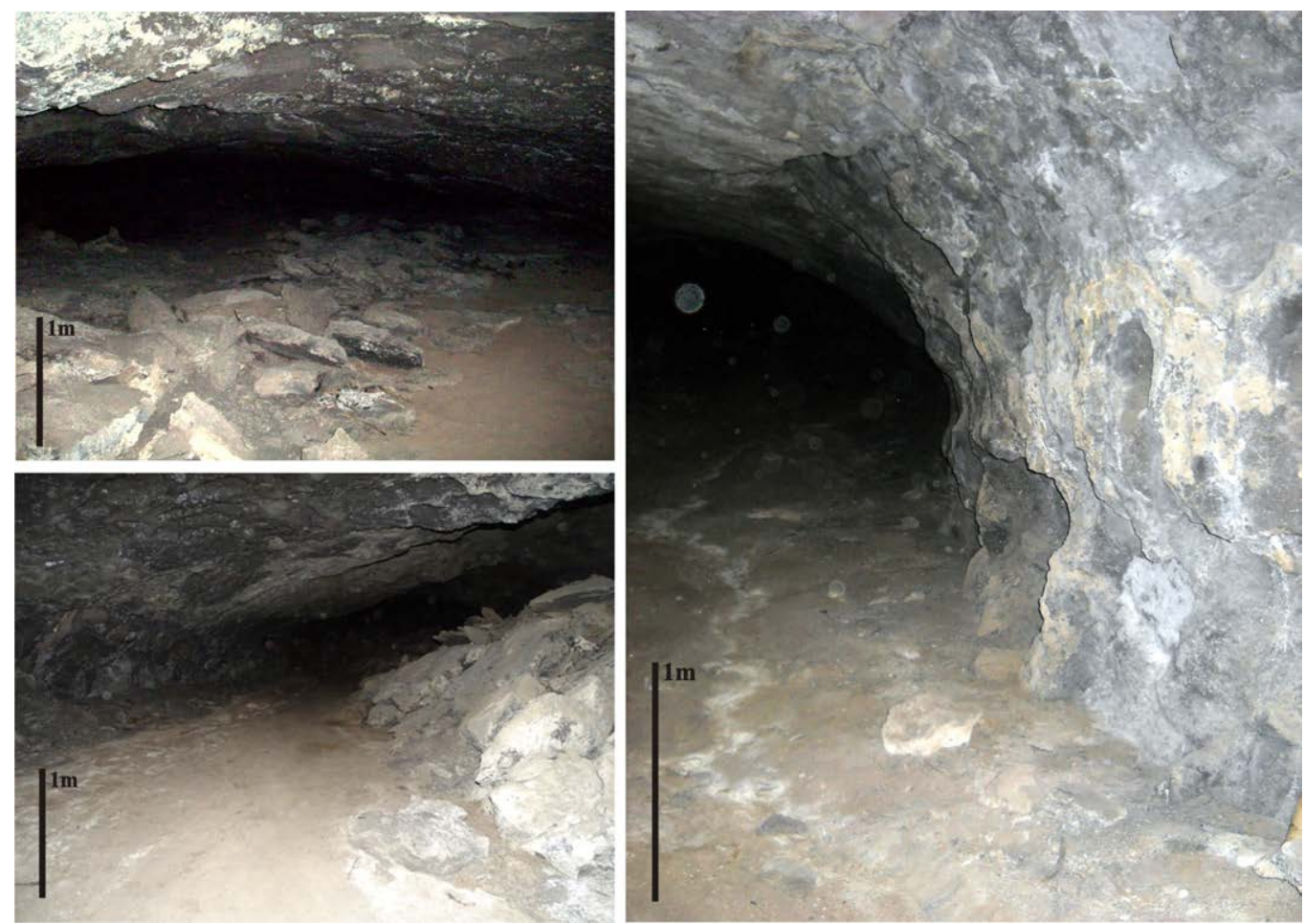

FIG. 9. Túnel de lava maestro "Cueva de Halada" en la colada de lava El Puesto. Sección transversal del sector del túnel debajo de la boca de acceso. Esta sección es la que presenta el mayor ancho de toda la estructura y corresponde al conducto o galería principal. Presenta techo arqueado y una altura máxima de $2 \mathrm{~m}$.

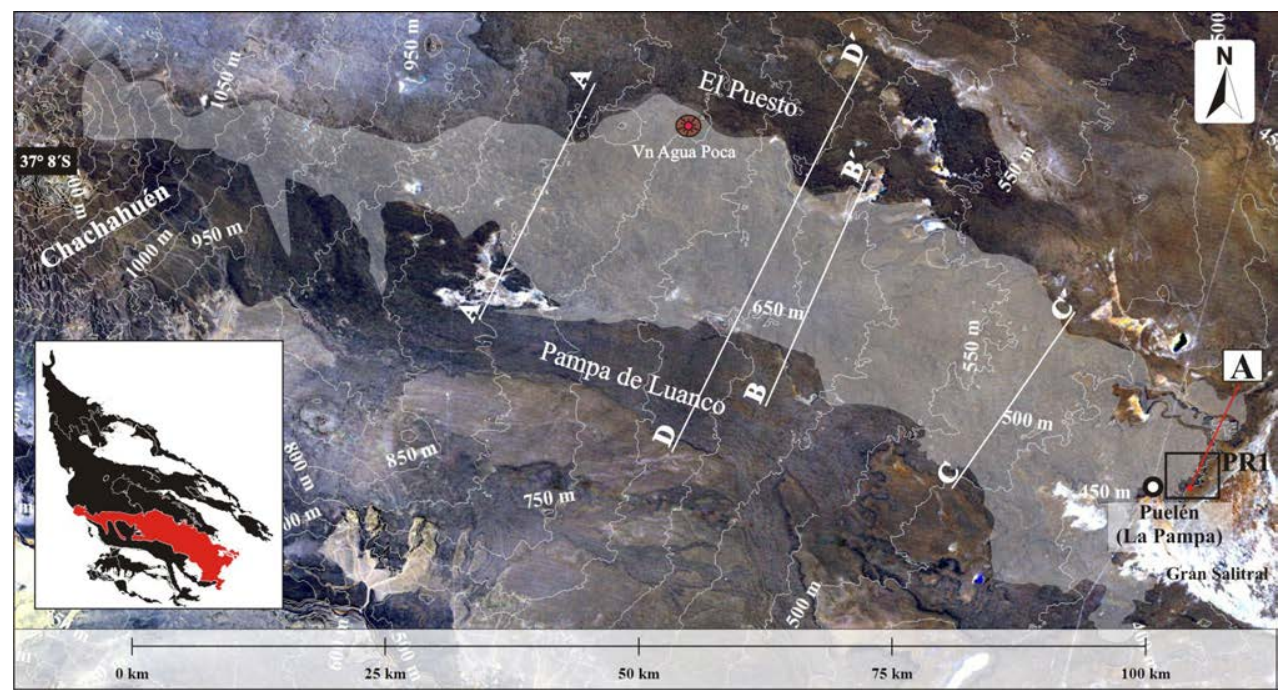

FIG. 10. Colada de lava Pampa de Ranquelcó. Imagen Landsat 3 en falso color compuesto (RGB431). Se representan las curvas de nivel y se indica la localización del sitio de estudio (PR1). Las líneas blancas A-A', B-B', C-C' y D-D' corresponden a los perfiles transversales a la dirección de flujo de la colada que se muestran en la figura 11. En el recuadro ubicado en la parte inferior izquierda de la figura se indica la posición de la colada de lava Pampa de Ranquelcó (en rojo) en relación al resto de

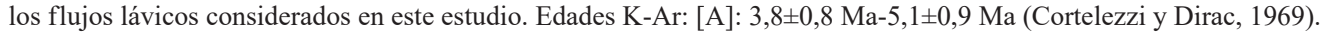


La colada Pampa de Ranquelcó tiene una longitud mínima de $116 \mathrm{~km}$, la mayor amplitud lateral es alcanzada en el frente del flujo con $28 \mathrm{~km}$ de ancho, en el cual la potencia de los afloramientos varía desde 2 a $6 \mathrm{~m}$ en los alrededores de la localidad de Puelén (sitio PR1). Este flujo lávico descendió desde una altitud de aproximadamente $1300 \mathrm{~m}$ s.n.m. en las Sierras de Chachahuén hasta los 430 m s.n.m. en el Gran Salitral, lo cual determina una pendiente regional promedio de $0,4^{\circ}$ hacia el sureste para el sector de emplazamiento de esta colada. Asumiendo que el centro de efusión se ubica en el cuadrante noreste del complejo volcánico Chachahuén, la pendiente local sobre el faldeo del complejo alcanza los 1,4 $4^{\circ} \mathrm{SE}$ somerizándose hasta hacerse casi plana en las porciones medio-distales. La colada se desarrolló como un vasto manto lávico cuyo techo exhibe morfologías lobuladas en planta y perfiles transversales escarpados (Fig. 11). Se estimó un volumen mínimo de $9,5 \mathrm{~km}^{3}$ de lava que se dispersó en un área aproximada de $1.890 \mathrm{~km}^{2}$, la mayor cobertura superficial relevada en el área de estudio. Las irregularidades topográficas de la colada son conferidas por túmulos, elevaciones de techo plano, dorsales de inflación y pozos de inflación. Las elevaciones de techo plano ocupan el mayor porcentaje superficial de la colada mientras que los túmulos aparecen en grupos de manera intermitente en todo el ámbito de la misma. La colada Pampa de Ranquelcó está constituida por lavas pahoehoe infladas que, según las características de su estructura interna, clasifican como flujos tipo P.

\subsection{Colada de lava Pampa de Luanco}

La colada Pampa de Luanco (CPL) es un flujo basáltico de gran extensión situado en la región centro-sur del área de estudio (Fig. 12). Su sector de origen no se focaliza en un volcán en particular, sino que, al igual que la colada Pampa de Ranquelcó, se extruyó simultáneamente desde varios centros eruptivos situados en el cuadrante noreste del complejo ígneo Chachahuén.
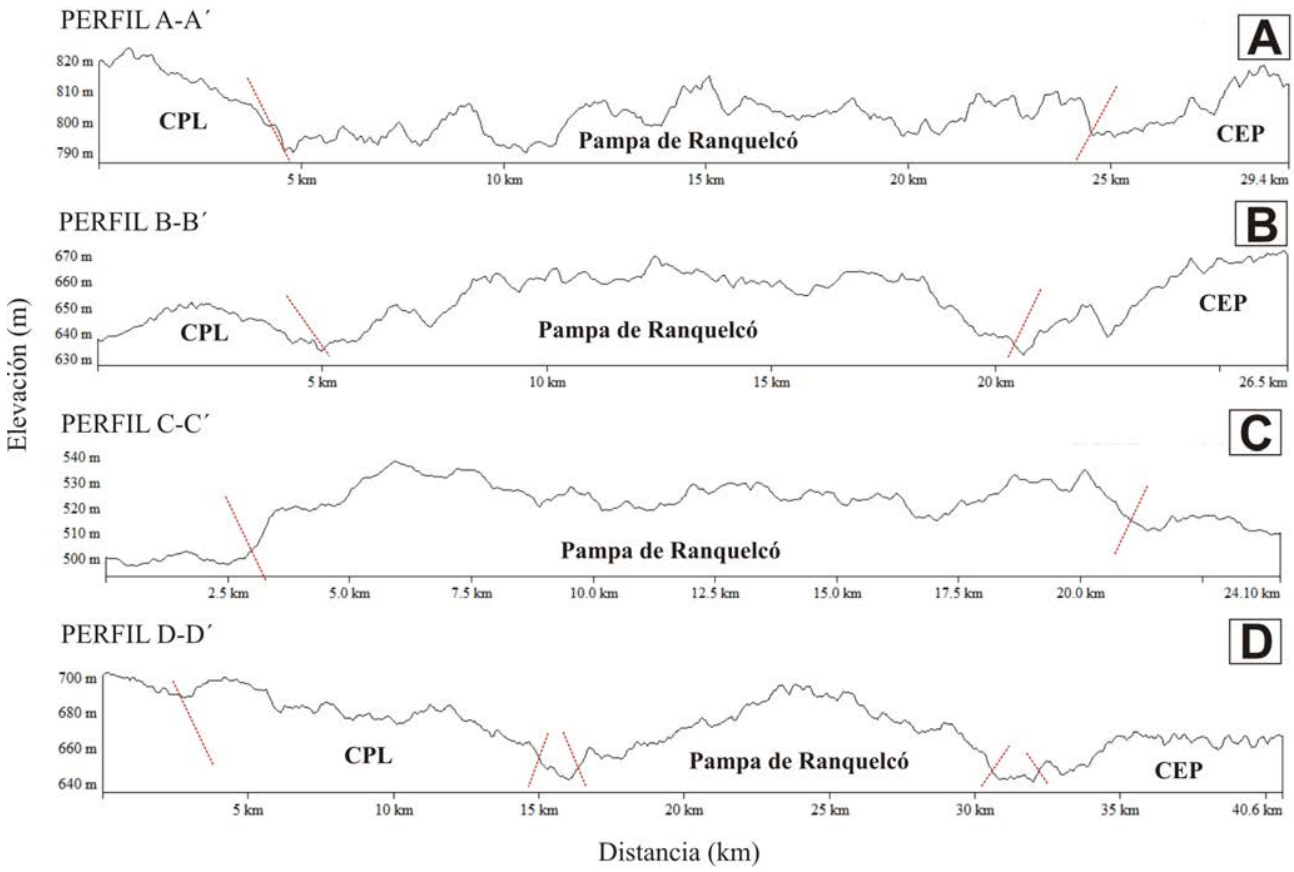

FIG. 11. Perfiles transversales relevados digitalmente en diferentes sitios de la colada de lava Pampa de Ranquelcó, indicados en la figura 10. A. Perfil de la colada en su sector medio inferior. Se destaca el relieve escarpado y deprimido con respecto a la topografía circundante; B. Perfil de sector medio. El relieve escarpado se hace menos acentuado; C. Perfil del sector distal, en el que se invierten las características topográficas observadas en los sectores medios inferiores y el relieve es más uniforme; D. Perfil sur-norte a escala regional de los sectores distales de las coladas Pampa de Luanco (CPL), Pampa de Ranquelcó y El Puesto (CEP). Las líneas de trazos rojos indican los límites entre las coladas 
La CPL es delimitada en su margen norte por el flujo lávico Pampa de Ranquelcó $(3,8 \pm 0,8-5,1 \pm 0,9 \mathrm{Ma})$ y en su sector medio-distal actúa como barrera de la colada El Corcovo de 0,84 $\pm 0,05 \mathrm{Ma}$ (Bertotto et al., 2006b). Cortelezzi y Dirac (1969) incluyeron a las lavas de Pampa de Luanco dentro de un período ubicado entre el Plioceno inferior y Pleistoceno inferior a partir de la obtención de edades $\mathrm{K}-\mathrm{Ar}$ comprendidas entre $2,2 \pm 0,3,2,5 \pm 0,3$ y $5,0 \pm 0,9 \mathrm{Ma}$ sobre muestras de las porciones terminales del flujo (sitio PL1, Fig. 12). Durante este trabajo se obtuvo

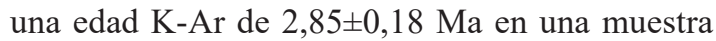
extraída de la porción distal del flujo (sitio PL2, Fig. 12), ubicando a la efusión lávica en el Plioceno superior. En los sectores proximales y medios, el sustrato está conformado por rocas volcánicas y depósitos sedimentarios del Mioceno, Plioceno y Pleistoceno inferior (Holmberg, 1962). En el sector distal, esta colada se subdividió en dos grandes ramales los cuales circularon sobre depósitos sedimentarios del Mioceno superior.

La CPL se encuentra representada por un flujo simple, según lo observado en sus porciones medias y distales, con un desarrollo longitudinal de $122 \mathrm{~km}$. El ancho del flujo varía entre $8 \mathrm{~km}$ (sector proximal) y un máximo de $15 \mathrm{~km}$ (sector medio superior) y exhibe un área de cobertura mínima de $1.020 \mathrm{~km}^{2}$. La lava se movilizó inicialmente con sentido sureste en su tramo

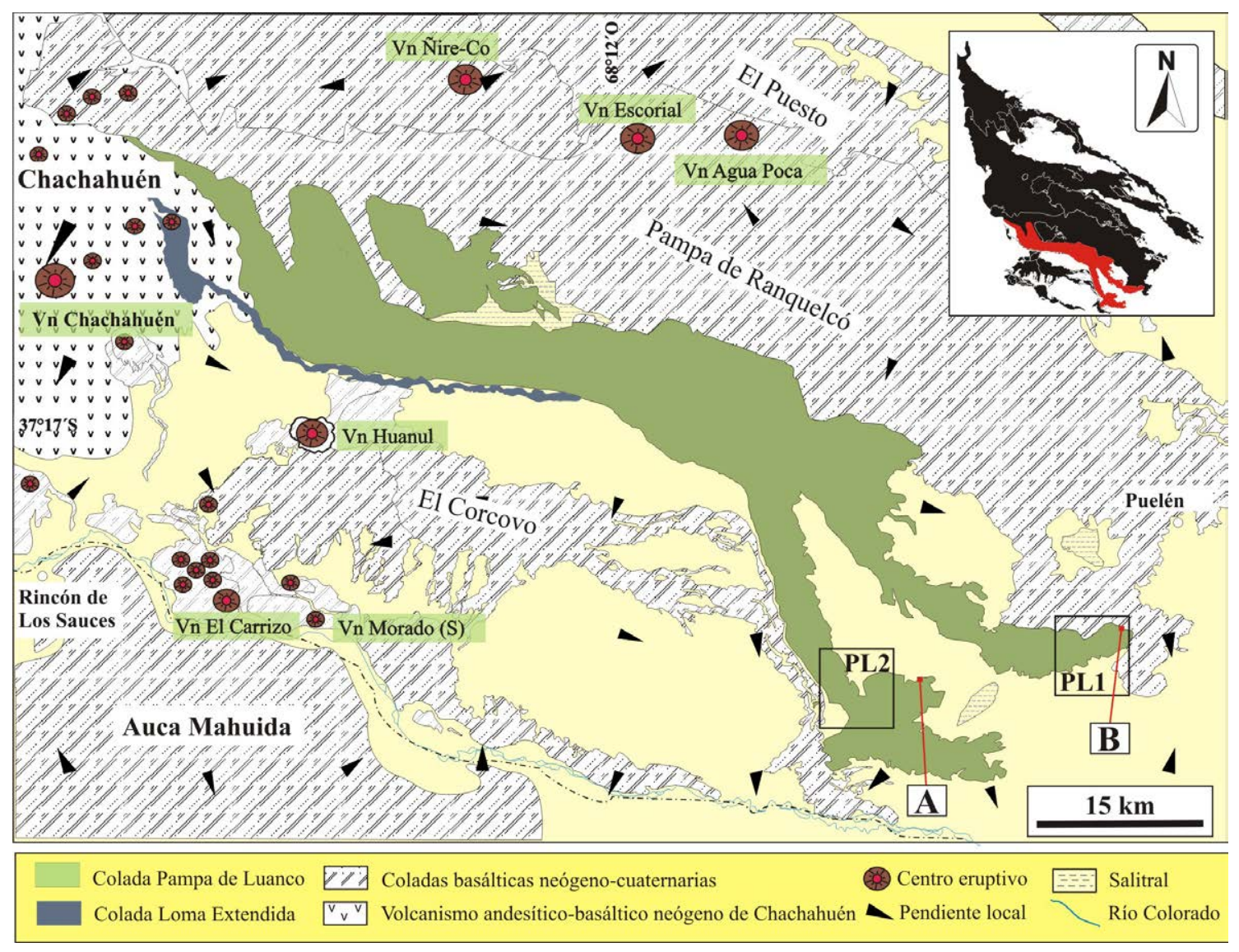

FIG. 12. Mapa de detalle de la colada de lava Pampa de Luanco en la que se observa la ubicación de sector de extrusión, la relación con otros flujos lávicos del sector y las direcciones de las pendientes locales actuales del terreno circundante. Además se indican los centros eruptivos cercanos y la localización de los sitios de estudio (PL1 y PL2). En color gris azulado se indica una angosta colada aquí denominada Loma Extendida, la cual actuó como dique de contención de la CPL en todo su tramo medio. Referencias: A. Muestra MD63: 2,85 $\pm 0,18$ Ma, B. 2,2 $\pm 0,3-2,5 \pm 0,3-5,0 \pm 0,9$ (Cortelezzi y Dirac, 1969). En el recuadro ubicado en la parte superior derecha de la figura se indica la posición de la colada de lava Pampa de Luanco en relación al resto de los flujos lávicos considerados en este estudio. 
proximal y hacia el este en su tramo medio. En su sector distal la misma se subdividió en dos ramales, un ramal oeste con una longitud de $36,7 \mathrm{~km}$ y un ancho de 2 a $4 \mathrm{~km}$ en sus tramos medios y $10 \mathrm{~km}$ en su porción terminal y un ramal este de $33,6 \mathrm{~km}$ de longitud y anchos de entre 3 y $6 \mathrm{~km}$. Ambos brazos se desplazaron casi paralelamente en dirección sursureste y hacia el este en sus terminaciones. La CPL exhibe una trayectoria de traza curvilínea la cual fue controlada en mayor medida por la topografía previa. Los sectores proximales y medios presentan un techo plano-cóncavo y una extensa cubierta de sedimentos arenosos que cubre parcialmente la superficie del flujo. Se determinaron espesores aflorantes entre 6 y $8 \mathrm{~m}$ en los sectores medios inferiores del flujo mientras que en los brazos terminales del mismo se midieron espesores promedio de $6 \mathrm{~m}$ para el ramal oeste y potencias de hasta $4 \mathrm{~m}$ para el ramal este. Se estimó que el volumen mínimo de lava emitido fue de $7,5 \mathrm{~km}^{3}$.

El techo del flujo no exhibe geoformas relacionadas a acumulación de lava sino que se encuentra definido por una red de lóbulos lávicos elongados e interconectados. La colada se observa disectada longitudinalmente por surcos alargados y en algunos sectores los lóbulos individuales presentan ondulaciones transversales, frecuentemente curvadas hacia el frente de avance. Estas últimas se interpretan como posibles remanentes de estructuras cordadas de gran escala, mientras que los surcos longitudinales corresponderían a los límites interlobulares, sobre los que se instaló una densa red hídrica de carácter temporal. Estos límites definen lóbulos con anchos que varían entre 300 y $800 \mathrm{~m}$. En los sectores proximales se observan con frecuencia potenciales canales desarrollados sobre lavas pahoehoe de márgenes lobulados. La estructura interna de las porciones distales revela el desplazamiento del flujo a través de túneles secundarios y canales de lava internos desarrollados sobre la misma colada (Fig. 13). El patrón de distribución de sectores vesiculares y masivos en los perfiles transversales relevados en la colada responde al de los flujos pahoehoe tipo P (Fig. 14).

La CPL corresponde al tercer flujo de mayor extensión del área de estudio, y su morfología responde a un emplazamiento con un control topográfico notable. Inicialmente el flujo se movilizó en el flanco oriental del complejo volcánico Chachahuén sobre terrenos con pendientes de hasta $2^{\circ}$, las cuales se redujeron en los sectores medios. Las características morfoestructurales de la colada revelan un desplazamiento a través de lóbulos paralelos alargados donde la presencia de relieves laterales sirvió para centrar la dirección del flujo y evitar la expansión lateral de los lóbulos.

\subsection{Colada de lava El Corcovo}

La colada basáltica El Corcovo (CEC) comprende un extenso flujo lávico del tipo pahoehoe que se extiende entre los $37^{\circ} 16^{\prime}$ y $37^{\circ} 36^{\prime} \mathrm{S}$ y desde $68^{\circ} 32^{\prime}$ a $67^{\circ} 54^{\prime} \mathrm{O}$ (Figs. 15 y 16). La misma tuvo origen en el volcán Huanul, el cual tiene morfología en escudo con un cráter de $4 \mathrm{~km}$ de diámetro medio, delimitado por un anillo de lava de $20 \mathrm{~m}$ de altura sobre el terreno circundante. Dentro del cráter se observan depósitos de aglomerados volcánicos y pequeñas coladas basálticas. Basado en observaciones de campo, Holmberg (1962) sugirió una edad pleistocena para la formación del cerro Huanul, la cual fue posteriormente confirmada a partir de una datación K-Ar de 0,84 $\pm 0,05 \mathrm{Ma}$ (Bertotto et al., 2006b).

Se determinaron al menos 8 unidades lávicas emitidas por el volcán Huanul, dentro de las cuales las de mayor importancia fueron denominadas El Corcovo y Los Pozos (Bernardi et al., 2015; Bernardi, 2016). La colada El Corcovo es la más antigua y la de mayor desarrollo areal y longitudinal (Figs. 15 y 16). El sustrato en sus porciones proximales está compuesto por rocas sedimentarias del Cretácico superior, mientras que en sus porciones distales suprayace a areniscas y conglomerados del Mioceno superior.

La colada El Corcovo alcanzó una distancia de $70 \mathrm{~km}$ y cubrió un área mínima de $415 \mathrm{~km}^{2}$ (Bernardi et al., 2015). En su tramo proximal y medio la CEC se dispersó radialmente sobre el cuadrante sureste del centro de emisión y luego transitó sobre una superficie con pendiente no mayor a $0,5^{\circ} \mathrm{E}$, alcanzando una amplitud lateral máxima de $11 \mathrm{~km}$. En el sector medio (sitio EC1 en Fig. 16) parte de las lavas de la CEC se derramaron hacia el sur-suroeste descendiendo unos $10 \mathrm{~km}$ sobre una pendiente de $0,8^{\circ}$ a $1^{\circ}$, resultante del pasaje gradual entre dos niveles de piedemonte. En este sector la colada El Corcovo exhibe espesores aflorantes de entre 4 y $6 \mathrm{~m}$ y se encuentra cubierta por el flujo lávico Los Pozos, con potencias similares. A $26 \mathrm{~km}$ del punto de emisión (sitio EC2 en Fig. 16), el frente principal de la CEC divergió en dos segmentos subparalelos (SN y SS en 

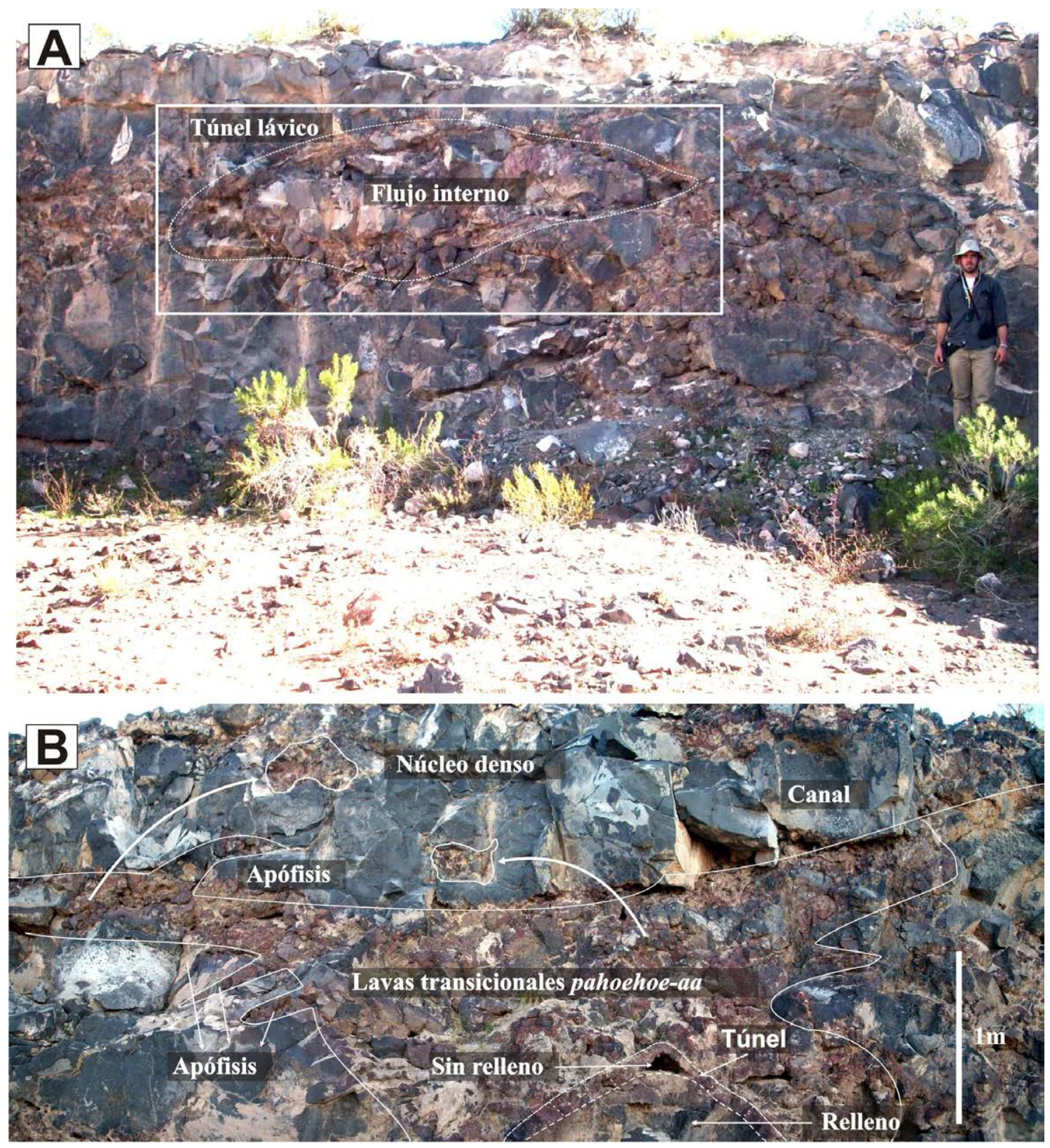

FIG. 13. Estructura interna de la colada de lava Pampa de Luanco en el sector distal (Sitio PL1). A. Vista frontal de un sector del frente del flujo en el que se observa una estructura con geometría elíptica conformada por bolsones de basalto muy vesiculado y rojizo que rodea a un basalto gris oscuro afanítico. Este tipo de estructura fue interpretada como un túnel secundario colmatado por el flujo que circulaba en su interior; B. Vista frontal de un sector del frente del flujo en el que se observan estructuras canaliformes conformadas por una alternancia de basalto pahoehoe gris oscuro afanítico y afírico y un basalto blocoso muy oxidado, con estructuras de lavas de tipo toothpaste. Posiblemente estos rasgos sean el resultado de una transición entre lavas pahoehoe-aa. Se observa que los sectores blocosos se inyectan a través de fracturas al basalto pahoehoe encajonante dando lugar a pequeñas apófisis. Se distinguen fragmentos del sector blocoso contenidos en el interior del basalto encajonante. 


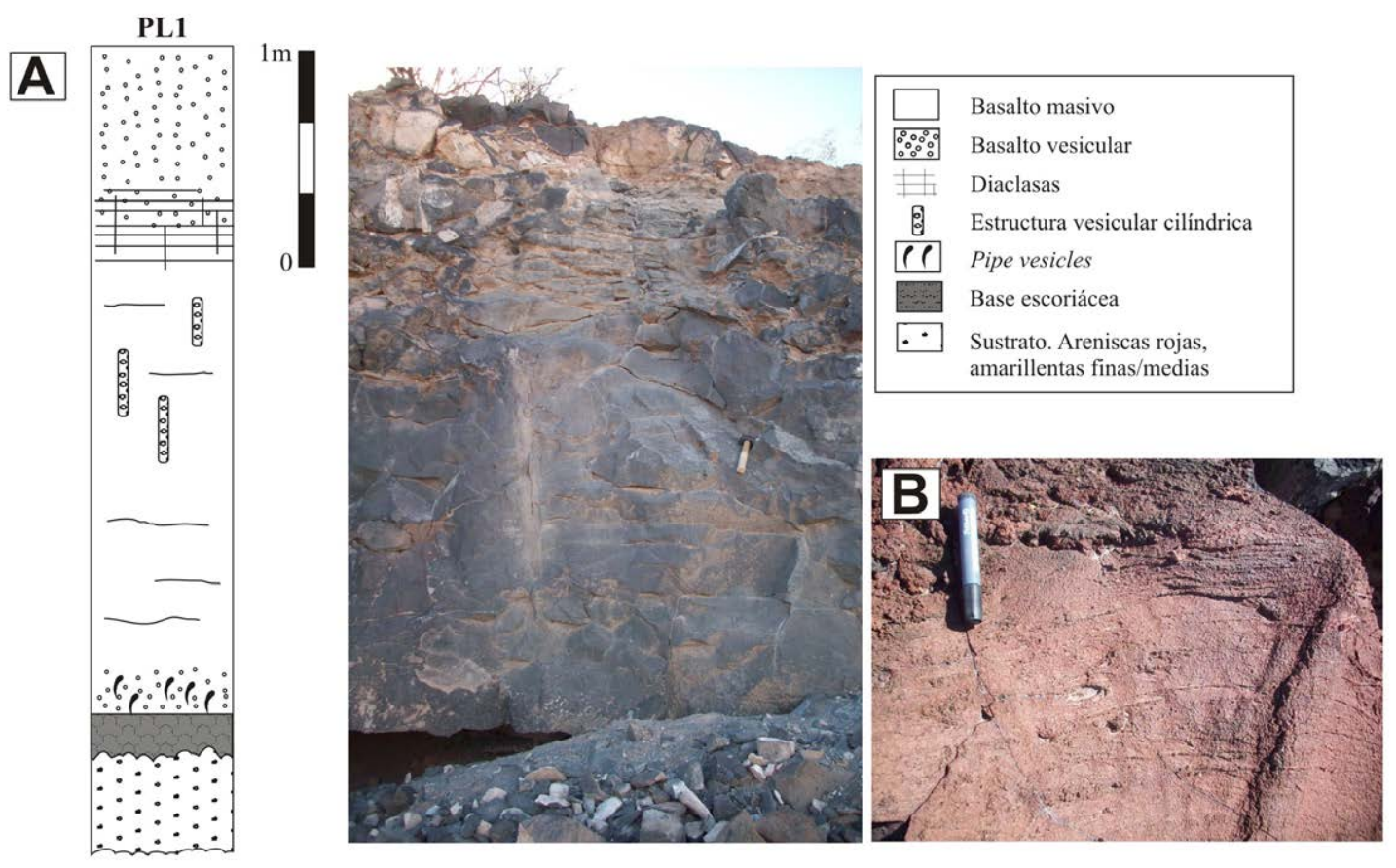

FIG. 14. Estructura interna de la colada de lava Pampa de Luanco. A. Sección transversal del frente del flujo. Se observa el intenso diaclasamiento que afecta a los sectores vesiculares superiores y parte del núcleo; B. Sector basal de la colada con surcos, estrías de arrastre y clastos recogidos del sustrato.

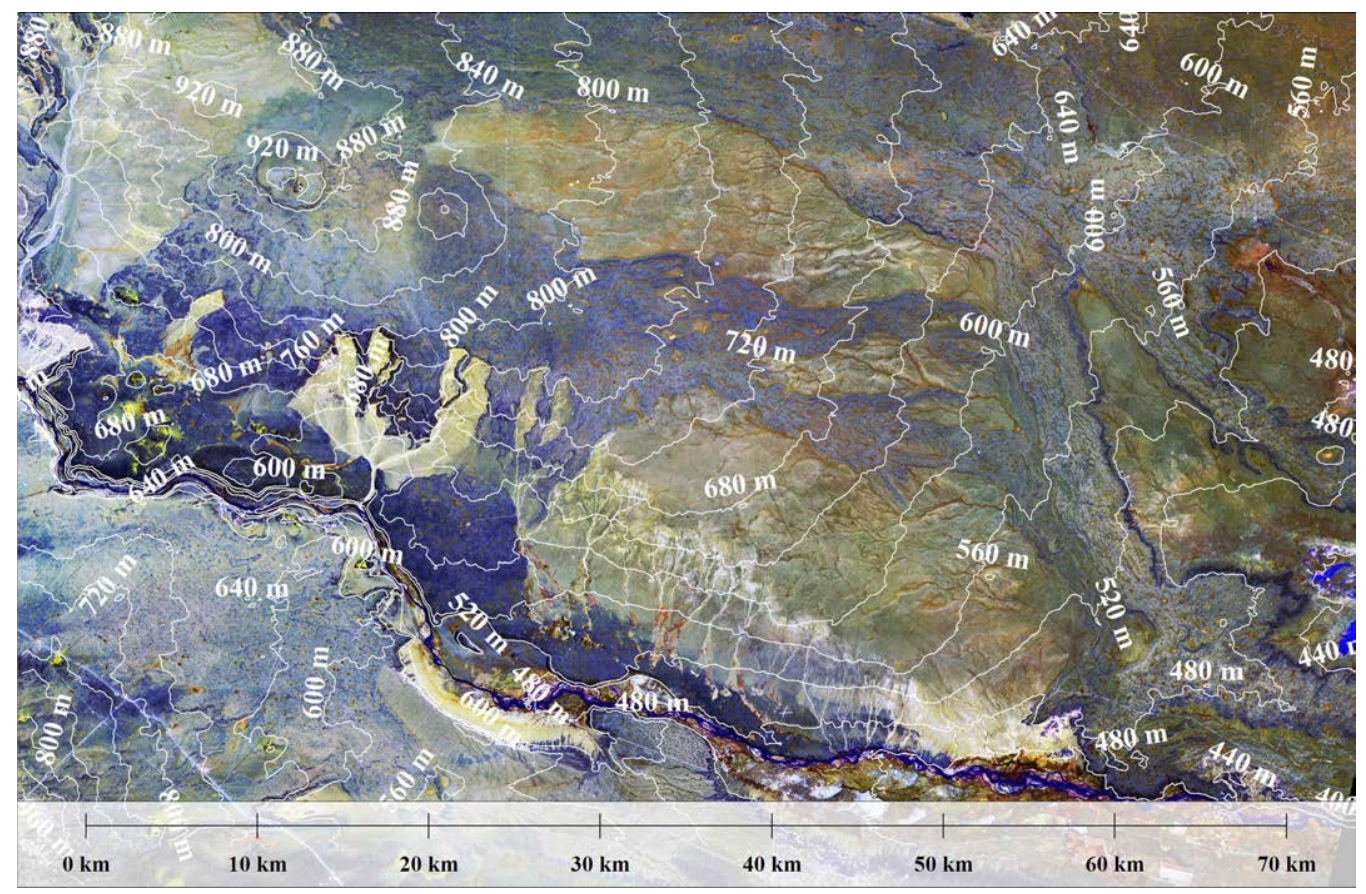

FIG. 15. Colada de lava El Corcovo. Imagen Landsat 7 en falso color compuesto (RGB753). Se indican curvas de nivel. 


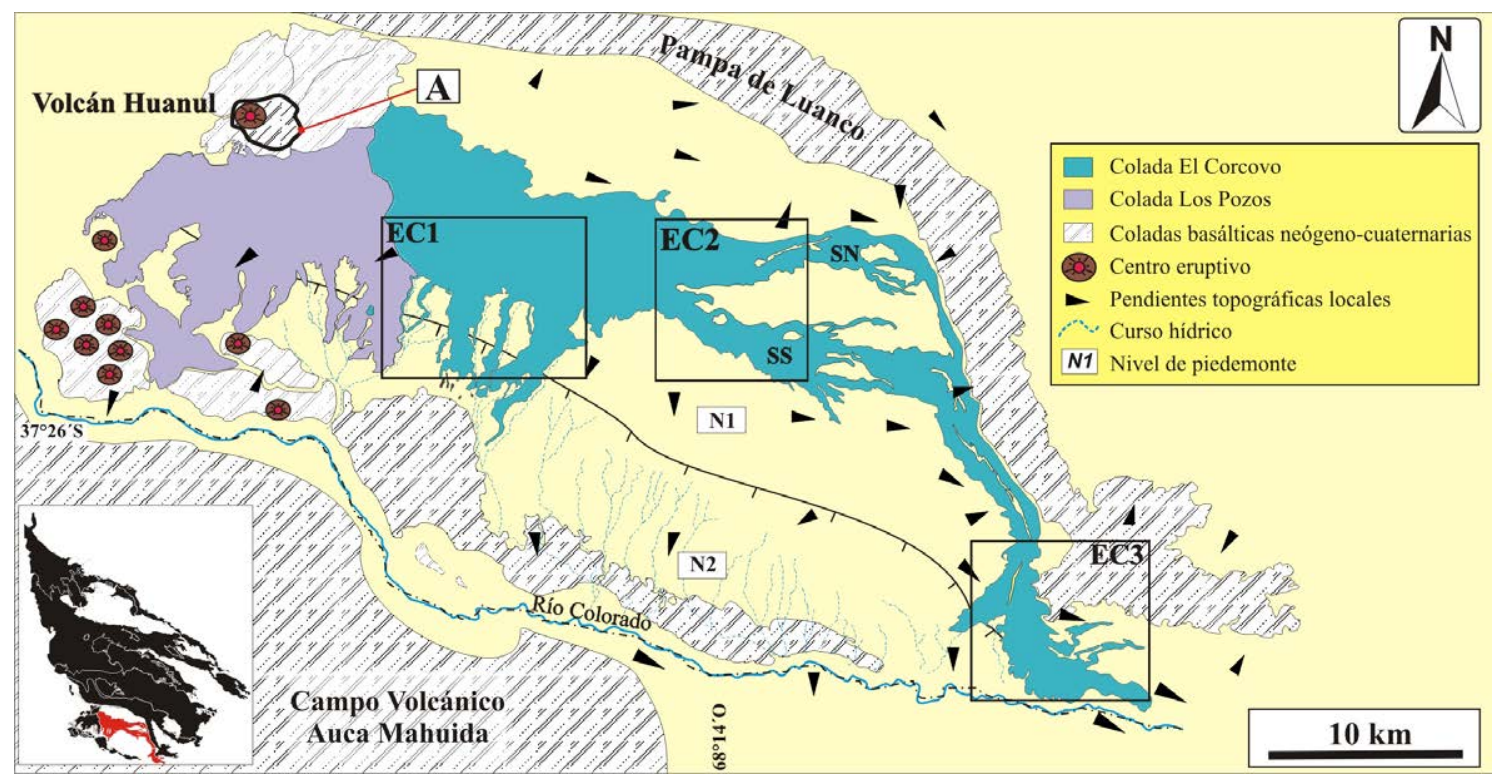

FIG. 16. Mapa de detalle de la colada de lava El Corcovo en la que se observa la ubicación del sector de extrusión, la relación con otros flujos lávicos extruidos del mismo centro eruptivo y con aquellos provenientes de otros sectores. Se indican las direcciones de las pendientes locales actuales del terreno circundante. Además se muestran los centros eruptivos cercanos y la localización de los sitios de estudio (EC1, EC2 y EC3). En el recuadro ubicado en la parte inferior izquierda de la figura se indica la posición de la colada de lava El Corcovo en relación al resto de los flujos lávicos considerados en este estudio Edad K-Ar: A. $0,84 \pm 0,05 \mathrm{Ma}$ (Bertotto et al., 2006a).

Fig. 16). Ambos frentes continuaron su avance unos $14 \mathrm{~km}$, distancia a la cual se produjo un quiebre en el rumbo general de la colada hacia el sur-sureste como consecuencia de la interposición de la colada Pampa de Luanco. A partir de este sector ambos segmentos continuaron su tránsito paralelamente y bordeando a esta colada previa, descendiendo sobre una pendiente de $0,5^{\circ}$ y separados por una dorsal generada por la interacción entre ambos segmentos. El segmento SS culminó su recorrido $20 \mathrm{~km}$ al sur del punto de cambio de rumbo mientras que el segmento SN prosiguió su avance bordeando la colada Pampa de Luanco y en su tramo distal transitó sobre un terreno escalonado con una pendiente de $\sim 1,5^{\circ}$ resultante del pasaje hacia un nivel de piedemonte más bajo $(\mathrm{N} 1>\mathrm{N} 2)$. En su porción terminal, la colada se movilizó con rumbo oeste-este, paralelamente al curso del río Colorado. El perfil y la imagen de la figura 17 corresponden al frente distal del flujo en el sitio EC3 (Fig. 16) y revelan una estructuración típica de un flujo pahoehoe tipo P. Los rasgos más característicos corresponden al ordenamiento en la distribución del tamaño de las vesículas en la corteza superior y a la presencia de pipe amygdales

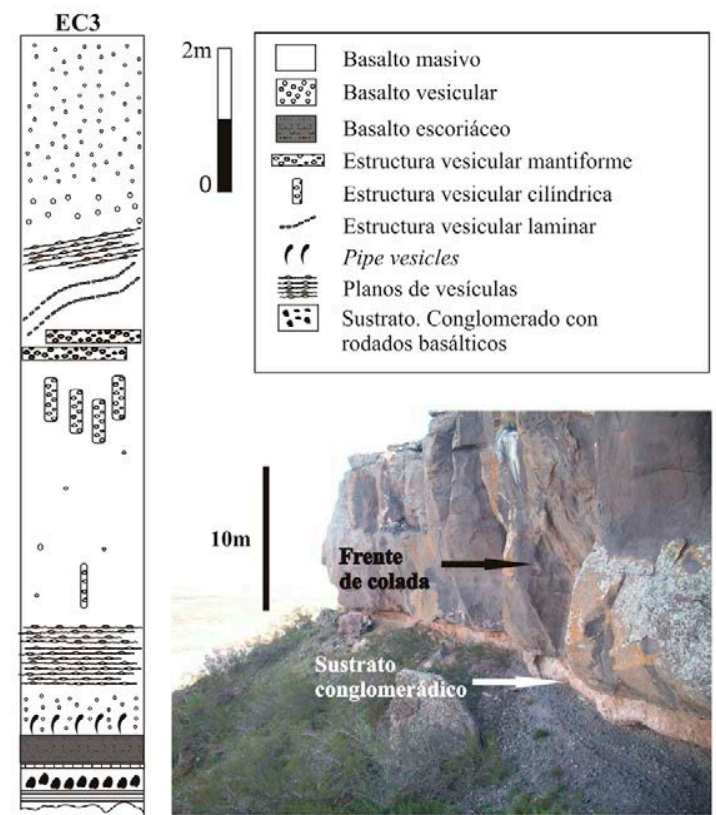

FIG. 17. Estructura interna de la colada de lava El Corcovo. Imagen y perfil del frente distal de la colada en el sitio EC3. 

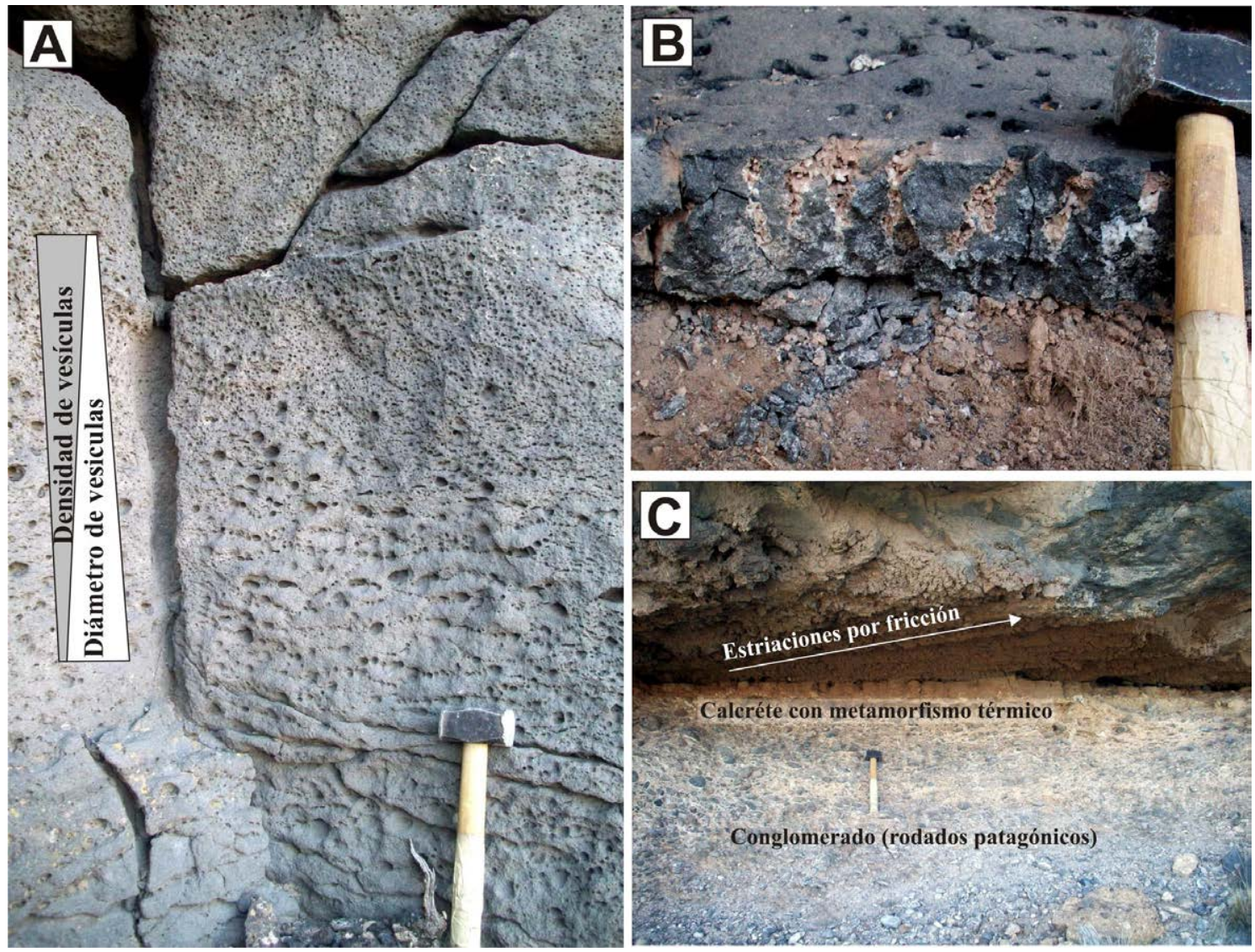

FIG. 18. Estructura interna de la colada de lava El Corcovo. A. Corteza vesicular superior en la que se indica el patrón de distribución de tamaños y cambios en la densidad de la vesiculación; B. Corteza vesicular inferior con pipe amygdales; C. Sector basal del flujo en el que se observa el sustrato conglomerádico coronado por un horizonte de calcrete sobre el que apoya el flujo, el cual muestra una serie de estriaciones y surcos paralelos por fricción.

en la corteza inferior (Fig. 18A y B). El espesor alcanzado por el frente del flujo es de $10 \mathrm{~m}$, el cual se reduce a valores de 1,5 y $2 \mathrm{~m}$ hacia los sectores situados inmediatamente detrás de este frente. La pendiente topográfica de este sitio es casi nula, por lo que esta variación brusca de los espesores estaría sugiriendo que la colada ingresó, acumuló, infló y niveló una depresión del terreno, la cual pudo tratarse de un paleocauce del río Colorado, evidenciado por los depósitos sedimentarios de origen fluvial que subyacen el flujo en este sitio (Fig. 18C). En las porciones medias inferiores, los albardones marginales muestran hasta $3 \mathrm{~m}$ de altura y los canales centrales exhiben espesores aflorantes de hasta 1,5 m. En los tramos medio superiores, la dorsal que separa los dos segmentos angostos muestra entre 3 y $4 \mathrm{~m}$ de altura, mientras que cada segmento exhibe espesores aflorantes de hasta 1 y $2 \mathrm{~m}$. Estos valores junto a los medidos para los sectores proximales, corresponden a espesores promedio mínimos y permitieron calcular un volumen de lava aproximado de $2 \mathrm{~km}^{3}$ para la colada El Corcovo.

En los sectores proximales y distales de la colada se observan frecuentes geoformas asociadas a acumulaciones locales de lava. Estos rasgos morfológicos comprenden principalmente: túmulos, elevaciones de techo plano y dorsales de inflación. Según su modalidad de emplazamiento, la colada El Corcovo exhibe una transición entre tres tipos de flujos. Los tramos proximales presentan características de flujo laminar con techos planos, espesores uniformes y expansión radial acentuada; en los tramos medios, la colada se subdividió en dos segmentos, los cuales posteriormente fueron desviados de su trayectoria y 
se redujeron drásticamente a dos frentes estrechos y canalizados mientras que el tramo distal presenta características de un flujo tipo hummocky, con un campo de estructuras de inflación que otorgan al sector un microrelieve de escala métrica (Fig. 19) (Bernardi et al., 2015).

\subsection{Meseta Basáltica Valle del Colorado}

La Meseta Basáltica Valle del Colorado se encuentra representada por un apilamiento de 4 coladas basálticas limitadas al sur por el valle del Río Colorado, el cual corta verticalmente a la secuencia y define una escarpa de rumbo general sureste, con un desnivel de hasta $70 \mathrm{~m}$ de altura con respecto al lecho del río. Este relieve bordea el margen norte del cauce del río de manera casi ininterrumpida por unos $60 \mathrm{~km}$ (Figs. 20 y 21). Se infiere que la meseta basáltica forma parte de los sectores más distales de coladas emitidas desde el Campo Volcánico Auca Mahuida (CVAM), ya que se observan afloramientos similares en el margen opuesto del río Colorado y con el mismo número de unidades (Fig. 22A). El techo de la meseta se encuentra interrumpido por conos piroclásticos monogenéticos más antiguos, entre los cuales se encuentran los cerros El Águila, Rial, El Pozo, La Yegua y El Carrizo en el extremo occidental de la misma. A unos $8 \mathrm{~km}$ al este del cerro El Carrizo se encuentra el volcán Morado (S) el cual originó depósitos hidromagmáticos (Bertotto et al., 2013) y un pequeño flujo de lava de 2,6 km de longitud, en sentido oeste-este, sobre las unidades superiores de la meseta (colada Del Morado, Bernardi, 2016).

Los basaltos de la Meseta Basáltica Valle del Colorado fueron agrupados por Holmberg (1962) en un intervalo de tiempo comprendido entre Pleistoceno superior y el Holoceno inferior. Las edades obtenidas para las lavas del CVAM fueron de 1,52 $\pm 0,21 \mathrm{Ma}$ (K-Ar, Bermúdez et al., 2000), $0,88 \pm 0,03 \mathrm{Ma}$ a $1,7 \pm 0,2 \mathrm{Ma}$ (Ar/Ar, Rosello et al., 2002) y $1,39 \pm 0,14$ Ma a $1,78 \pm 0,1 \mathrm{Ma}(\mathrm{Ar} / \mathrm{Ar}$, Kay et al., 2006a). Para el sector de la Meseta Basáltica, Gudnason et al. (2012) obtuvieron una edad de $1,54 \pm 0,13 \mathrm{Ma}(\mathrm{K}-\mathrm{Ar})$ para el cono piroclástico El Águila. En este trabajo se obtuvieron edades (K-Ar) de 0,862 $\pm 0,056 \mathrm{Ma}$ (muestra MD46, sitio Bajada

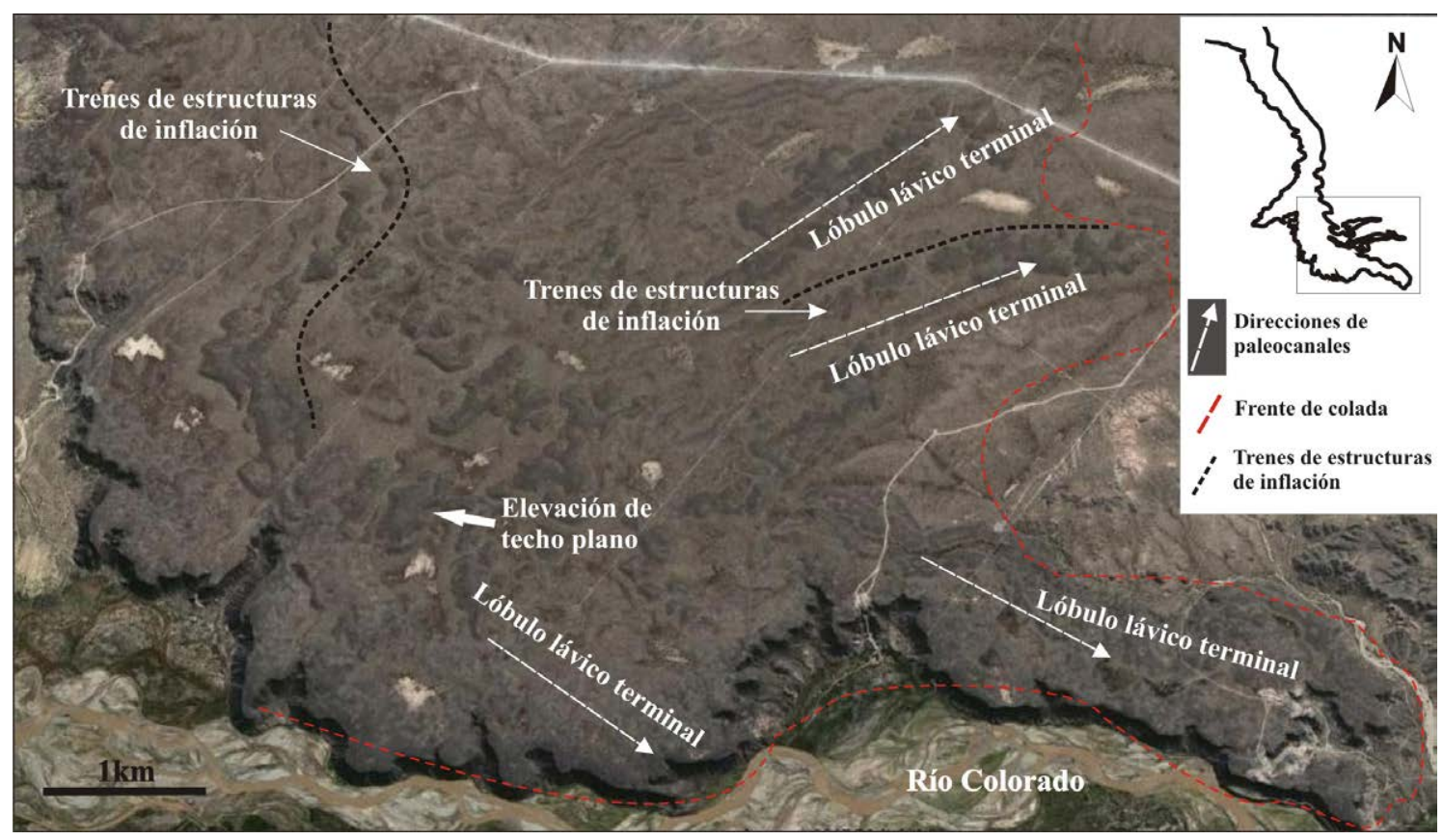

FIG. 19. Campo de estructuras de inflación desarrollado en el sector distal de la colada de lava El Corcovo, indicado en el recuadro ubicado en sector superior derecho de la figura. Se señalan algunos lineamientos observados entre estructuras de inflación (flechas gruesas), y la dirección y ubicación de paleocauces del río Colorado que pudieron actuar como canales confinantes de los últimos lóbulos del frente de colada (flechas con líneas de trazos). 


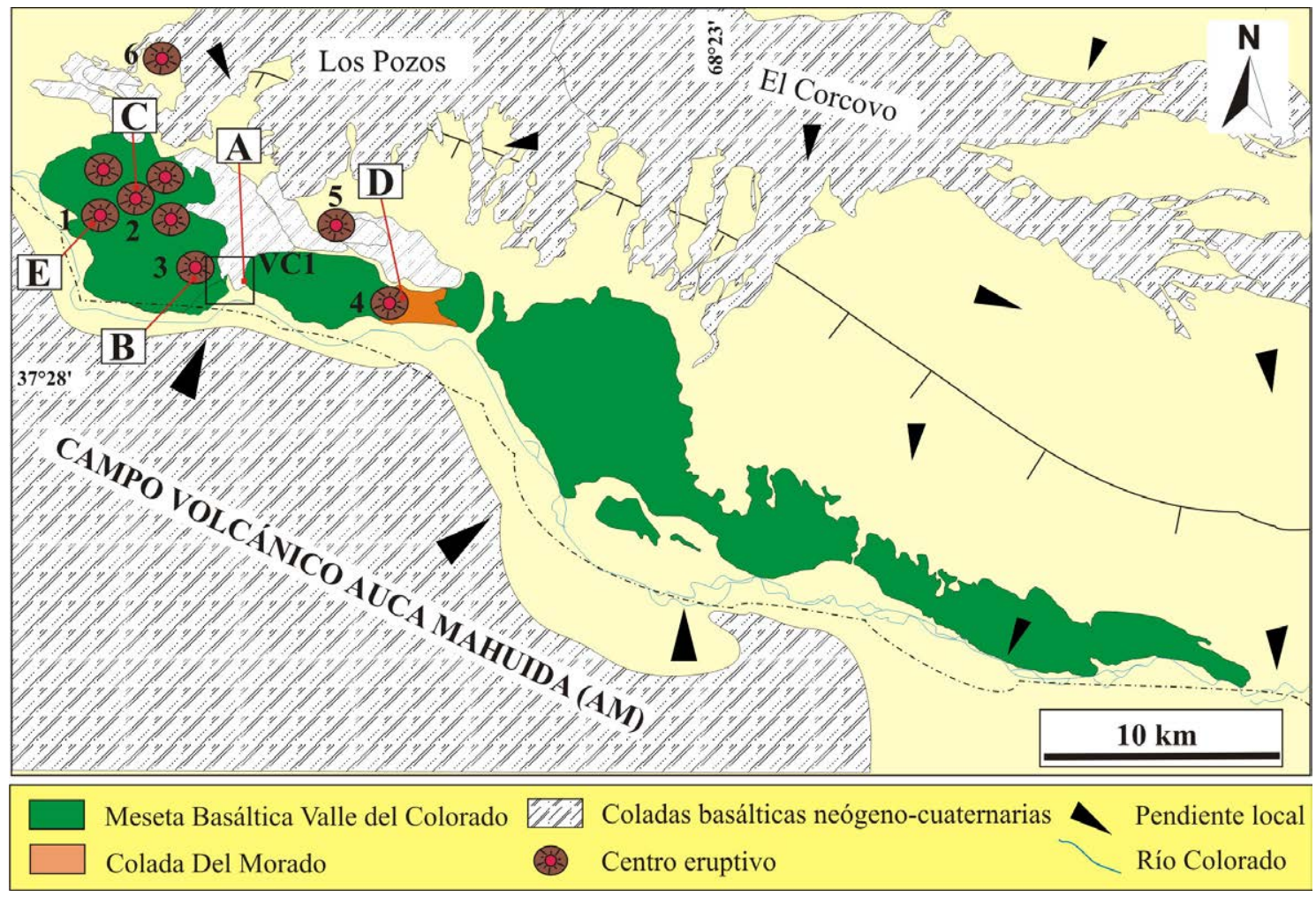

FIG. 20. Mapa de detalle del sector de emplazamiento de las lavas de la Meseta Basáltica Valle del Colorado. El sector de extrusión estaría localizado en el cuadrante suroeste del mapa, en el volcán Auca Mahuida. Se observa la relación espacial con otros flujos lávicos emplazados en el sector y las direcciones de las pendientes locales actuales del terreno circundante. Se indican: los centros eruptivos cercanos y la localización del sitio de estudio VC1. Centros eruptivos 1. El Águila, 2. Rial, 3. Carrizo, 4. Morado (S), 5. La Blanca, 6. Chato (S). Edades K-Ar: A. Muestra MD46: 0,862 $\pm 0,056$ Ma, B. Muestra MD37: 2,73 $\pm 0,14$

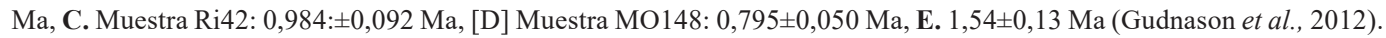

Del Carrizo) para la unidad lávica basal de la Meseta Basáltica Valle del Colorado, 2,73 $\pm 0,14$ Ma para el volcán Carrizo (muestra MD37), 0,984 $\pm 0,092 \mathrm{Ma}$ para el volcán Rial, situado al oeste del anterior y

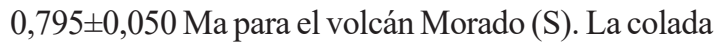
Los Pozos, proveniente desde el norte, culminó su recorrido en la zona de la Bajada del Carrizo, emplazándose sobre la unidad superior de la Meseta Basáltica. Bertotto et al. (2006b) obtuvieron una edad

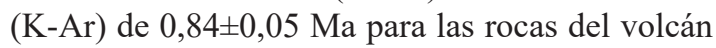
Huanul, la cual se estima que también incluye a la efusión del flujo de lava Los Pozos y otras coladas asociadas a este volcán.

Asumiendo un área de erupción cercana al volcán Auca Mahuida, se estima que estas coladas mantiformes recorrieron distancias entre 40 y $60 \mathrm{~km}$. La superficie mínima que abarca la meseta basáltica sobre el margen norte del río Colorado es de $176 \mathrm{~km}^{2}$. Las coladas que la conforman exhiben geometrías tabulares y espesores uniformes que varían entre 6 y $8 \mathrm{~m}$ (Fig. 22B). La unidad lávica basal de la secuencia asienta sobre un sustrato areno-conglomerádico de hasta $15 \mathrm{~m}$ de potencia probablemente del Pleistoceno (Holmberg, 1962) (Fig. 22C). La base de cada unidad lávica se encuentra separada de la siguiente por bolsones de hasta $2 \mathrm{~m}$ de espesor de una brecha formada por bloques irregulares y lajas de basalto de diferentes tamaños y disposición caótica mezclados con material escoriáceo vítreo (Fig. 22D). Este aspecto evidencia una posible interacción entre las unidades lávicas y agua del río Colorado. La estructuración interna de las coladas responde a la de los flujos pahoehoe de tipo $P$, con cortezas vesiculares de espesores variables y núcleos de baja vesiculación (Fig. 23). 


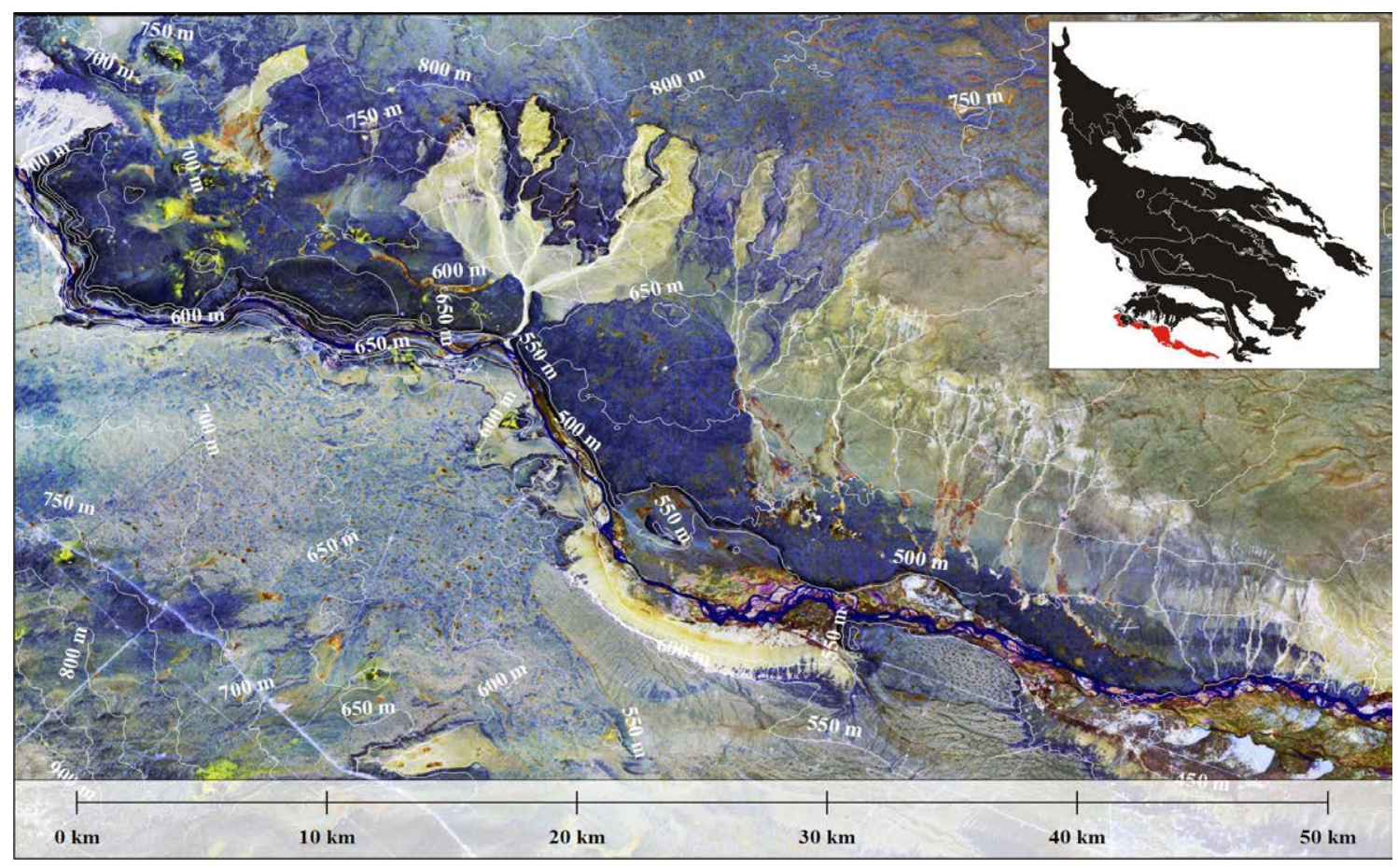

FIG. 21. Meseta Basáltica Valle del Colorado. Imagen Landsat 7 en falso color compuesto (RGB753). Se indican las curvas de nivel. En el recuadro ubicado en la parte superior derecha de la figura se indica la posición de las coladas de lava de la Meseta Basáltica Valle del Colorado (en rojo) en relación al resto de los flujos lávicos considerados en este estudio.

\section{Discusión}

Se estudiaron varias de las coladas basálticas más extensas emplazadas en el sector austral de la Provincia Volcánica Payenia, entre los $36^{\circ} 22^{\prime} \mathrm{S}$ y $37^{\circ} 36^{\prime} \mathrm{S}$ y los $69^{\circ} 11^{\prime} \mathrm{O}$ y $67^{\circ} 15^{\prime} \mathrm{O}$. Mediante el análisis de imágenes satelitales y el relevamiento de campo de las coladas se identificaron los centros de emisión de las mismas. Además, se estableció un ordenamiento cronológico sobre la base de edades radimétricas obtenidas durante este trabajo y por otros autores, las que permitieron definir que la efusión de estas lavas se produjo principalmente en el lapso Plioceno superior-Pleistoceno medio, correspondiente al segundo pico de actividad volcánica de Payenia (e.g., Kay et al., 2006a; Ramos y Kay, 2006) (Tablas 1 y 2). Las edades radimétricas concuerdan, en general, con el orden de emplazamiento establecido a partir de las relaciones de campo y de la interpretación de las imágenes satelitales. Las coladas de lava más modernas, provenientes del sector oriental del complejo volcánico Payún Matru (Pampas Onduladas y Pampa de Los Carrizales, Figs. 1 y 3), suprayacen o son controladas en su distribución por la topografía de los relictos de las lavas previas palaocolitenses (Mioceno inferior), en tanto que circulan sobre la planicie lávica de La Barranca (Fig. 3), en sus porciones medio-superiores. La colada El Puesto (Figs. 6 y 7) se desplazó en parte sobre Pampa de Los Carrizales y en el tramo medio de su margen sur, sobre Pampa de Ranquelcó. Hacia el sur, éste último flujo es limitado por la margen norte de la colada Pampa de Luanco (Fig. 10), cuya trayectoria fue controlada por la topografía previa. En su porción media superior el flujo Pampa de Luanco desvía la trayectoria de la colada El Corcovo proveniente del volcán Huanul (Fig. 12). La unidad Los Pozos (Fig. 16) con origen en este cerro se superpone al flujo El Corcovo a la salida del centro eruptivo, aunque se infiere que ambas coladas son coetáneas, debido a la ausencia de horizontes sedimentarios intercalados que indiquen un hiato temporal prolongado entre ambas efusiones. El flujo lávico Los Pozos es confinado en su porción distal por un relieve deprimido labrado sobre la Meseta Basáltica Valle del Colorado y su paso es obstaculizado por conos monogenéticos 

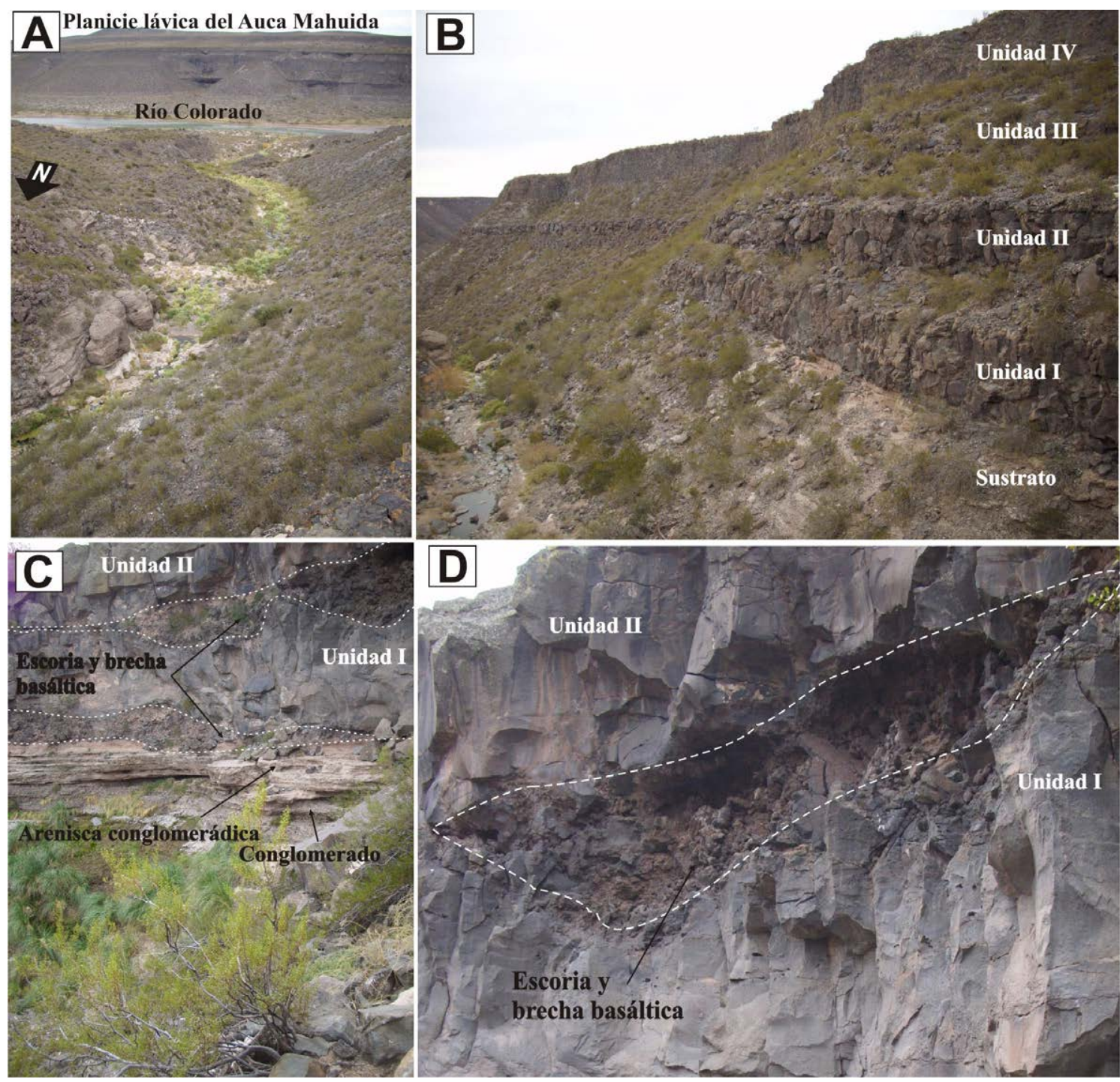

FIG. 22. Estructura de las coladas de la Meseta Basáltica Valle del Colorado. A. Vista al sur de la quebrada en la que se observa el río Colorado y la planicie lávica del Auca Mahuida disectada por el mismo; B. Secuencia de la MBVC compuesta por las cuatro unidades de lava analizadas. La unidad lávica III se encuentra en su mayor parte cubierta por desmoronamientos de la unidad superior; C. Sustrato de la Meseta Basáltica Valle del Colorado en el sector de la Bajada del Carrizo. Se observan depósitos de areniscas conglomerádicas y conglomerados; D. Bolsón de aglomerado escoriáceo y brecha basáltica que separa la Unidad I de la II.

más antiguos (Cerro Chato (S) y Cerro La Blanca). La Meseta Basáltica Valle del Colorado (Figs. 20 y 21) se interpreta como un relieve remanente correspondiente a la porción distal de secuencias lávicas provenientes del complejo volcánico Auca Mahuida. Éstas fueron luego disectadas por el río Colorado, aspecto que también fue observado previamente por Holmberg (1962). Sobre la porción oriental de estas secuencias se formó el volcán Morado (S) para cuyas lavas se obtuvo una edad $\mathrm{K}$-Ar de 0,795 $\pm 0,050 \mathrm{Ma}$. Asociados a este volcán se observan depósitos piroclásticos tipo surge que reflejan interacción agua/magma (Bertotto et al., 2013) y constituye la evidencia de un paleorío Colorado activo desde tiempos anteriores al Pleistoceno medio. 


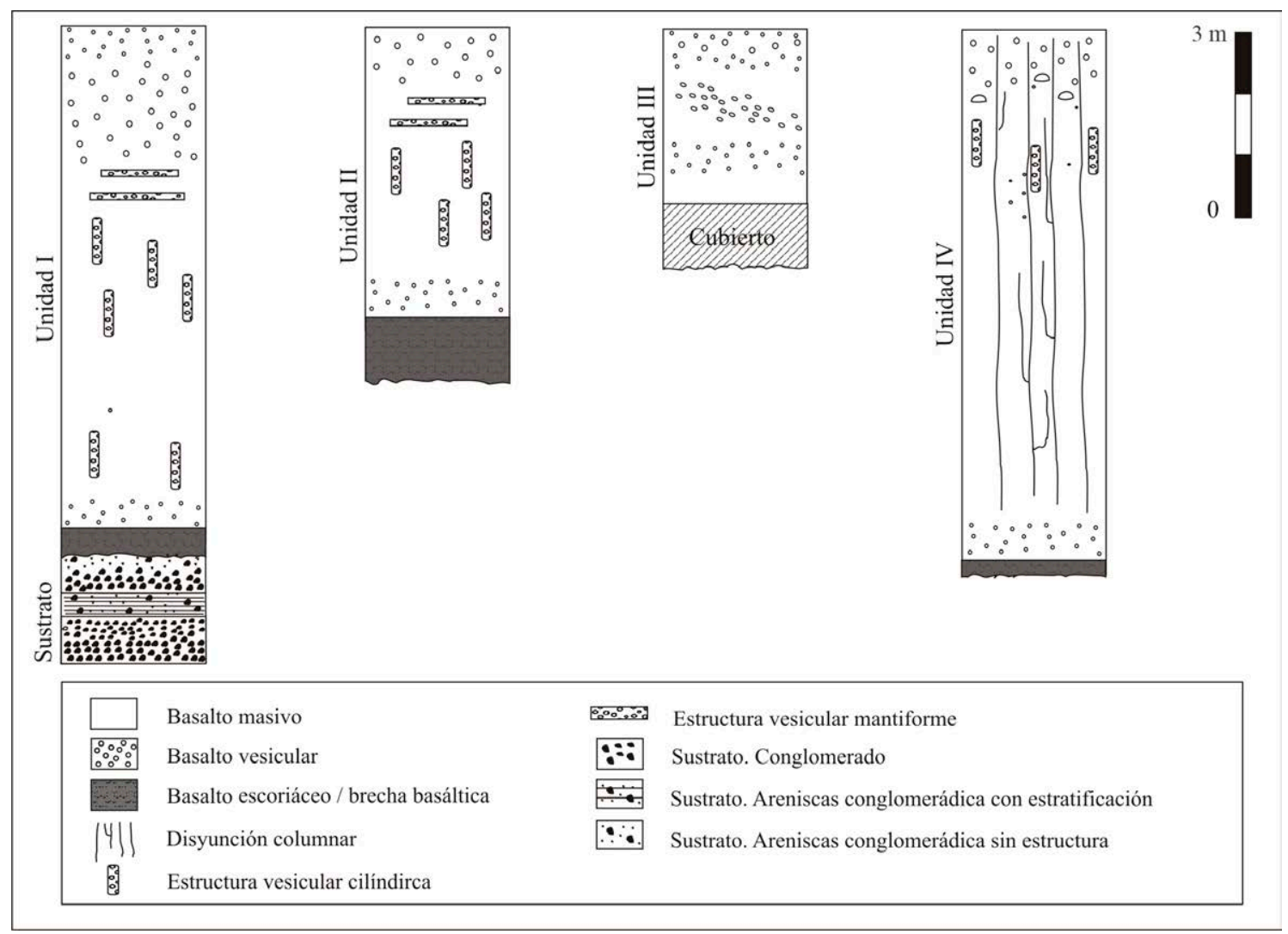

FIG. 23. Estructura interna de las coladas de la Meseta Basáltica Valle del Colorado. Perfiles de las 4 unidades lávicas laminares relevadas en el sitio VC1.

En lo que respecta al desarrollo longitudinal que presentan las coladas de lavas estudiadas, estas pueden agruparse en dos categorías: 1) Flujos de gran extensión longitudinal ( $30 \mathrm{a} 100 \mathrm{~km})$, incluyendo El Puesto (70 km), El Corcovo (70 km) y las Coladas de la Meseta Basáltica Valle del Colorado (40 a $60 \mathrm{~km}$ ) y 2) Flujos extremadamente largos (>100 km), como Pampa de Los Carrizales (181,2 km), Pampa de Luanco (122 km) y Pampa de Ranquelcó (116 km). En relación a los volúmenes de lava estimados se consideran coladas de volumen bajo a moderado a aquellas con valores entre 0,1 y $10 \mathrm{~km}^{3}$ (El Puesto, El Corcovo, Coladas de la Meseta Basáltica Valle del Colorado, Pampa de Luanco y Pampa de Ranquelcó) y coladas de volumen alto a aquellas entre $10 \mathrm{y}$ $1.000 \mathrm{~km}^{3}$ (Pampa de Los Carrizales) según se define en Hon et al. (1994).

Las coladas estudiadas presentan características de lavas pahoehoe con superficies relativamente suaves $\mathrm{y}$ fueron emplazadas sobre terrenos peneplanizados con pendientes regionales subhorizontales de no más de $1,5^{\circ}$ y generalmente menores a $1^{\circ}$. Las direcciones de paleopendientes determinadas para las coladas en general coinciden con la pendiente este-sureste actual del piedemonte andino (Fig. 1). Los relieves escalonados o de mayor pendiente son registrados principalmente en los sectores próximos a los principales aparatos volcánicos y en las adyacencias del valle del río Colorado donde reflejan la dinámica del mismo y de sus afluentes. Hon et al. (1994) demostraron que los flujos de lavas pahoehoe que se mueven sobre superficies de escasa pendiente, cercanas a la horizontal, se engrosan durante su emplazamiento por el proceso de inflación y, que sería el caso de Hawái, los flujos inflados están ausentes en relieves escalonados o irregulares. En base a esto, observaron que los flujos canalizados en zonas de relieves escalonados experimentan una transición a flujos laminares al encontrarse con pendientes suaves. La reducción del ángulo de la pendiente 
causa un decrecimiento en la velocidad de avance lo cual permite a la colada expandirse lateralmente. Este aspecto quedó bien registrado en los sectores medios superiores y distales de la colada inflada El Corcovo (Fig. 16) donde la misma se movilizó sobre una topografía escalonada con pendientes de $1,5^{\circ}$ a algo más de $2^{\circ}$ dando lugar a una colada angosta y encauzada, sin dispersión lateral, de poco espesor (1-2 m) y carente de estructuras de inflación. Cuando esta colada ingresó a un sector de pendiente casi nula, interpretado como una paleoplanicie fluvial del río Colorado, se dispersó dando lugar a un flujo laminar (Sector EC3, Fig. 16). Una pendiente de bajo ángulo provee pocos impedimentos al movimiento lateral del flujo y favorece la expansión radial por coalescencia e inflación de lóbulos (Hon et al., 1994; Self et al., 1998).

Las coladas estudiadas exhiben una estructura interna con un patrón similar a la de los flujos pahoehoe de tipo $\mathrm{P}$ definidos por Wilmoth y Walker (1993) para coladas de Hawái. Además, Self et al. $(1997,1998)$ sugirieron que si la estructura interna de un lóbulo de lava dado consiste en una corteza vesicular superior con una distribución ordenada de vesículas esféricas, un núcleo denso y una delgada corteza vesicular basal, es suficiente para identificar dicha lava como un flujo pahoehoe inflado e indicaron que las zonas vesiculares horizontales de la corteza superior vesicular se forman durante la inflación activa. Las investigaciones referidas a coladas pahoehoe de tipo P asocian el desarrollo de este tipo de flujos a los siguientes aspectos: 1) paleopendientes de muy poca inclinación $\left(\sim<2^{\circ}\right)$ que permiten desplazamientos lentos y discontinuos a través de la generación y coalescencia de lóbulos en el frente de la colada, 2) aislamiento térmico del núcleo interno líquido de los lóbulos por desarrollo de una costra rígida externa, 3 ) desarrollo de túneles capilares, secundarios y mayores por los que circula la lava hacia los sectores distales (Fig. 9) y, 4) actuación del proceso de inflación con desarrollo de estructuras, fracturas y escape de gases (Fig. 8). Las tasas y el alcance local o regional del proceso de inflación estarán condicionados principalmente por el suministro lávico de la fuente (Hon et al., 1994; Self et al., 1998). Las coladas estudiadas exhiben perfiles con un patrón en la distribución de vesículas determinado por un sector vesicular superior que puede abarcar entre el 30 y el $50 \%$ del espesor total del flujo y un sector vesicular inferior de menor desarrollo (Figs. 4, 17 y 23 ). El porcentaje de vesículas del sector superior varía entre 20 y $40 \%$ mostrando en ocasiones diferentes patrones en la distribución y geometría de las vesículas. La corteza vesicular inferior exhibe normalmente una vesiculación moderada a baja (10 a 30\%) y muestra con frecuencia estructuras características denominadas pipe vesicles (Fig. 18B). Estas últimas comprenden vesículas de morfología tubular y alargada con o sin relleno de minerales secundarios. Las mismas pueden alcanzar hasta $15 \mathrm{~cm}$ de longitud y tienen disposición subvertical. Este tipo de estructuras son uno de los rasgos determinantes de los flujos de tipo P. El piso de las coladas se caracteriza por una estructura escoriácea, con pliegues y estrías producidas como resultado del arrastre del flujo lávico sobre el sustrato (Fig. 14B y Fig. 18C). Este sector se presenta notablemente oxidado y contiene clastos del sustrato. Ambas cortezas vesiculares rodean un núcleo de estructura masiva o baja vesiculación, el cual es común que hospede estructuras de segregación vesicular (e.g., Goff, 1996; Caroff et al., 1997, 2000; Bernardi et al., 2016, 2018). Aubele et al. (1988) sugirieron que los patrones de zonificación de la vesiculación en las coladas serían el resultado del crecimiento y ascenso de burbujas de gas y de su interacción con los frentes de enfriamiento superior e inferior que avanzan hacia el interior del flujo. Usualmente las vesículas de la corteza superior aumentan su diámetro $\mathrm{y}$, a su vez, disminuyen su densidad hacia los sectores internos del flujo (Fig. 18A). En concordancia con lo planteado por Aubele et al. (1988) se interpreta que este rasgo es el resultado de la diferencia en la tasa de enfriamiento existente entre los sectores internos y externos del flujo. Las zonas superficiales de la colada se enfrían rápidamente inhibiendo el desarrollo en el tamaño de las vesículas. Asimismo, en las zonas internas y aisladas por la corteza superficial, el enfriamiento se produce más lentamente permitiendo el crecimiento de las burbujas, principalmente por coalescencia entre las mismas. Este último aspecto explicaría la reducción en la población de vesículas hacia la base de la corteza superior vesicular observada en algunas coladas.

La estructuración predominante de las coladas de lavas estudiadas de Payenia presenta una geometría laminar/tabular con espesores relativamente uniformes. Estos últimos varían de un flujo a otro en un rango de 1 a $13 \mathrm{~m}$ (Fig. 17), siendo más frecuentes las potencias 
entre 4 y 8 m (Fig. 14). En una misma unidad lávica el espesor puede permanecer invariable durante decenas de kilómetros. Las coladas se caracterizan por exhibir perfiles longitudinales plano-cóncavos o plano-rectos sin resaltos abruptos, al menos a gran escala, y morfologías elongadas e irregulares en planta con desarrollo de kipukas, particularmente en los flujos de mayor extensión. Cuando los perfiles son trazados de manera transversal a la dirección del flujo (Fig. 11) se pueden establecer dos tipos de coladas según su topografía externa: 1) coladas con techos planos y bordes suaves a algo escarpados, definidas como flujos laminares/tabulares o sheet flows (Fig. 22B) y 2) coladas con topografía superficial irregular otorgada por microrelieves, denominados flujos hummocky (Fig. 5 y 19), según las acepciones adoptadas por Hon et al. (1994). Dentro de la primera categoría se pueden agrupar a la colada Pampa de Luanco y a las unidades de la Meseta Basáltica Valle del Colorado, mientras que la segunda categoría comprende las coladas El Puesto, Pampa de Los Carrizales, Pampa de Ranquelcó y El Corcovo, aunque cabe mencionar que la mayoría de estos últimos flujos exhiben características de ambos tipos, según el sitio de estudio de la colada. Los mejores ejemplos de flujos laminares con espesores constantes de gran continuidad son aquellos expuestos por las coladas de la Meseta Basáltica Valle del Colorado (Fig. 22B). Hon et al. (1994) observaron que los flujos laminares activos del Kilauea y Mauna Loa se propagaron inicialmente como finas capas de lava pahoehoe fluida de entre 10 y $50 \mathrm{~cm}$ de espesor que posteriormente se inflaron y alcanzaron hasta $4 \mathrm{~m}$ de potencia en un periodo de tiempo de una semana. Keszthelyi y Denlinger (1996) postularon que los flujos lávicos de gran extensión deben estar inevitablemente inflados ya que el avance de las lavas pahoehoe se lleva a cabo a través de lóbulos de no más de $15-50 \mathrm{~cm}$ de espesor señalando además que los flujos de gran extensión deben inflarse al menos 5 $\mathrm{m}$ para continuar su progreso. Las coladas relevadas aquí y definidas como flujos laminares exhiben estructuras que revelan lóbulos interconectados frontal y lateralmente, las cuales son observadas más nítidamente en las zonas marginales de los flujos. Este aspecto permitió inferir un emplazamiento a través de formación de lóbulos en los frentes de los flujos, con tasas similares de inflación, cuya coalescencia lateral dio lugar a sucesivas coladas mantiformes con amplitudes laterales continuamente en aumento y espesores constantes. Por otro lado, aquellas coladas relevadas referidas como flujos hummocky (Figs. 5B y C y Fig. 19) exhiben sectores marcados por una topografía irregular otorgada por estructuras típicas de procesos de inflación local como son: túmulos lentiformes con longitudes de entre $\sim 25$ y $80 \mathrm{~m}$ (Fig. $8 \mathrm{~A}$ ), elevaciones de techo plano de morfología irregular (Fig. 8B) con tamaños que superan ampliamente el centenar de metros ( 150-600 m), dorsales de inflación (Fig. 5D y 8 C) con longitudes hectométricas a kilométricas y relaciones longitud/ancho de entre 12 y 17 , pozos de inflación con diámetros de entre 130 y 180 m restringidos a elevaciones de techo plano (Fig. 8D), diferentes patrones de fracturamiento, asociados a esfuerzos distensivos durante el crecimiento de estas estructuras y túneles de lava con desarrollos a macro y mesoescala (Fig. 9). La presencia o ausencia de estas geoformas así como también la morfología final del flujo dependerán en primer lugar de las tasas de efusión, de la topografía y de la duración de la erupción los cuales son los parámetros que condicionarán el proceso de inflación (Self et al., 1997; Hon et al., 1994; Walker, 1991; Rowland y Walker, 1990; Gregg y Fink, 2000).

Hon et al. (1994) señalaron para flujos activos de Hawái, que las tasas altas de suministro favorecerán la formación de flujos pahoehoe canalizados en pendientes escalonadas y, de flujos laminares, en pendientes suaves. A su vez Rowland y Walker (1990) determinaron que las erupciones hawaianas que generan flujos pahoehoe inflados presentan tasas de efusión promedio de $5 \mathrm{~m}^{3} / \mathrm{s}$ y que a tasas de 15 a $20 \mathrm{~m}^{3} / \mathrm{s}$ se producen transiciones entre flujos pahoehoe y flujos a canalizados. Por lo tanto, se puede asumir una tasa de efusión de $15 \mathrm{~m}^{3} / \mathrm{s}$ como el límite máximo para la formación de los flujos pahoehoe laminares emplazados en Payenia.

Por otra parte, aquellas coladas coronadas por geoformas de inflación se caracterizan por exhibir con frecuencia grupos sectorizados de estructuras, como es el caso de las coladas El Corcovo (Fig. 19) y Pampa de Ranquelcó. Otras coladas muestran una distribución algo más dispersa y aleatoria en todo el ámbito de emplazamiento con fajas de alta concentración de estructuras, como el caso de las coladas Pampa de Los Carrizales (Figs. 5B y C) y El Puesto. Este último aspecto fue observado también en la colada Pampas Onduladas. Hon et al. (1994) y Self et al. (1998) postularon que los flujos 
con microrelieve hummocky se emplazan a bajas y moderadas tasas de efusión en topografías irregulares o escalonadas. Asimismo, señalaron que los flujos laminares inflados que son atrapados u obstaculizados temporalmente por barreras topográficas pueden ser solapados por brotes que pueden desarrollar campos de túmulos y enmascarar la morfología original del flujo laminar. Este es el caso de la colada El Corcovo, en la cual el campo de estructuras de inflación que se ubica en su sector distal presenta un evidente origen por obstaculización del flujo como resultado del ingreso del mismo al interior de un paleocauce del río Colorado (Bernardi et al., 2015) (Fig. 19). El proceso de inflación llevó a la nivelación e incluso inversión del relieve. El confinamiento de la colada en la depresión dio lugar a la formación de hinchamientos locales sobre su techo, posiblemente en las últimas etapas de la actividad efusiva, cuando el suministro se restringió a tubos de lava. Estos últimos rasgos no fueron observados directamente en el campo, pero se infieren a través de alineaciones kilométricas de túmulos y pequeñas dorsales. Este tipo de asociaciones entre túmulos y túneles han sido observadas en flujos lávicos de los volcanes Santa Helena (Greeley y Hyde, 1972), Etna (Guest et al., 1984) y en flujos de Hawái (Mattox et al., 1993; Hon et al., 1994) entre otros. Las coladas con las mejores exposiciones de estructuras de inflación son Pampa de Los Carrizales y El Puesto siendo esta última la que presenta la mayor densidad y variedad de estructuras de inflación de todas las coladas relevadas en el área de estudio. En general las estructuras se observan dispersas en todo el ámbito de las coladas; sin embargo, existen sectores en los que las mismas se disponen en extensas fajas longitudinales sobre un flujo de tipo laminar, en la dirección y sentido del mismo (Figs. 5B y C). Se interpreta que estos microrelieves tuvieron origen a partir de corrientes de lava concentradas en un conjunto de vías preferenciales de transporte (tubos de lava) orientadas y formadas como resultado de un suministro lávico moderado y continuo en el interior de un flujo laminar en enfriamiento. Self et al. (1998) atribuyeron ejemplos similares en flujos lávicos de Hawái a la circulación por tubos capilares y no a través de tubos maestros. En este sentido, algunas de estas fajas muestran una notable direccionalidad, un relieve sobreelevado con respecto al flujo laminar adyacente y anchos de hasta $500 \mathrm{~m}$ sobre las que se disponen túmulos y elevaciones de techo plano. Por esto, a diferencia de lo propuesto por Self et al. (1998) se plantea que algunas de estas fajas de geoformas de inflación se han formado a partir de brotes inflados sobre el techo de túneles bloqueados con secciones de importante magnitud. El caso opuesto lo constituye el túnel maestro de Halada en la colada El Puesto (Fig. 9), el cual cuenta con numerosos túneles tributarios. Este flujo no exhibe estructuras de inflación superficiales asociadas, ni un relieve positivo sobre el terreno, lo que se interpreta como el resultado del vaciamiento de lava que posteriormente dio lugar a la caverna. Con respecto a la distribución aleatoria de estructuras observada en otros sectores de la superficie de ambas coladas, esta sí se considera generada a través de una red intrincada de tubos menores o capilares, cuya formación es favorecida por la reducción del suministro lávico como consecuencia del avance del enfriamiento hacia el interior de los lóbulos. Se estima que el bloqueo o la reducción del diámetro de estas vías, generó parcelas de lava líquida que al continuar siendo inyectadas produjeron túmulos, elevaciones de techo plano y dorsales de inflación en la superficie del flujo, los cuales pueden aparecer de manera individual y aislados o bien formando cadenas de estructuras alineadas con la trayectoria del túnel preexistente (Fig. 5D). Algunas de estas vías capilares pudieron observarse como tubos cilíndricos drenados con diámetros de escala métrica-decimétrica atravesando longitudinalmente la estructura de algunos túmulos. Los túmulos analizados en las coladas relevadas se clasificaron dentro de la categoría flow-lobe tumuli propuesta por Rossi y Gudmunsson (1996). Para un campo de estructuras de inflación instalado en la porción distal de la colada El Puesto, Bernardi (2016) midió el tiempo de inflación y la tasa de suministro para un túmulo promedio típico con un volumen de $235 \mathrm{~m}^{3}$ el cual arrojó valores de $370,8 \mathrm{hrs}$ ( $\sim 15$ días) y $1,810^{-4} \mathrm{~m}^{3} / \mathrm{s}$ respectivamente, asumiendo un suministro sostenido de lava y una tasa diaria de inflación uniforme. Estos valores concuerdan con los obtenidos en flujos de lava islándicos por Rossi y Gudmunsson (1996) quienes señalaron que este tipo de túmulos se forman a muy bajas tasas de efusión, del orden de $10^{-2}-10^{-5} \mathrm{~m}^{3} / \mathrm{s}$ en un rango de tiempo de entre 4 y 21 días.

La colada Pampa de Luanco reviste el único caso, en el sector estudiado, de un flujo laminar con control topográfico predominante en casi toda su trayectoria. Alcanza valores de inflación de hasta $6 \mathrm{~m}$ y en su porción distal presenta sectores donde 
el perfil de la colada exhibe cortes transversales de túneles de escala métrica colmatados y estructuras canaliformes rellenas con lavas transicionales pahoehoe-aa (Fig. 13).

A partir de las características intrínsecas y extrínsecas analizadas se postula que todas las coladas relevadas en este trabajo se emplazaron, en un principio, como flujos laminares o sheet flows bajo un régimen de tasas de efusión del orden de los $\sim 10-15 \mathrm{~m}^{3} / \mathrm{s}$ sobre pendientes de muy bajo ángulo $\left(<1,5^{\circ}\right)$ y posteriormente, al reducirse las tasas de efusión a valores menores a $5 \mathrm{~m}^{3} / \mathrm{s}$, algunos de estos flujos sufrieron episodios de inflación localizados que pudieron abarcar todo el ámbito de la colada o bien una parcialidad de la misma. Se infiere que aquellas coladas del tipo sheet flows (e.g., Meseta Basáltica Valle del Colorado) en las que no se observan desarrollo de estructuras de inflación, estarían revelando erupciones de duración variable pero con tasas de efusión altas y sostenidas. Posteriormente, el suministro de lava podría haber experimentado un descenso gradual al finalizar la actividad eruptiva, lo cual impediría el desarrollo de un relieve hummocky en su superficie.

Los flujos estudiados se desplazaron siguiendo el mecanismo de inflación modelado y definido para las coladas activas hawaianas, tal como lo demuestran sus rasgos morfoestructurales (Fig. 24). Se interpreta que este proceso es el único que pudo conducir a un incremento en promedio de 8 a 20 veces el espesor inicial de los flujos lávicos, teniendo en cuenta el rango de espesores medidos en las coladas de Payenia y tomando como referencia los valores de espesores iniciales observados en los flujos laminares activos de Hawái $(\sim 0,5 \mathrm{~m})$. Las coladas relevadas con desarrollos longitudinales más extensos presentan entre $70 \mathrm{~km}$ (El Corcovo y El Puesto) y $181 \mathrm{~km}$ (Pampa de Los Carrizales). Las mismas deben su gran desarrollo, en parte, a que la inflación es un proceso térmicamente eficiente como resultado del movimiento de lava a través de túneles, a lo que Keszthelyi y Self(1998) definieron como emplazamiento aislado (insulated).

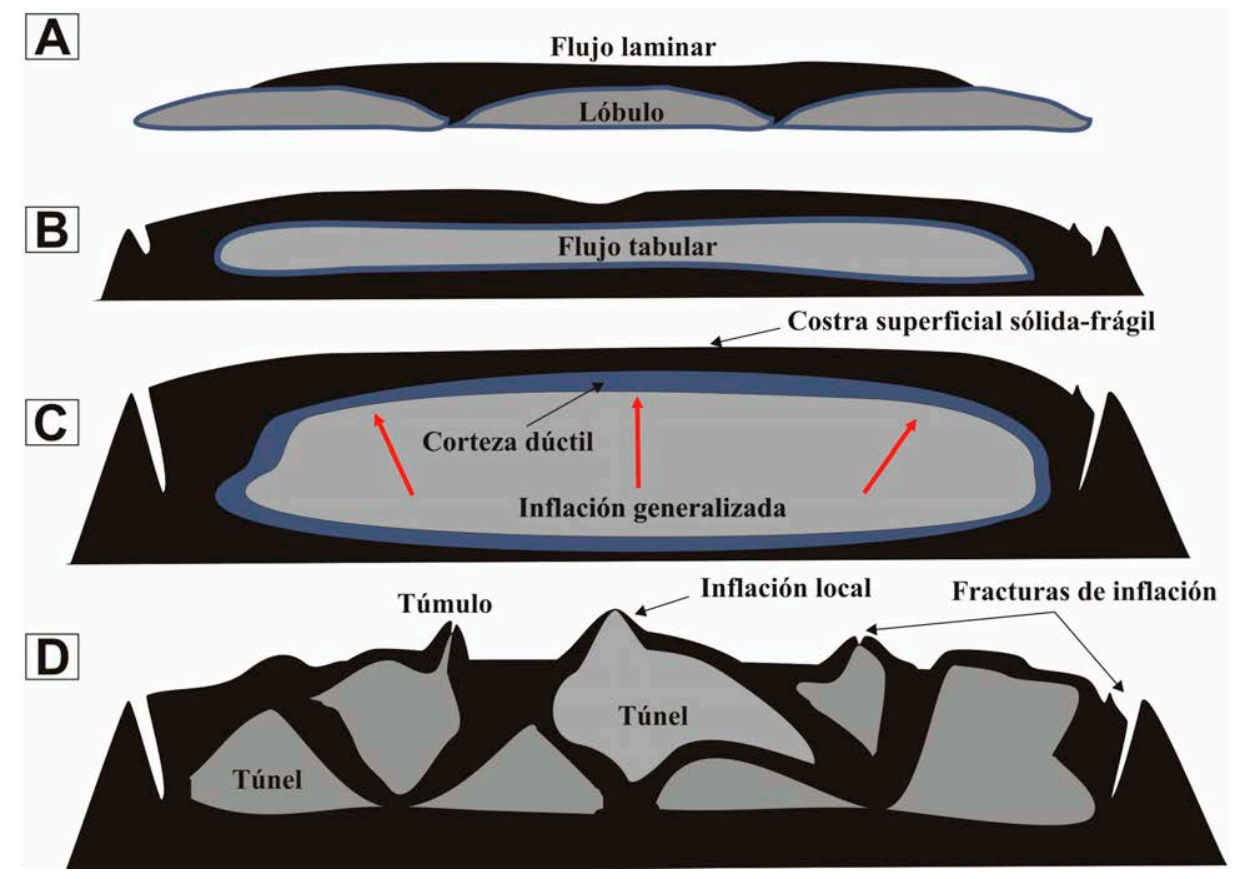

FIG. 24. Esquema de emplazamiento por inflación de lóbulos lávicos. A. Desarrollo de lóbulos en el frente de un manto de lava de menos de $1 \mathrm{~m}$ de espesor; B. Las bajas pendientes $\left(<2^{\circ}\right)$ promueven la coalescencia lateral de los lóbulos. Se forma una colada de geometría tabular, C. Las altas tasas de efusión dan lugar a una inflación a gran escala que actúa de manera uniforme y generalizada, D. El decrecimiento de las tasas de efusión con el tiempo, conlleva a la solidificación de los sectores internos de la colada. La lava circula por vías preferenciales (túneles) y se produce inflación de manera localizada, dando como resultado un microrelieve en domos (e.g., túmulos) y cuencas, sobre la superficie del flujo (hummocky). 
La viscosidad de las lavas es un parámetro fundamental a tener en cuenta al momento de argumentar sobre la extensión de los flujos lávicos (Walker, 1973). La viscosidad de un magma aumenta con la concentración de sólidos; sin embargo, Pinkerton y Stevenson (1992) sugirieron que, en lavas basálticas, una concentración de sólidos por debajo del $30 \%$ tendrá un efecto reducido en el incremento de la viscosidad de las mismas. En Hawái, la viscosidad aparente calculada en flujos pahoehoe de Mauna Loa y Kilauea varía en el rango de 500 a $5.000 \mathrm{~Pa}$ s (Shaw et al., 1968; Shaw, 1969; Rowland y Walker, 1988) y el flujo lávico pahoehoe de mayor longitud, expulsado por el volcán Mauna Loa, exhibe una longitud de $51 \mathrm{~km}$ (Rowland y Walker, 1990). Para los flujos basálticos de Columbia River, con longitudes entre 200 y 600 $\mathrm{km}$, se determinaron viscosidades efectivas de entre 120 y $5.500 \mathrm{~Pa}$ s. En el flujo basáltico cuaternario Toomba $(120 \mathrm{~km})$, situado en el noreste australiano, las viscosidades aparentes (vidrio) han sido estimadas en el rango de 10 a $30 \mathrm{~Pa}$ s a temperaturas de liquidus de $1.150{ }^{\circ} \mathrm{C}$, mientras que los valores de viscosidad efectiva para un $22 \%$ de sólidos en suspensión arrojó valores de $232 \mathrm{~Pa} \mathrm{~s}$ (Whitehead y Stephenson, 1998). Para valores de temperatura del liquidus entre $1.144^{\circ} \mathrm{C}$ y $1.175^{\circ} \mathrm{C}$ los valores de viscosidad aparente para las coladas en estudio fueron estimados mediante la metodología de Bottinga y Weill (1972) en un rango de 9 a 38 Pa s (Tabla 3). A partir de análisis experimentales, Murase y McBirney (1973) determinaron un rango de viscosidad de entre 10 y $10^{3} \mathrm{~Pa}$ s para fundidos basálticos a temperaturas por encima de $1.200{ }^{\circ} \mathrm{C}$, con entre 0 y $3 \%$ de cristales en suspensión. Estos datos en conjunto con aquellos valores determinados para otras coladas en otras regiones del planeta (con excepción del flujo lávico Toomba) permiten plantear que las viscosidades aparentes obtenidas para las coladas aquí estudiadas son notablemente bajas. Valores similares de viscosidad también han sido obtenidos para la colada Pampas Onduladas ( $\eta$ (efectiva) $=96$ Pa s, Espanon et al. (2014a) y $\eta$ (aparente)=2-73 Pa s, Pasquarè et al. (2008)) la cual exhibe parámetros petrográficos y composicionales que varían dentro del mismo rango que los de las coladas analizadas. Por otra parte, varios autores estimaron que las pérdidas de calor en lavas que circulan a través de túneles varían entre 0,5 y $1{ }^{\circ} \mathrm{C} / \mathrm{km}$ (Greeley, 1987; Helz et al., 1991; Keszthelyi y Self, 1998; Harris y Rowland, 2009). En contraste, para flujos de estructura laminar que avanzan a velocidades de hasta 2 órdenes de magnitud más lentos (Hon et al.,
1994; Keszthelyi y Self, 1998) las pérdidas de calor varían entre 5 y $10{ }^{\circ} \mathrm{C} / \mathrm{km}$. Se plantea que las bajas viscosidades de estas lavas, el movimiento en flujos laminares y el posterior desarrollo de túneles lávicos, con la consecuente reducción de los gradientes de enfriamiento, fueron los factores determinantes en el emplazamiento de coladas de volúmenes bajos a moderados, que alcanzaron longitudes de entre 70 y $180 \mathrm{~km}$.

\section{Conclusiones}

Los centros eruptivos y los períodos temporales establecidos para las coladas relevadas son los siguientes:

Plioceno-Pleistoceno inferior: Pampa de Ranquelcó (K-Ar 3,8 $\pm 0,8-5,1 \pm 0,9$ Ma) y Pampa de Luanco (K-Ar 2,85 $\pm 0,18 \mathrm{Ma}$ ) con centros efusivos en volcanes periféricos del complejo ígneo Chachahuén.

Pleistoceno inferior-Pleistoceno medio: El Puesto con centro de efusión en los volcanes Morado (C) (edad K-Ar 0,200 $\pm 0,027 \mathrm{Ma}$ ); Pampa de Los Carrizales (K-Ar 0,40 $\pm 0,10 \mathrm{Ma}$ ) con origen en el sector oriental del Campo Volcánico Payún Matru; El Corcovo con centro de efusión en el volcán Huanul (K-Ar 0,84 $\pm 0,05$ Ma) y la Meseta Basáltica Valle del Colorado (edad $\mathrm{K}$-Ar de colada basal 0,862 $\pm 0,056 \mathrm{Ma}$ ).

Sobre la base del desarrollo longitudinal de las coladas se definieron 2 categorías: 1) flujos de gran extensión longitudinal (30 a $100 \mathrm{~km})$ : coladas de la Meseta Basáltica Valle del Colorado (40 a $60 \mathrm{~km}$ ), El Puesto $(70 \mathrm{~km})$ y El Corcovo $(70 \mathrm{~km})$ y 2 ) flujos extremadamente largos $(>100 \mathrm{~km})$ : Pampa de Ranquelcó (116 km), Pampa de Luanco (122 km) y Pampa de Los Carrizales (181,2 km).

Los valores de espesores de las coladas varían entre 1 y $13 \mathrm{~m}$, siendo más frecuentes las potencias de 4 a $8 \mathrm{~m}$.

Los lóbulos de las coladas presentan una estructura interna de flujos pahoehoe tipo P con dos sectores vesiculares externos; una corteza vesicular superior que conforma entre el 30 y el $50 \%$ del espesor total del flujo y una corteza vesicular inferior con menor desarrollo. Ambas encierran un núcleo cristalino masivo, el cual aloja frecuentemente estructuras de segregación in situ, muy vesiculadas y de variada geometría. En la corteza vesicular superior la distribución, forma y tamaño de las vesículas resultaron del contraste térmico y reológico existente entre los sectores superficiales e internos subyacentes durante la desgasificación y solidificación del flujo. 
TABLA 3. DATOS DE VISCOSIDADES APARENTES CALCULADOS PARA LAS COLADAS DE LAVA CONSIDERADAS EN ESTE ESTUDIO, SEGÚN ECUACIONES DE BOTTINGA Y WEILL (1972), CON LOS DATOS DE ELEMENTOS MAYORES DE BERNARDI (2016).

\begin{tabular}{|c|c|c|c|c|c|c|c|c|c|c|c|}
\hline \multirow{2}{*}{$\begin{array}{l}\text { Colada } \\
\text { Latitud }\end{array}$} & \multicolumn{2}{|c|}{ EL Puesto } & \multicolumn{4}{|c|}{ PAMPA de Los Carrizales } & \multicolumn{5}{|c|}{ PAMPA de Ranquelcó } \\
\hline & $36^{\circ} 51^{\prime} \mathrm{S}$ & $36^{\circ} 58^{\prime} \mathrm{S}$ & $36^{\circ} 39^{\prime} S$ & $36^{\circ} 48^{\prime} \mathrm{S}$ & $37^{\circ} 10 ’ \mathrm{~S}$ & $37^{\circ} 9 ’ \mathrm{~S}$ & $37^{\circ} 5 ' S$ & $37^{\circ} 2 ’ \mathrm{~S}$ & $37^{\circ} 21 ’ S$ & $37^{\circ} 211^{\prime} \mathrm{S}$ & $37^{\circ} 20^{\prime} \mathrm{S}$ \\
\hline Longitud & $68^{\circ} 21^{\prime} O$ & $68^{\circ} 8^{\prime} O$ & $68^{\circ} 39^{\prime} O$ & $68^{\circ} 33^{\prime} O$ & $67^{\circ} 15^{\prime} \mathrm{O}$ & $67^{\circ} 14 ’ 0$ & $68^{\circ} 19^{\prime} O$ & $68^{\circ} 2^{\prime} O$ & $67^{\circ} 36^{\prime} \mathrm{O}$ & $67^{\circ} 34^{\prime} O$ & $67^{\circ} 37^{\prime} \mathrm{O}$ \\
\hline Muestra & M100 & MD174 & MD155 & MD159 & PB24 & PB12 & MD168 & ORN20 & ORN3 & SO8 & ORN7 \\
\hline$\eta(\log \mathrm{Pa} s)$ & 23,8 & 10,9 & 13,7 & 14,9 & 21,4 & 20,5 & 21 & 17,7 & 37,8 & 17,3 & 17 \\
\hline
\end{tabular}

\begin{tabular}{|c|c|c|c|c|c|c|c|c|c|c|c|c|}
\hline \multirow{2}{*}{$\begin{array}{l}\text { Colada } \\
\text { Latitud }\end{array}$} & \multicolumn{3}{|c|}{ Pampa de Luanco } & \multicolumn{2}{|c|}{ El Corcovo } & \multirow[b]{2}{*}{$37^{\circ} 36^{\prime} \mathrm{S}$} & \multirow[b]{2}{*}{$37^{\circ} 33 ' S$} & \multicolumn{5}{|c|}{ Meseta basáltica Valle del Colorado } \\
\hline & $37^{\circ} 15^{\prime} \mathrm{S}$ & $37^{\circ} 27^{\prime} \mathrm{S}$ & $37^{\circ} 26^{\prime} \mathrm{S}$ & $37^{\circ} 25 ’ \mathrm{~S}$ & $37^{\circ} 24$ 'S & & & $37^{\circ} 25^{\prime} \mathrm{S}$ & $37^{\circ} 25^{\prime} \mathrm{S}$ & $37^{\circ} 25^{\prime} \mathrm{S}$ & $37^{\circ} 26^{\prime} \mathrm{S}$ & $37^{\circ} 32^{\prime} \mathrm{S}$ \\
\hline Longitud & $67^{\circ} 58 ' O$ & $67^{\circ} 59^{\prime} \mathrm{O}$ & $67^{\circ} 41^{\prime} O$ & $68^{\circ} 20^{\prime} O$ & $68^{\circ} 25^{\prime} O$ & $67^{\circ} 55^{\prime} \mathrm{O}$ & $68^{\circ} 3^{\prime} O$ & $68^{\circ} 37^{\prime} O$ & $68^{\circ} 34^{\prime} O$ & $68^{\circ} 30^{\prime} O$ & $68^{\circ} 24^{\prime} O$ & $68^{\circ} 15^{\prime} O$ \\
\hline Muestra & MD187 & MD63 & ORN21 & MD1 & MD3 & ORN13 & ORN15 & MD40 & MD57 & MD59 & MD60 & MD62 \\
\hline$\eta(\log P a s)$ & 13,6 & 13 & 29,2 & 16,1 & 22,8 & 28,2 & 29 & 20,4 & 17,2 & 19,5 & 21,6 & 18,6 \\
\hline $\mathrm{T}^{\mathrm{o}} \mathrm{Liq}\left(\mathrm{C}^{\mathrm{o}}\right)$ & 1.158 & 1.161 & 1.162 & 1.161 & 1.167 & 1.164 & 1.158 & 1.162 & 1.162 & 1.159 & 1.150 & 1.157 \\
\hline
\end{tabular}


Se establecieron dos tipos de coladas sobre la base de su morfoestructura externa y topografía superficial: flujos laminares o sheet flows y flujos tipo hummocky. Los primeros se emplazaron a través del desarrollo, inflación y coalescencia lateral de lóbulos en los frentes de los flujos dando lugar a sucesivas coladas mantiformes con amplitudes laterales crecientes y espesores uniformes de gran continuidad lateral. El microrelieve de los flujos tipo hummocky fue otorgado por procesos de inflación local que dieron lugar a túmulos, elevaciones de techo plano, dorsales de inflación y pozos de inflación. Los abombamientos exhiben fracturas anulares o radiales que se produjeron a favor de planos de debilidad previos y son el resultado de los esfuerzos distensivos que genera el proceso.

Los flujos estudiados se desplazaron siguiendo el mecanismo de inflación modelado para las coladas activas hawaianas, tal como lo demuestran las asociaciones de sus rasgos morfológicos y estructurales. Se propone que las coladas de lavas de Payenia se emplazaron inicialmente como flujos laminares bajo un régimen sostenido de altas tasas de efusión, con un límite máximo de $\sim 15 \mathrm{~m}^{3} / \mathrm{s}$ establecido para la formación de flujos pahoehoe inflados en Hawái.

Las pendientes sobre las que se desplazaron las coladas relevadas fueron relativamente suaves y de muy bajo ángulo $\left(<1,5^{\circ}\right)$, con dirección predominante noroeste-sureste y con cambios locales como resultado de escalonamientos e irregularidades de la topografía.

Los valores de inflación pudieron incrementar entre 8 y 20 veces el espesor inicial de los flujos laminares.

Al reducirse el suministro lávico desde la fuente, la circulación de lava se restringió a una red interna de tubos capilares y secundarios que en algunas coladas evolucionaron a túneles maestros. A través de éstos se produjeron episodios de inflación localizados que abarcaron todo el ámbito de las coladas o bien sectores puntuales de las mismas.

Se estimó que las coladas de gran extensión $(>70 \mathrm{~km})$ experimentaron tasas de enfriamiento muy bajas $\left(5 \mathrm{a} 10{ }^{\circ} \mathrm{C} / \mathrm{km}\right)$ durante el emplazamiento del flujo laminar inicial lo cual en conjunto con las bajas viscosidades obtenidas para estas lavas ( 9 a $38 \mathrm{~Pa} \mathrm{~s}$ ) y el desarrollo de túneles lávicos con reducción del gradiente de enfriamiento $\left(0,5\right.$ a $\left.1{ }^{\circ} \mathrm{C} / \mathrm{km}\right)$ fueron los factores determinantes para el sobredimensionamiento longitudinal y superficial de coladas con volúmenes bajos a moderados y altos.

\section{Agradecimientos}

Se agradece a la Facultad de Ciencias Exactas y Naturales (UNLPam), al CONICET y al FONCyT por el apoyo económico (PI 3-G, PIO2015-12CO y PICT 2016-2530). La realización de los análisis químicos en roca total utilizados en los cálculos de valores de viscosidad fue posible gracias a la colaboración de T. Jalowitzki (Universidade Federal do Rio Grande do Sur) y M. Mazzucchelli (Università di Modena e Reggio Emilia, Italia). Se agradecen también las valiosas sugerencias y correcciones por parte de las revisoras del trabajo, Gabriela I. Massaferro y Clara E. Cisterna.

\section{Referencias}

Araña Saavedra, V.; Aparicio, A.; Bellido, F.; García Cacho, L.; Viramonte, J.C. 1984. El volcanismo reciente de la vertiente oriental de los Andes entre los $34^{\circ} \mathrm{y}$ $37^{\circ}$ de Lat. Sur (Mendoza). In Congreso Geológico Argentino, No. 9, Actas 2: 492-503. Bariloche.

Aubele, J.C.; Crumpler, L.S.; Elston, W.E. 1988. Vesicle zonation and vertical structure of basalt flows. Journal of Volcanology and Geothermal Research 35: 349-374.

Bermúdez, A.; Delpino, D. 1989. La Provincia Basáltica Andino Cuyana (35-37 L.S.). Revista de la Asociación Geológica Argentina 44 (1-4): 35-55.

Bermúdez, A.; Delpino, D.; Frey, F.; Saal, A. 1993. Los basaltos de retroarco extraandinos. In Congreso Geológico Argentino, No.12 y Congreso de Exploración de Hidrocarburos, No. 2, Relatorio: 161-172. Mendoza.

Bermúdez, A.; Delpino, D.; Zencich, S.; Bolatti, N. 2000. Evolución volcanológica y petrológica del sector sur del campo volcánico Auca Mahuida, provincia del Neuquén, Argentina. In Congreso Geológico Chileno, No. 9, Actas 2: 1-6.

Bernardi, M.I. 2016. Petrología y volcanología de los flujos basálticos neógeno-cuaternarios del retroarco extraandino entre $\operatorname{los} 36^{\circ}$ y $37^{\circ} 30^{\prime} \mathrm{LS}$, provincias de Mendoza y La Pampa, Argentina. Tesis de Doctorado (Inédito), Universidad Nacional de Córdoba: 353 p.

Bernardi, M.I.; Bertotto, G.W.; Jalowitzki, T.L.R; Orihashi, Y.; Ponce, A. 2015. Emplacement history and inflation evidences of a long basaltic lava flow located in Southern Payenia Volcanic Province, Argentina. Journal of Volcanology and Geothermal Research 293: 46-56.

Bernardi, M.I.; Bertotto, G.W.; Ponce, A.D. 2016. Estructuras de segregación vesiculadas alojadas en coladas basálticas pahoehoe de Payenia, provincias de Mendoza y La Pampa, Argentina. Aspectos morfogenéticos y petrográficos. Revista de la Asociación Geológica Argentina 73 (1): 50-63. 
Bernardi, M.I.; Bertotto, G.W.; Ponce, A.D. 2018. Procesos de diferenciación in situ en coladas basálticas pliopleistocenas del sur de Payenia. Revista de la Asociación Geológica Argentina 75 (1): 152-166.

Bertotto, G.W. 1996. Morfología del túnel lávico cenozoico “Cueva de Halada". Departamento Puelén, provincia de La Pampa. In Jornadas Pampeanas de Ciencias Naturales, NO. 6, COPROCNA, No. 6: 13-15. Santa Rosa.

Bertotto, G.W. 2000. Cerro Agua Poca, un cono basáltico cuaternario portador de xenolitos ultramáficos, en el oeste de la provincia de La Pampa, Argentina. Revista de la Asociación Geológica Argentina 55 (1-2): 59-71.

Bertotto, G.W.; Bjerg, E.A.; Cingolani, C.A. 2006a. Hawaiian and Strombolian style monogenetic volcanism in the extra-Andean domain of central-west Argentina. Journal of Volcanology and Geothermal Research 158: 430-444.

Bertotto, G.W.; Orihashi, Y.; Nagao, K.; Motoki, A. 2006b. New K-Ar ages on retroarc basalts of Mendoza-La Pampa. In Encuentro Científico del ICES, No. 2, Actas CD, Buenos Aires.

Bertotto, G.W.; Cingolani, C.A.; Bjerg, E.A. 2009. Geochemical variations in Cenozoic back-arc basalts at the border of La Pampa and Mendoza provinces, Argentina. Journal of South American Earth Sciences 28: 360-373.

Bertotto, G.W.; Bernardi, M.I.; Ponce, A.D. 2013. Centro eruptivo Cerro Morado, un ejemplo de interacción de magma basáltico con agua superficial en el sureste de la Payunia. In Simposio sobre Petrología Ígnea y Metalogénesis Asociada, No. 2, Actas, 14-15, San Luis.

Bottinga, Y.A.; Weil, D.F. 1972. The viscosity of magmatic silicate liquids: a model for calculation. American Journal of Science 272: 438-473.

Calvari, S.; Pinkerton, H. 1999. Lava tube morphology on Etna and evidence for lava flow emplacement mechanisms. Journal of Volcanology and Geothermal Research 90: 263-280.

Caroff, M.; Ambrics, C.; Maury, R.C.; Cotten, J. 1997. From alkali basalt to phonolite in hand-size samples: Vapor-differentiation effects in the Bouzentes lava flow (Cantal, France). Journal of Volcanology and Gethermal Research 79: 47-61.

Castruccio, A.; Rust, A.C.; Sparks, R.S.J. 2013. Evolution of crust-and core-dominated lava flows using scaling analysis. Bulletin of volcanology 75 (1): 1-15.

Cortelezzi, C.R.; Dirac, M. 1969. Edad de los basaltos de Neuquén y La Pampa. In Congreso Geológico Argentino, No. 4, Actas 2: 95-100. Mendoza.
Espanon, V.R.; Chivas, A.R.; Phillips, D.; Matchan, E.L.; Dosseto, A. 2014a. Geochronological, morphometric and geochemical constraints on the Pampas Onduladas long basaltic flow (Payún Matrú Volcanic Field, Mendoza, Argentina). Journal of Volcanology and Geothermal Research 289: 114-129.

Espanon,V. R.; Honda, M.; Chivas, A.R. 2014 b. Cosmogenic $3 \mathrm{He}$ and $21 \mathrm{Ne}$ surface exposure dating of young basalts from Southern Mendoza, Argentina. Quaternary Geochronology 19: 76-86.

Folguera, A.; Naranjo, J. A.; Orihashi, Y.; Sumino, H.; Nagao, K.; Polanco, E.; Ramos, V.A. 2009. Retroarc volcanism in the northern San Rafael block (34-35 30' S), Southern Central Andes: occurrence, age, and tectonic setting. Journal of Volcanology and Geothermal Research 186: 169-185.

Germa, A.; Quidelleur, X. 2007. Volcanic evolution of the back-arc complex of Payún Matru (Argentina) and its geodynamic implications for caldera-forming eruption in a complex slab geometry setting. International Union of Geodesy and Geophysics (IUGG) XXIV General Assembly.

Germa, A.; Quidelleur, X.; Gillot, P.Y.; Tchilinguirian, P. 2010. Volcanic evolution of the back-arc Pleistocene Payún Matru Volcanic Field (Argentina). Journal of South American Earth Sciences 29: 717-730.

Goff, F. 1996. Vesicles cylinders in vapor-differentiated basalt flows. Journal of Volcanology and Geothermal Research 71: 167-185.

González Díaz, E.F. 1972a. Descripción Geológica de la Hoja 30e, Agua Escondida, provincias de Mendoza y La Pampa. Servicio Nacional Minero Geológico, Boletín 135: 1-79. Buenos Aires.

González Díaz, E.F. 1972b. Descripción Geológica de la Hoja 30d Volcán Payún Matru. Dirección Nacional de Geología y Minería, Boletín 130: 1-88. Buenos Aires.

González Díaz, E.F. 1972c. Descripción Geológica de la Hoja 27d San Rafael, provincia de Mendoza. Servicio Nacional Minero Geológico, Boletín 132: 1-127. Buenos Aires.

González Díaz, E.F. 1979. Descripción Geológica de la Hoja 31d, la Matancilla, provincia de Mendoza. Servicio Geológico Nacional, Boletín 173: 97 p. Buenos Aires.

Greeley, R. 1987. The role of lava tubes in Hawaiian volcanoes. United States Geological Survey Professional Paper 1350: 1589-1602.

Greeley, R.; Hyde, J.H. 1972. Lava tubes of the cave basalt, Mount St. Helens, Washington. Geological Society of America Bulletin 83: 2397-2418. 
Gregg, T.K.P.; Fink, J.H. 2000. A laboratory investigation into the effects of slope on lava flow morphology. Journal of Volcanology and Geothermal Research 96: 145-149.

Groeber, P. 1929. Líneas fundamentales de la geología del Neuquén, sur de Mendoza y regiones adyacentes. Dirección Nacional de Geología y Minería, Publicación 58: 1-110. Buenos Aires.

Groeber, P. 1946. Observaciones Geológicas a lo largo del meridiano 70. 1, Hoja Chos Malal. Sociedad Geológica Argentina, Revista 1 (3): 177-208.

Gudnason, J.; Holm, P.M.; Søager, N.; Llambías, E.J. 2012. Geochronology of the late Pliocene to Recent volcanic activity in the Payenia back-arc volcanic province, Mendoza Argentina. Journal of South American Earth Sciences 37: 191-201.

Guest, J.E.; Chester, D.K.; Duncan, A.M. 1984. The Valle del Bove, Mount Etna: its origin and relation to the stratigraphy and structure of the volcano. Journal of Volcanology and Geothermal Research 21: 1-23.

Harris, A.J.L.; Rowland, S.K. 2009. Effusion rate controls on lava flow length and the role of heat loss: a review. Studies in volcanology: the legacy of George Walker. Special Publications of IAVCEI 2: 33-51.

Helz, R.T.; Heliker, C.; Mangan, M.; Hon, K.; Neal, C.A.; Simmons, L. 1991. Thermal history of the current Kilauean East Rift eruption. In A.G.U. Fall Meeting Abstracts: 557-558. San Francisco.

Hernando, I.R.; Aragón, E.; Frei, R.; González, P.D.; Spakman,W. 2014. Constraints on the origin and evolution of magmas in the Payún Matrú Volcanic Field, Quaternary Andean back-arc of Western Argentina. Journal of Petrology 55 (1): 209-239.

Holmberg, E. 1962. Descripción Geológica de la Hoja 32d-Chachahuén, provincias de Neuquén y Mendoza. Carta Geológico-Económica de la República Argentina, escala 1:200.000: 65 p. Buenos Aires.

Hon, K.; Kauahikaua, J.; Denlinger, R.; Mackay, K. 1994. Emplacement and inflation of pahoehoe sheet flows: Observations and measurements of active lava flows on Kilauea Volcano, Hawaii. Geological Society of America Bulletin 106: 351-370.

Inbar, M.; Risso, C. 2001. A morphological and morphometric analysis of a high density cinder volcanic field Payún Matrú, south-central Andes, Argentina. Zeitschrift fuer Geomorphologie 45: 321-343.

James, D.E.; Sacks, I.S. 1999. Cenozoic formation of the Central Andes: A geophysical perspective. In Geology and Ore Deposits of the Central Andes (Skinner, B.J.; editor). Society of Economic Geology, Special Publication 7: 1-26.
Kay, S.M. 2002. Tertiary to Recent transient shallow subduction zones in the Central and Southern Andes. In Congreso Geológico Argentino, No. 15, Actas 3: 282-283. El Calafate.

Kay, S.M.; Mancilla, O. 2001. Neogene shallow subduction segments in the Chilean/Argentine Andes and Andean-type margins. Geological Society of America, Abstracts with Programs 34 (6): A-156.

Kay, S.M.; Gorring, M.; Ramos, V. 2004. Magmatic sources, setting and causes of Eocene to Recent Patagonian plateau magmatism $\left(36^{\circ} \mathrm{S}\right.$ to $52^{\circ} \mathrm{S}$ latitude). Revista de la Asociación Geológica Argentina 59 (4): 556-568.

Kay, S.M.; Godoy, E.; Kurtz, A. 2005. Episodic arc migration, crustal thickening, subduction erosion, and magmatism in the south-central Andes. Geological Society of America Bulletin 117: 67-88.

Kay, S.M.; Burns, W.M.; Copeland, P.; Mancilla, O. 2006a. Upper Cretaceous to Holocene magmatism and evidence for transient Miocene shallowing of the Andean subduction zone under the northern Neuquén basin. In Evolution of an Andean Margin: a tectonic and magmatic view from the Andes to the Neuquén

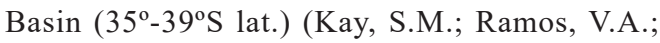
editors). Geological Society of America Bulletin, Special Paper 407: 67-96.

Kay, S.M.; Mancilla, O.; Copeland, P. 2006b. Evolution of the late Miocene Chachahuen volcanic complex at $37^{\circ} \mathrm{S}$ over a transient shallow subduction zone under the Neuquen Andes. In Evolution of an Andean margin: A tectonic and magmatic view from the Andes to the Neuquen basin $\left(35^{\circ}-39^{\circ} \mathrm{S}\right.$ lat $)$ (Kay, S.M.; Ramos, V.A.; editores). Geological Society of America, Special Paper 407: 215-246.

Keszthelyi, L.; Denlinger, R. 1996. The initial cooling of pahoehoe flow lobes. Bulletin of Volcanology 58: 5-18.

Keszthelyi, L.; Self, S. 1998. Some physical requirements for the emplacement of long basaltic lava flows. Journal of Geophysical Research 103 (B11): 27447-27464.

Kilburn, C.R.J. 2000. Lava flows and flow fields. In Encyclopedia of volcanoes (Sigurdsson, H.; Houghton, B.; McNutt, S.; Rymer, H.; Stix, J.; editors). Academic Press: 291-305. San Diego.

Kilburn, C.R.J.; Lopes, R. 1991. General patterns of flow field growth: Aa and blocky lavas. Journal of Geophysical Research 96: 19721-19732.

Linares, E.; Llambías, E.J.; Latorre, C.O. 1980. Geología de la provincia de La Pampa, República Argentina y geocronología de sus rocas metamórficas y eruptivas. Revista de la Asociación Geológica Argentina 35 (1): 87-146. 
Llambías, E.J. 1966. Geología y petrografía del volcán Payún Matrú. Acta Geológica Lilloana 8: 256-310. Tucumán. Macdonald, G.A. 1972. Volcanoes. Prentice-Hall, Englewood Cliffs: 510 p. New Jersey.

Martínez, O.N. 1998. Descripción topográfica y geológica de la caverna Halada y su entorno, Provincia de La Pampa. Grupo Espeleológico Argentino, Revista Salamanca No. 10: 5-10. Buenos Aires.

Mattox, T.N.; Heliker, C.; Kauahikaua, J.; Hon, K. 1993. Development of the 1990 Kalapana flow field, Kilauea volcano, Hawaii. Bulletin of Volcanology 55: 407-413.

May, V.R.; Chivas, A.R.; Dosseto, A.; Honda, M.; Matchan, E.L.; Phillips, D.; Price, D.M. 2018. Quaternary volcanic evolution in the continental back-arc of southern Mendoza, Argentina. Journal of South American Earth Sciences 84: 88-103.

Mazzarini, F.; Fornaciai, A.; Bistacchi, A.; Pasquarè, F.A. 2008. Fissural volcanism, polygenetic volcanic fields, and crustal thickness in the Payen Volcanic Complex on the central Andes foreland (Mendoza, Argentina). Geochemistry, Geophysics, Geosystems 9 (9): Q09002.

Melchor, R.; Casadío, S. 1999. Hoja Geológica 3766-III La Reforma, provincia de La Pampa. Servicio Geológico Minero Argentino, Boletín 295: 63 p. Buenos Aires.

Murase, T.; McBirney, A.R. 1973. Properties of some common igneous rocks and their melts at high temperatures. Geological Society of America Bulletin 84 (11): 3563-3592.

Nagao, K.; Ogata, A.; Miura, Y.; Matsuda, J.; Akimoto, S. 1991. Highly reproducible 13 and $17 \mathrm{ka} \mathrm{K}$-Ar ages of two volcanic rocks. Geochemical Journal 25: 447-451.

Núñez, E. 1976. Descripción geológica de la Hoja 31e, Chical Co, provincias de Mendoza y La Pampa. Servicio Geológico Nacional (Inédito). Buenos Aires.

Orihashi, Y.; Naranjo, J.A.; Motoki, A.; Sumino, H.; Hirata, D.; Anma, R.; Nagao, K. 2004. Quaternary volcanic activity of Hudson and Lautaro volcanoes, Chilean Patagonia: new constraints from K-Ar ages. Revista Geológica de Chile 31 (2): 207-224. doi: 10.5027/andgeoV31n2-a02.

Pasquarè, G.; Bistacchi, A.; Francalanci, L.; Bertotto, G.W.; Boari, E.; Massironi, M.; Rossotti, A. 2008. Very long pahoehoe inflated basaltic lava flows in the Payenia Volcanic Provinc (Mendoza and La Pampa, Argentina). Revista de la Asociación Geológica Argentina 63 (1): 131-149.

Pinkerton, H.; Stevenson, R.J. 1992. Methods of determining the rheological properties of magmas at sub-liquidus temperatures. Journal of Volcanology and Geothermal Research 53: 47-66.
Pinkerton, H.; Norton, G. 1995. Rheological properties of basaltic lavas at sub-liquidus temperatures: laboratory and field measurements on lavas from Mount Etna. Journal of Volcanology and Geothermal Research 68: 307-323.

Polanski, J. 1954. Rasgos geomorfológicos del territorio de la provincia de Mendoza. Cuadernos de investigaciones y estudios, Ministerio de Economía del Gobierno de Mendoza: 4-10. Mendoza.

Ramos, V.A.; Folguera, A. 2005. Tectonic evolution of the Andes of Neuquén: constraints derived from the magmatic arc and foreland deformation. In The Neuquén Basin: a case study in sequence stratigraphy and basin dynamics (Veiga, G.; editor). The Geological Society, Special Publication 252: 15-35.

Ramos, V.A.; Kay, S.M. 2006. Overview of the tectonic evolution of the Southern Central Andes of Mendoza and Neuquén $\left(35^{\circ}-39^{\circ} \mathrm{S}\right.$ latitude). In Evolution of an Andean Margin: a tectonic and magmatic view from the Andes to the Neuquén Basin (35-39 $\mathrm{S}$ ) (Kay, S.M.; Ramos, V.A.; editores). Geological Society of America, Special Paper 407: 1-18.

Risso, C.; Németh, K.; Combina, A.M.; Nullo, F.; Drosina, M. 2008. The role of phreatomagmatism in a Plio-Pleistocene high-density scoria cone field: Llancanelo Volcanic Field (Mendoza), Argentina. Journal of Volcanology and Geothermal Research 169: 61-86.

Rossello, E.A.; Cobbold, P.R.; Diraison, M.; Arnaud, N. 2002. Auca Mahuida (Neuquén Basin, Argentina): a Quaternary shield volcano on a hydrocarbon-producing substrate. In International Symposium on Andean Geodynamics, No. 5 (ISAG), Extended Abstracts 549-552. Toulouse.

Rossi, M.J.; Gudmundsson, A. 1996. The morphology and formation of flow-lobe tumuli on Icelandic shield volcanoes. Journal of Volcanology and Geothermal Research 72: 291-308.

Rowland, S.K.; Walker, G.P. 1988. Mafic-crystal distributions, viscosities, and lava structures of some Hawaiian lava flows. Journal of Volcanology and Geothermal Research 35: 55-66.

Rowland, S.K.; Walker, G.P.L. 1990. Pahoehoe and aa in Hawaii: volumetric flow rate controls the lava structure. Bulletin of Volcanology 52: 615-628.

Self, S.; Thordarson, Th.; Keszthelyi, L.P. 1997. Emplacement of continental flood basalt lava flows. In Large Igneous Provinces; Continental, Oceanic, and Planetary Flood Volcanism (Mahoney, J.J.; Coffin, M.F.; editors). Geophysical Monograph 100, American Geophysical Union: 381-410. Washington. 
Self, S.; Keszthelyi, L.; Thordarson, Th. 1998. The importance of pahoehoe. Annual Review of Earth and Planetary Sciences 26: 81-110.

Shaw, H.R. 1969. Rheology of basalt in the melting range. Journal of Petrology 10: 510-535.

Shaw, H.R.; Wright, T.L.; Peck, D.L.; Okamura, R. 1968. The viscosity of basaltic magma; an analysis of field measurements in Makaopuhi lava lake, Hawaii. American Journal of Science 266: 225-264.

Sobral, J.M. 1942. Geología de la región occidental del Territorio de La Pampa, situada al occidente del Chadi-Leuvú. Boletín de Informaciones Petroleras 212: 33-81. Buenos Aires.

Stappenbeck, R. 1913. Apuntes hidrogeológicos sobre el sudeste de la provincia de Mendoza. Dirección General de Minas, Geología e Hidrología, Boletín 6, Serie B. Buenos Aires.

Stern, C.R. 2004. Active Andean volcanism: its geologic and tectonic setting. Revista Geológica de Chile 31: 161-206.

Søager, N.; Holm, P.M. 2013. Melt-peridotite reactions in upwelling eclogite bodies: constraints from EM1type alkaline basalts in Payenia, Argentina. Chemical Geology 360: 204-219.
Søager, N.; Holm, P.M.; Llambías, E.J. 2013. Payenia volcanic province, southern Mendoza, Argentina: OIB mantle upwelling in a backarc environment. Chemical Geology 350: 36-53.

Walker, G.P.L. 1973. Length of lava flows. Philosophical Transactions of the Royal Society A274: 107-118.

Walker, G.P.L. 1991. Structure, and origin by injection under surface crust of tumuli, "lava rises," "lava-rise pits" and "lava inflation clefts" in Hawaii. Bulletin of Volcanology 53: 546-58.

Whitehead, P.W.; Stephenson, P.J. 1998. Lava rise ridges of the Toomba basalt flow, north Queensland, Australia. Journal of Geophysical Research 103 (B11): 2737127382.

Wichmann, R. 1928. Contribución a la Geología de los departamentos Chical Co y Puelén, de la parte occidental de La Pampa Central. Dirección General de Minas, Geología e Hidrogeología, Publicación 40: 33 p. Buenos Aires.

Wilmoth, R.A.; Walker, G.P.L. 1993. P-type and S-type pahoehoe: A study of vesicle distribution patterns in Hawaian lava flows. Journal of Volcanology and Geothermal Research 55: 129-142.

Manuscript received: March 23, 2018; revised/accepted: January 19, 2019; available online: February 4, 2019. 